TM-1620

[SSC-N-663]

\title{
Conceptual Design Report for a Superconducting Coil Suitable for Use in the Large Solenoid Detector at the SSC*
}

\author{
R. W. Fast, J. H. Grimson, H. J. Krebs, R. D. Kephart, D. Theriot, and R. H. Wands \\ Fermi National Accelerator Laboratory \\ P.O. Box 500, Batavia, Llinois 60510
}

September 15, 1989 
TM 1620

SSC-N-663

\section{CONCEPTUAL DESIGN REPORT FOR A SUPERCONDUCTING COIL \\ SUITABLE FOR USE IN THE LARGE SOLENOID DETECTOR AT THE SSC}

R.W. Fast, J.H. Grimson, H.J. Krebs, R.D. Kephart, D. Theriot, and R.H. Wands Fermi National Accelerator Laboratory, Batavia, Illinois, USA

September 15, 1989 


\section{TABLE OF CONTENTS}

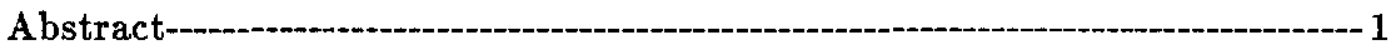

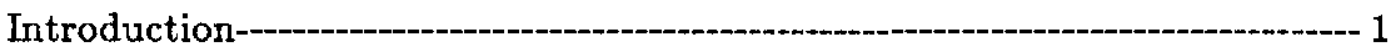

General requirements

Calorimeter support structure

Solenoid fabrication and assembly plan

Quench Protection and Conductor Specification-..........-4

Quench and electrical circuit parameters

Conductor dimensions, current density

Eddy current heating in conductor and helium vessel

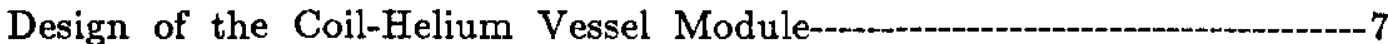

Ampere-turns, number of turns and layers

Turn-to-turn and ground insulation

Coil winding

Helium vessel design criteria and standards

Thermosiphon cooling

Design of the Radiation Shields

Shield design

Liquid nitrogen cooling scheme

Design of the Support System

Separated vs combined function systems

Design requirements

Calculation of Magnetostatic Fields and Forces--........- 13

Use of ANSYS for magnetostatics

Ideal fields and forces

Fields and forces under fault conditions

Radial and axial decentering forces

Liquid Helium Storage Dewar

Specifications and standards

Vapor-cooled current leads

Pressure relief and vent line

Manufacturing, Assembly, and Testing Considerations-------------------16

Refrigeration System-- 16

Liquid helium system

Liquid nitrogen system

Cooldown time 
Appendix B: Calculations of Conductor and Coil Parameters-a-c----- 25

Appendix C: Magnetostatic Calculations Using ANSYS------------_-_-_-_34

Appendix D: Ground Transportation of Solenoid Modules--------------- 42

Appendix E: Refrigeration System Parameters---- 45

Additional Reference Documents: Fermilab SSC Detector Solenoid Design Notes (unpublished)

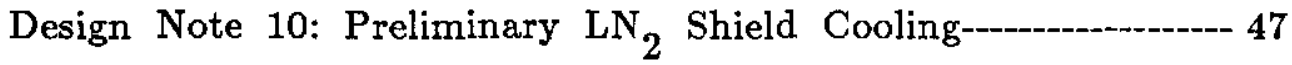

Design Note 18: Quench Safety--_-..-- 56

Design Note 20: Charge/Discharge times, Eddy Current Power and Energy--.--- 61

Design Note 24: Conceptual Design of a Superconducting Solenoid for a Magnetic SSC Detector (ICEC-12 paper)-------68

Design Note 25: Conductor and Coil Parameters for Coils in Series Electrically; Eddy Current Heating--.---.-...- 74

Design Note 26: SSC Detector Solenoid (1988 ASC paper)---.--82

Design Note 31: A Very Large Superconducting Solenoid (IISSC-89 paper)--.---- 87 


\section{ABSTRACT}

The conceptual design of a large superconducting solenoid suitable for a magnetic detector at the Superconducting Super Collider (SSC) was done at Fermilab. The magnet will provide a magnetic field of $1.7 \mathrm{~T}$ over a volume $8 \mathrm{~m}$ in diameter by $16 \mathrm{~m}$ long. The particle-physics calorimetry will be inside the field volume and so the coil will be bath cooled and cryostable; the vessels will be stainless steel. Predictibility of performance and the ability to safely negotiate all probable failure modes, including a quench, are important items of the design philosophy. Our conceptual design of the magnet and calorimeter has convinced us that this magnet is a reasonable extrapolation of present technology and is therefore feasible. The principle difficulties anticipated are those associated the the very large physical dimensions and stored energy of the magnet.

\section{INTRODUCTION}

A large solenoid is being considered as part of a detector for an experiment to be performed on the Superconducting Super Collider (SSC). The conceptual design of a solenoid suitable for such a detector was done at Fermilab and some preliminary specifications have been developed. Some of the requirements placed on the SSC detector magnet by the nature of $20 \mathrm{TeV}$ proton-proton interactions are similar to those for other large diameter solenoids found at high-energy physics laboratories around the world, but others are remarkably different. One significant difference in the detector is that, unlike collider detectors for LEP at CERN and the Tevatron at Fermilab, both electromagnetic and hadronic calorimetry for the SSC detector will be inside the bore of the magnet. As a result, the coil and cryostat do not have to be "thin" in terms of radiation or absorption lengths. We have chosen to adopt a bath-cooled, cryostable coil design and to use stainless steel rather than aluminum for the helium and vacuum vessels. We believe that these choices will contribute greatly to the reliability and predictability of the magnet system.

Our magnet design provides a magnetic field of $1.7 \mathrm{~T}$ over a cylindrical volume $8 \mathrm{~m}$ in diameter and $16 \mathrm{~m}$ long. An iron yoke will reduce the excitation required and will 
assist in providing muon identification and a redundant momentum measurement of the muons. The stored energy in the magnetic field is $1.4 \mathrm{GJ}$.

The calorimeter and central tracking chamber for the detector will occupy a volume 8 $\mathrm{m}$ in diameter by $16 \mathrm{~m}$ and will weigh about 5000 metric tonnes. This weight could be transmitted to the floor of the detector hall either through the vacuum vessel of the magnet cryostat or through an independent support structure. The calorimeter would be split at the longitudinal center for supports to minimize lost pseudorapidity coverage by the tracking and calorimetry. We have decided on two independent calorimetry support structures each $8 \mathrm{~m}$ long--the trussed cylinder shown in Fig. 1. This structure is a stainless steel weldment with a radial thickness of $250 \mathrm{~mm}$. The cylinders are 38 $\mathrm{mm}$ thick, while the truss web is made of $12 \mathrm{~mm}$ plates. The deflection of the structure when loaded with the calorimeter modules was calculated with a finite element analysis to be about $30 \mathrm{~mm}$; it would be attached to the iron yoke at both ends. The calorimeter modules would rest on rails along each side of the truss structure and could be installed from either or both ends.

We have adopted a fabrication and assembly plan in which eight 2-m long coil and vacuum vessel modules are fabricated and individually tested with liquid helium. These modules are then assembled into two 8-m cryostats, each with a liquid helium storage dewar. These coil-cryostat assemblies are then lowered into the experimental hall and mounted to the iron yoke.

A more detailed scenario for this plan is: (1) The coil is wound in 2-m long modules about a vertical axis, and each module closed to form a liquid helium vessel. (2) The coil-helium vessel module is installed inside a $2-\mathrm{m}$ outer vacuum vessel module, with liquid nitrogen cooled thermal shield attached, by a temporary support system. (3) The vacuum vessel is then closed with a temporary inner vacuum shell and annular heads. 


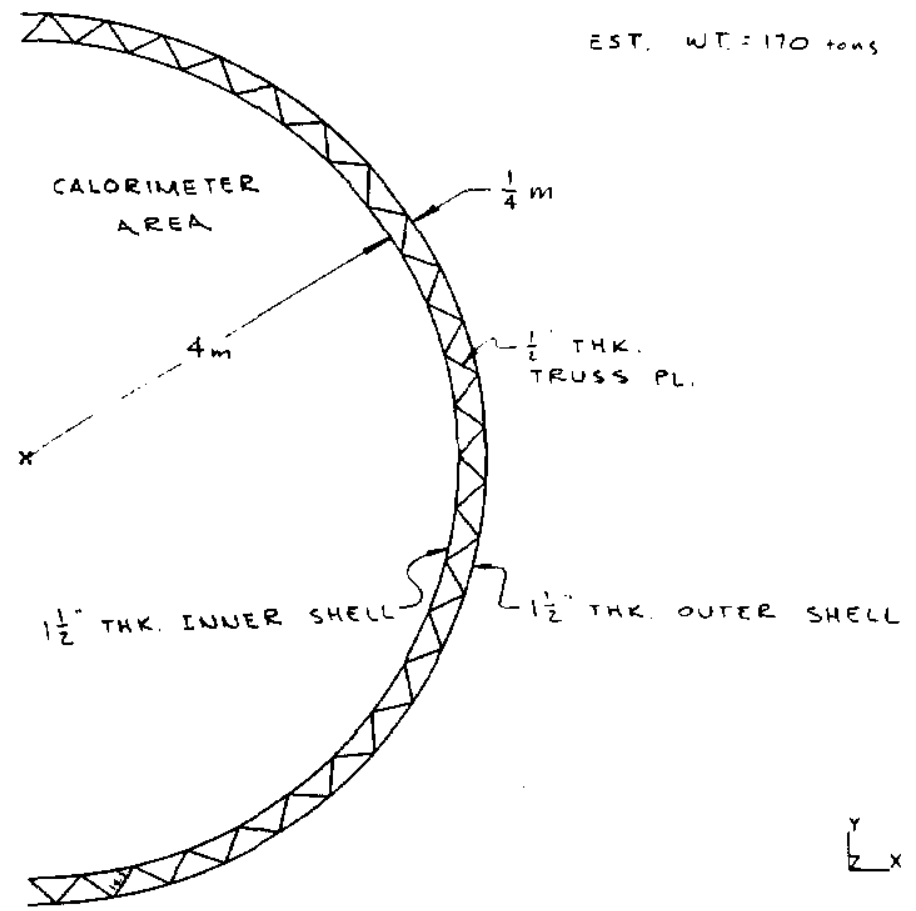

(b)

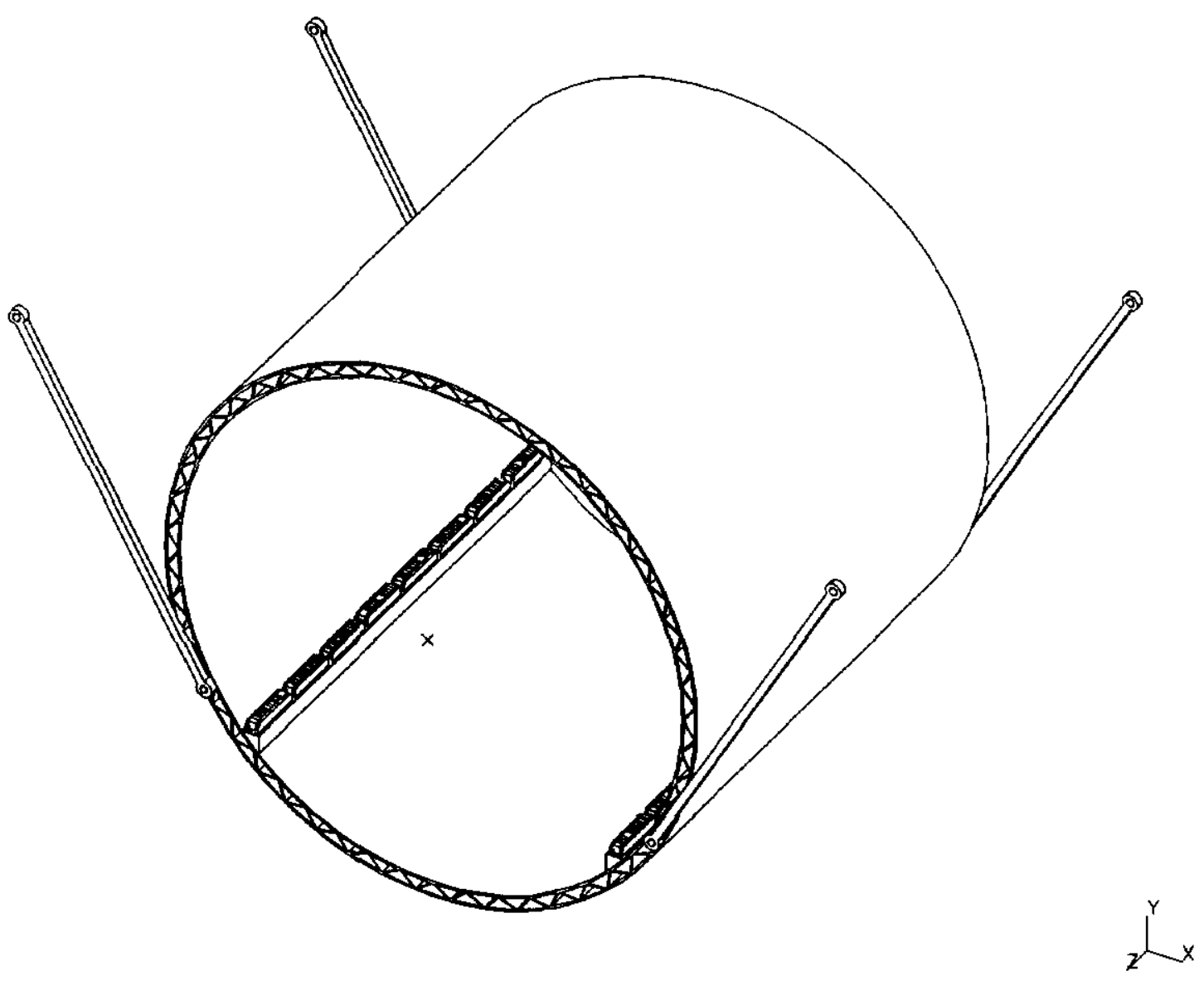

Fig. 1. Calorimeter support structure. (a) cross section geometry, (b) structure with module rails and Hillman rollers and support arms to iron yoke. 
(4) The current lead chimney is completed and the cryogenic lines connected to a temporary supply of liquid nitrogen and helium. (5) The 2-m module is cooled, filled with liquid helium, and tested to an appropriate current. (6) Four coil-outer vacuum shell modules are assembled and bolted together to form an 8-m cold mass supported in an 8-m outer vacuum shell with a radial-axial separated-function support system. The inner vacuum shell and thermal shield are inserted and the closure welds made. (8) The helium storage dewar and connecting piping are then attached to this 8-m cryostat assembly. (9) The two 8-m assemblies could be cryogenically and electrically tested at this point. (10) These finished $8-\mathrm{m}$ assemblies, each weighing about 800 metric tonnes, are lowered into the underground detector hall and secured to the iron yoke in a way that allows for a $20^{\circ} \mathrm{C}$ thermal contraction of the $8-\mathrm{m}$ vacuum vessel. Figure 2 shows an 8-m assembly.

The parameters adopted for this conceptual design report are given in Appendix A. Backup calculations related to conductor sizing, quench behavior, coil charging and discharging are given in Appendix B. We realize that further, more detailed calculations and reliability-cost optimizations will probably result in final design parameters somewhat different from these. However, we believe that these, usually conservative, parameters are useful in determining the engineering feasibility of the magnet.

\section{QUENCH PROTECTION AND CONDUCTOR SPECIFICATION}

In order to accomodate a calorimeter $8 \mathrm{~m}$ in diameter, the inner diameter of the inner vacuum shell is $8.9 \mathrm{~m}$. Cryostat shell thicknesses, the radiation shield, insulating vacuum space and electrical insulation occupy $337 \mathrm{~mm}(13.5 \mathrm{in})$ so the inner diameter of the first layer of the superconducting coil is $9.574 \mathrm{~m}$. To reduce the liquefaction 


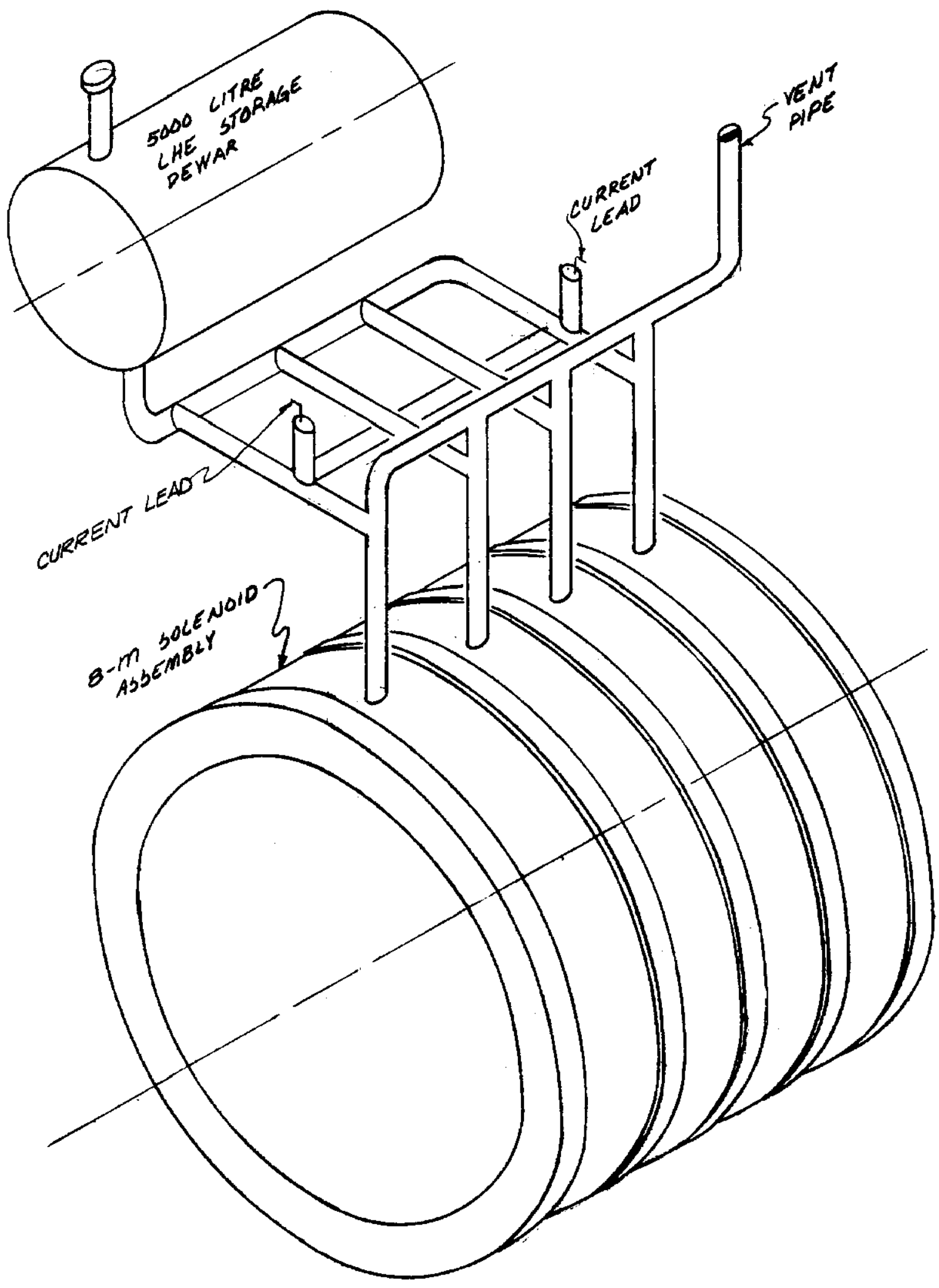

Fig. 2. Eight-meter assembly. 
demand on the helium system, we chose an operating current of $5 \mathrm{kA}$. All eight 2-m coil modules are connected in series electrically so that the same current flows in each. Each 2-m coil module has a pair of gas-cooled current leads which will be used for testing the module. The current lead chimneys will permit four $2-\mathrm{m}$ coil modules to be connected in series with superconducting bus in liquid helium. We believe that it is essential that the coil survive a $5-\mathrm{kA}$ quench without damage. We have chosen to provide this protection through the use of an external $0.1 \Omega$ fast discharge resistor and by specifying a conductor current density consistent with an adiabatic maximum hot spot temperature following a quench of $90 \mathrm{~K}$. The current density was calculated with the simplistic, very conservative heat balance method:

$$
\mathrm{J}_{0}^{2} \mathrm{~L} / \mathrm{R}=2_{\theta 0}{ }^{\theta \mathrm{m}} \gamma \mathrm{C}(\theta) / \rho(\theta) \mathrm{d} \theta
$$

where $\mathrm{J}_{0}=$ conductor (copper) current density at the operating current

$$
\begin{aligned}
& \mathrm{L}=\text { coil inductance }=112 \mathrm{H} \\
& \mathrm{R}=\text { fast discharge resistor }=0.1 \mathrm{\Omega} \\
& \mathrm{L} / \mathrm{R}=\text { maximum fast discharge time constant }=1120 \mathrm{~s} \\
& \gamma=\text { conductor (copper) density }\left[\mathrm{kg} / \mathrm{m}^{3}\right] \\
& \mathrm{C}(\theta)=\text { conductor (copper) specific heat }[\mathrm{J} / \mathrm{kg}-\mathrm{K}] \\
& \rho(\theta)=\text { conductor (copper) resistivity }[\mathrm{\Omega}-\mathrm{m}] \\
& \theta 0=\text { superconducting-normal transition temperature }=10 \mathrm{~K} \\
& \theta \mathrm{m}=\text { adiabatic maximum hot spot temperature }
\end{aligned}
$$

With $\theta \mathrm{m}=90 \mathrm{~K}$ and copper with $\mathrm{RRR}=100, \mathrm{~J}_{0}=1.07 \times 10^{7} \mathrm{~A} / \mathrm{m}^{2}=10.7$ $\mathrm{A} / \mathrm{mm}^{2}$. 
The conductor for the magnet will be built up with a $\mathrm{Nb}-\mathrm{Ti} / \mathrm{Cu}$ monolith or cable soldered into additional copper stabilizer. The dimensions of the conductor for all eight coil modules are $16 \mathrm{~mm} \times 18 \mathrm{~mm}$, a current density at $5 \mathrm{kA}$ of $10.7 \mathrm{~A} / \mathrm{mm}^{2}$. The specified short sample rating at $4.5 \mathrm{~K}$ and $2 \mathrm{~T}$ is $10 \mathrm{kA}$. With a current density in the superconductor of $3 \times 10^{9} \mathrm{~A} / \mathrm{m}^{2}$, the copper to superconductor area ratio will be about 140. The full surface heat flux at $5 \mathrm{kA}$ with a copper resistivity of $1.55 \times 10^{-10} \Omega$-m is $9.4 \mathrm{~mW} / \mathrm{cm}^{2}$. The operating current is $61 \%$ of short sample along the load line, a temperature margin of about $2.2 \mathrm{~K}$. A bout $150 \mathrm{~km}, 92$ miles, of conductor, weighing about 625 tonnes, is required for the magnet.

Normal discharge will be through a slow discharge resistor, with the power supply reversed so the discharge is at constant voltage. Eddy current heating during a slow discharge is less than $100 \mathrm{~W}$. There is, however, a significant heat load due to eddy current in the coil and helium vessel during a fast discharge, with peak or initial values approximately $700 \mathrm{~W}$ in the coil modules and $1500 \mathrm{~W}$ in the helium vessels. Since the modules are in series electrically, the current will decay the same way in all modules. However, this eddy current heat load could initiate a more or less simultaneous quench in each module in the event of a fast discharge. A fast discharge will therefore be initiated only when a quench is detected. A simplified electrical schematic of the magnet system is shown in Fig. 3.

\section{DESIGN OF THE COIL-HELIUM VESSEL MODULE}

Magnetostatic calculations showed that a central field of $1.7 \mathrm{~T}$ could be achieved if each of the eight coil modules provided an excitation of 2.81 megampere-turns. We designed each 2-m coil module to have seven layers of 88 turns for a total of 616 turns. At 5 $\mathrm{kA}$ this provides $3.08 \mathrm{MAt}$, about $10 \%$ more than the calculation indicated were necessary, a safety factor necessary because of uncertainties in the calculation. 


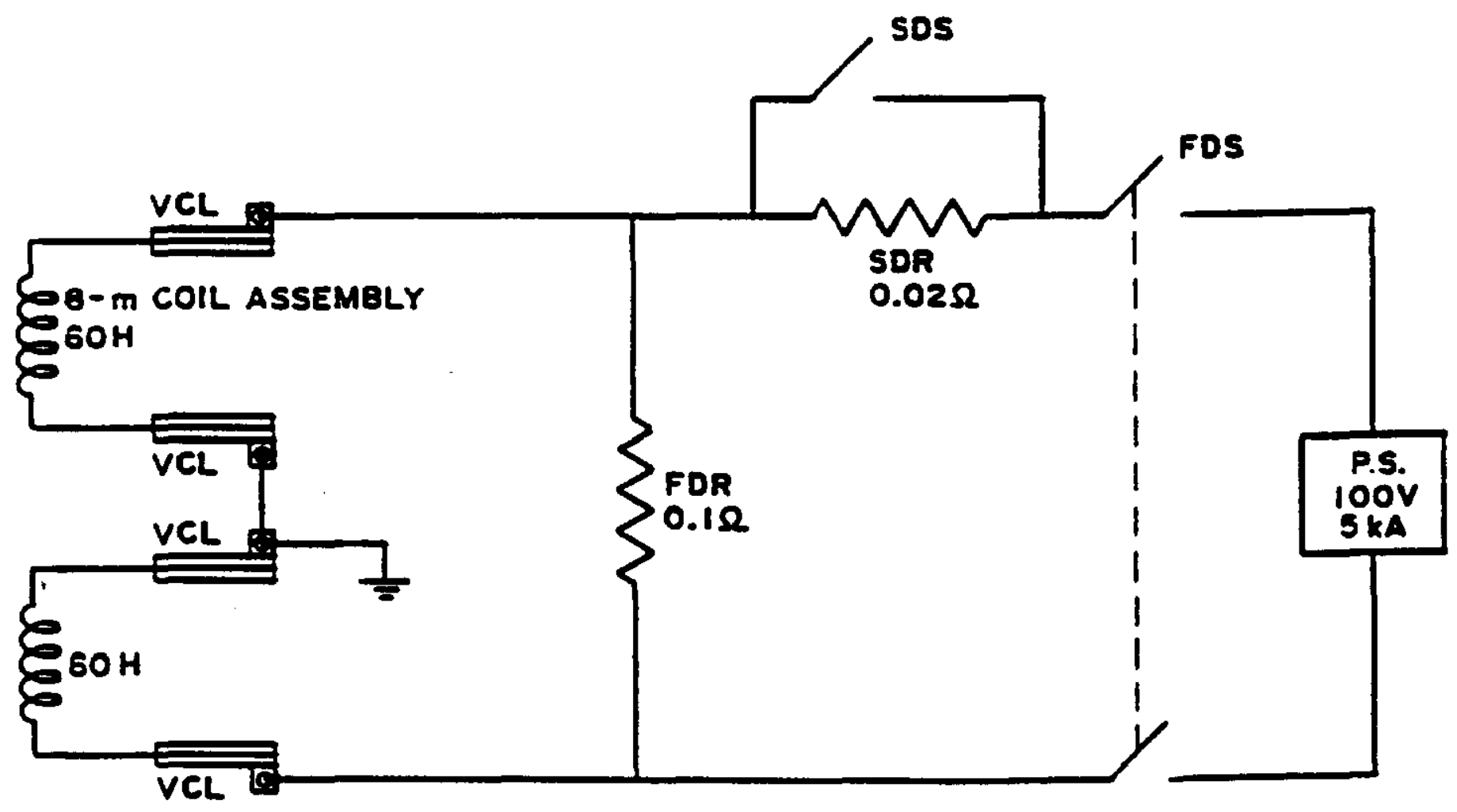

Fig. 3. Electrical schematic: FDR, fast discharge resistor; FDS, fast discharge switch (normally closed, opened to initiate a fast discharge); SDR, slow discharge resistor; SDS, slow discharge switch (normally closed, opened to initiate a slow discharge); VCL, vapor cooled leads; P.S., power supply 
We chose $2.62-\mathrm{mm} \mathrm{G-10}$ buttons on a string as the turn-to-turn insulation and 5-mm slotted G-10 sheets between layers. The ground insulation is $75 \mathrm{~mm}$ of slotted and channeled G-10 and Kapton.

The conductor is layer wound the "hard" way, beginning at the outside, or eighth layer, on a coil form made up of the outer shell and annular flat heads of the helium vessel. We visualize the coil form to be stationary with a vertical axis of rotation. The winding fixture carries a conductor spool, a reel of turn-to-turn insulation, and cleaning and insulation applying equipment. It rotates in a horizontal plane and traverses the vertical axis, applying a radial preload. Compression bars at the ends of the coil apply an axial preload to each layer as it is wound. The lead-in bus enters and exits the coil pack through channels in the ground insulation. We hope that the conductor can be procured in about $2.5-\mathrm{km}$ lengths so that the only splices are between layers.

Figure 4 is a cut-away view of the coil. The coil module will be closed by welding the inner shell, modularized circumferentially, to the coil form. The lead-in bus passes out the chimney of the module, which also serves as the return flow pipe and the quench vent.

The 2-m coil-helium vessel module was designed in accordance with the Boiler and Pressure Vessel Code of the American Society of Mechanical Engineers (ASME). The vessel was designed to be evacuated and for an internal gauge pressure of $0.7 \mathrm{MPa}$ (100 psig). The outward radial design pressure of the outer shell was $1.2 \mathrm{MPa}$ (175 psig) to permit the shell to react a portion of the radial electromagnetic pressure. The inner and outer shell thicknesses are adequate to carry the axial electromagnetic force from the coils to the axial supports. 


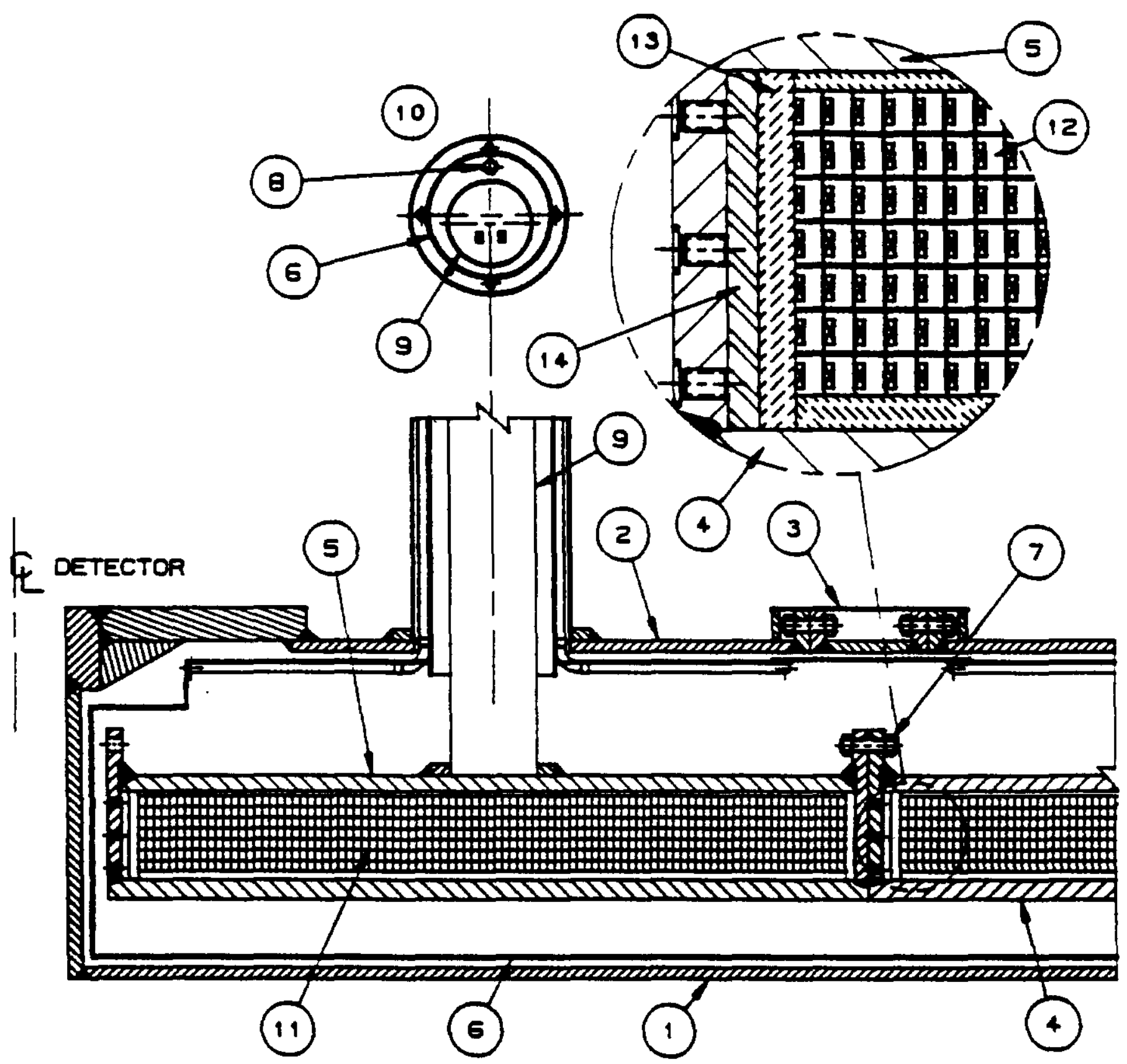

Fig. 4. Axial cross section of coil, helium and vacuum vessels: 1 , inner and 2, outer vacuum shells; 3 , assembly joint (if required); 4, inner and 5, outer helium vessel shell; 6 , radiation shield; 7 , coil module attachment; 8 , liquid helium supply pipe; 9 , helium return/vent pipe; 10, chimney to storage dewar; 11, coil winding; 12, conductor; 13 , insulation; 14, axial preload bar. 
We have not considered in depth the question of tolerances on the coil-helium vessel module. We have, however, provided generous vacuum spaces on either side of the module ( $100 \mathrm{~mm}$ on the inside, $300 \mathrm{~mm}$ on the outside) to accomodate the out-ofroundness of the modules and vacuum shells.

We propose to use a thermosiphon, as was used on the Aleph solenoid at LEP and the Mirror Fusion Test Facility solenoids at Livermore, to provide a flow of liquid helium through the coil package. Each of the coil-helium vessel modules will have a separate line from the storage dewar to supply helium which is $100 \%$ liquid to the bottom of the module.

\section{DESIGN OF THE RADIATION SHIELDS}

Liquid nitrogen cooled shields will reduce the radiation heat transfer from the vacuum vessel to the liquid helium system. The shields will be mounted to the inner and outer vacuum shells with low conductivity supports which allow the shields to contract when cooled. The shields are made of either copper or aluminum sheets with a cooling tube attached. The size of the cooling tube and the number of parallel circuits are determined by the $0.13 \mathrm{MPa}(19 \mathrm{psi})$ pressure difference available from the subcooled liquid nitrogen circulating system.

A flow of subcooled liquid nitrogen will be maintained through the series-parallel circuit. The pressure and temperature of the liquid entering the magnet are 6 atmospheres and $77.5 \mathrm{~K}$; the liquid leaves the magnet at 4.7 atmospheres and $89 \mathrm{~K}$. 


\section{DESIGN OF THE SUPPORT SYSTEM}

Four coil modules are connected together forming one $8-\mathrm{m}$ cold mass to be supported inside each $8-\mathrm{m}$ vacuum vessel. The support system could have been either combined function, where the load bearing members support both the axial and radial components of the total body force, or separated function with two types of members, one to support the axial component and another to support the radial component. The combined function style is attractive because by properly adjusting the angle between the support and the axis the force due to thermal contraction can be eliminated. However since the supports are at this angle a large buckling force is generated when reacting the axial decentering force. A separated function system with radial and axial members does not have this disadvantage and we have therefore chosen it. Another advantage of a radial-axial system is that the members can be much longer, which greatly reduces the conduction heat load to the helium system. The support system provides axial stiffness by using a number of axial members, either 24 or 48 , located at intervals around the outer circumference of the cold mass. Radial stiffness is provided by a set of approximately tangential members, in a plane normal to the axis, around the circumference at each end of the $8-\mathrm{m}$ cold mass.

We have decided that the support system should be adequate to permit operation of the magnet with one of the eight coils at zero current. This will allow the magnet and the detector to be operated, but at reduced field, should one of the coil modules fail. This could be important since it will be necessary to completely disassemble the detector to repair or replace a failed coil module. 
We have also decided that for reliability the support members should be metallic, probably Inconel 718 , and designed with an appropriate safety factor. We used the Specification for the Design, Fabrication and Erection of Structural Steel for Buildings of the American Institute of Steel Construction (AISC) as the source of allowable stress and column loading formulae. Each support member has spherical bearings on each end.

The 2-m coil-helium vessel modules will have temporary supports installed for testing. These supports will be removed when the coil modules are connected together to form the $8-m$ cold mass.

The warm ends of all support members will be attached near the ends of the vacuum vessels to avoid transmitting the electromagnetic loads and the weight through the vacuum shells. The cold ends of both the axial and the radial members are attached to the cold mass on its outer diameter. Each support member has two heat intercepts, one cooled by liquid nitrogen and another in the cold-end attachment block in a liquid helium thermosiphon circuit.

\section{CALCULATION OF MAGNETOSTATIC FIELDS AND FORCES}

The general purpose finite element program ANSYS (copyright Swanson Analysis Systems, Inc.), with two- and three-dimensional magnetostatic capabilities, was used to calculate the magnetic field, Lorentz forces, and the stored energy for different coil and iron geometries. Initial calculations were done assuming steel of infinite permeability; the final results are with finite permeability. The computational results are summarized in Appendix A, while the method and the details are given in Appendix D. A twodimensional axisymetric model was found to be adequate for much of the analysis, but a three-dimensional model was used to compute the radial decentering force. 
Figure 5 shows the value of the axial field component as a function of $\mathrm{z}$ with $\mathrm{r}=0$, $B_{z}(0, z)$, with each of the eight coils energized to 2.81 MAt and with one of the coil modules deenergized.

When installed on the iron yoke, each $8-\mathrm{m}$ cold mass has an axial body force on it which depends on the gap between the coil and the iron end wall and on the amount of re-entrant iron in the end plug. For a given set of coil-to-coil spacings and with all eight coils equally energized this force can be theoretically eliminated by the proper choice of end wall and plug geometry. In our case, with intercoil gaps of $138 \mathrm{~mm}$, a midplane gap of $568 \mathrm{~mm}$ and 2.81 MAt per coil, the axial force on each 8-m cold mass was calculated to be negligible if the coil-to-iron gap was $300 \mathrm{~mm}$ and if there was no

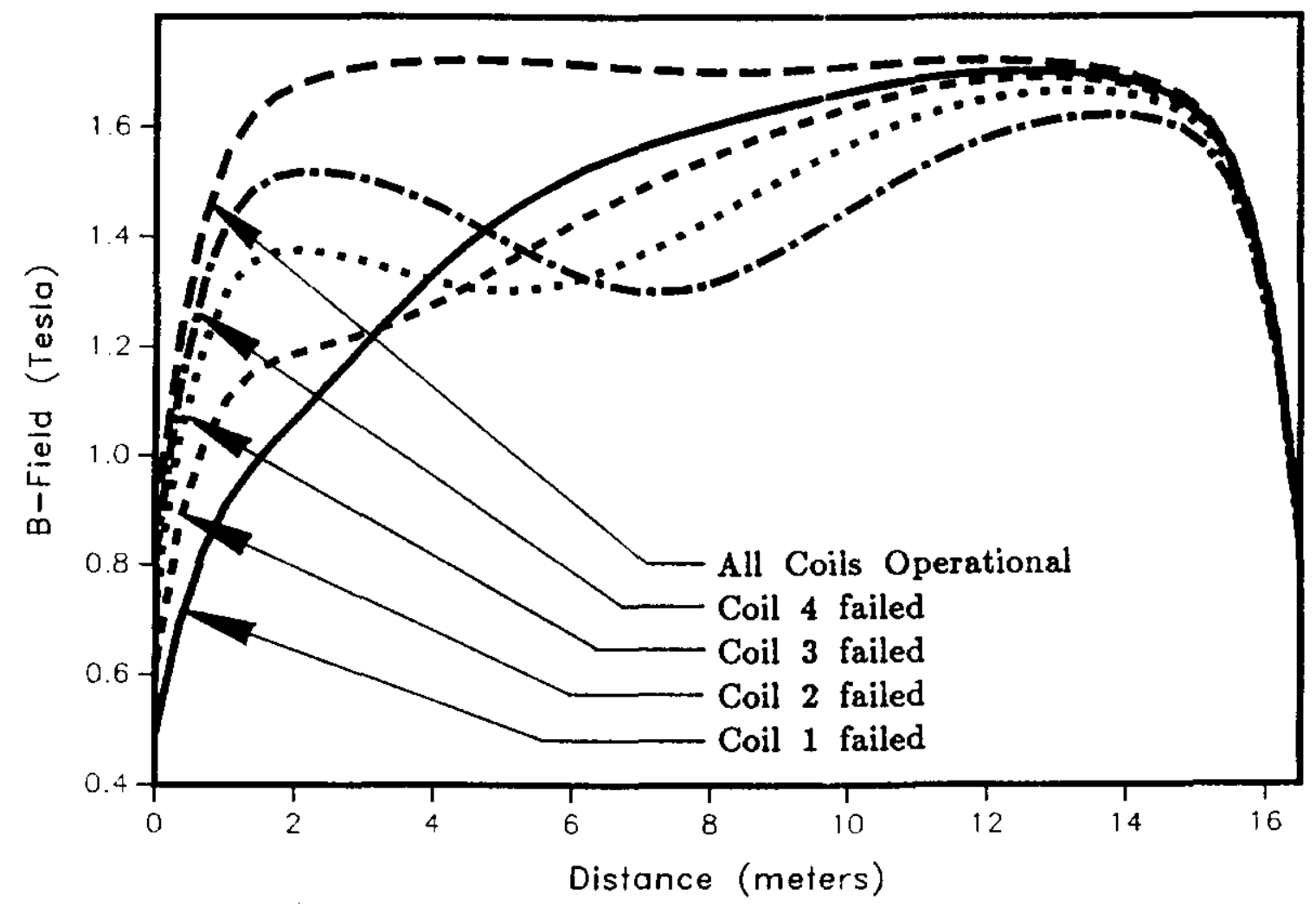

Fig. 5. Field on solenoid axis for various coil failure scenarios. Coil 1 is the outermost coil, coil 4 is nearest the axial mid-plane. 
re-entrant iron in the end plug. With one of the coils deenergized there is an axial force on the cold mass which depends on which coil is deenergized. Table 2 in Appendix D gives this force for different deenergized coils, with the other seven at full excitation. The maximum value of this axial force, $54.2 \mathrm{MN}$, about 12 million pounds, occurs with the outermost coil module deenergized. The axial support system is accordingly designed for a force of $54.2 \mathrm{MN}$ (12 Mlbf).

There are five ways that the two $8-\mathrm{m}$ cold masses can be axially decentered with respect to each other and the steel yoke. We calculated the axial force on each 8 -m cold mass for these decentering cases with all eight coils equally energized. The maximum force will occur when both $8-\mathrm{m}$ cold masses are displaced toward the midplane. The radial decentering force constant is $8 \mathrm{kN} / \mathrm{mm}(45,600 \mathrm{lbf} / \mathrm{in})$. From experience with the solenoid at the CDF at Fermilab we have chosen an axial and radial misalignment or the equivalent, due to non-uniform iron properties, of $25 \mathrm{~mm}$. This results in an axial decentering force of $12.4 \mathrm{MN}(2.8 \mathrm{Mlbf})$, which is much less than the design specification of the axial support system. The radial decentering force with a $25-\mathrm{mm}$ misalignment is $0.2 \mathrm{MN}(45,000 \mathrm{lbf})$, which is also much less than the 8$\mathrm{m}$ cold mass (664 tonnes, $1.46 \mathrm{Mlbf}$ ) to which the radial support system is designed.

\section{LIQUID HELIUM STORAGE DEWAR}

A horizontal, $5000 \mathrm{~L}$ liquid helium storage dewar, located above the iron yoke, is connected to the four coil-helium vessel modules in each 8 -m assembly through a chimney manifold as shown in Fig. 2. This manifold contains four gas-cooled current leads and has the provision for connecting the current leads in series in liquid helium. A vent pipe to relieve the individual modules in the event of a quench or loss of insulating vacuum is part of the interconnect manifold. The liquid vessel is designed in 
accordance with the ASME Boiler and Pressure Vessel Code for a gauge pressure 0.7 MPa (100 psig).

\section{MANUFACTURING, ASSEMBLY, AND TESTING CONSIDERATIONS}

The size and weight of the 8-m solenoid assemblies will preclude its fabrication and assembly at a vendor's off-site facility. A preliminary inquiry (Appendix D) indicates that a 2 -m coil-helium vessel module or even a completed 2 -m module could be fabricated elsewhere and transported to the Waxahatchie site by barge and truck. It is unclear whether the cryogenic testing of the 2 -m modules would take place at a vendor's facility or on site. A large hall will be provided on the SSC site for the assembly and cryogenic testing of the $8-\mathrm{m}$ modules. The hall will require at least a 200 tonne crane with a hook height of at least $12 \mathrm{~m}$. The access shaft from the surface to the detector hall will be about $14 \mathrm{~m}$ in diameter.

\section{REFRIGERATION SYSTEM}

The refrigeration plant will be located at ground level, while the magnet will be about $50 \mathrm{~m}$ below ground on the Texas SSC site. The plant will supply liquid helium to the two storage dewars atop the detector. A cold compressor will be used if necessary to maintain the liquid in the dewars at about $30 \mathrm{kPa}$ and $4.5 \mathrm{~K}$. Sub-cooled liquid nitrogen will be forced through the various shield and intercept circuits by a circulator pump at detector hall level.

The cold mass of each 8-m assembly is about 650 tonnes; a cooldown time of about two weeks is desirable. Energy must be extracted at an average rate of about $50 \mathrm{~kW}$ to cool down an $8-\mathrm{m}$ assembly in $300 \mathrm{~h}$. It is likely that a separate cooldown refrigerator will be used. 
The parameters of the refrigeration system are given in Appendix E.

\section{CONCLUSION}

We concluded, as a result of this preliminary study, that the magnet is a reasonable extrapolation of superconducting magnet technology. The optimization of parameters through more detailed study might result in a more cost-effective design, but we believe we have established the feasibility of the magnet. 
$-18$

APPENDIXES 


\section{Appendix A: Solenoid Parameters and Dimensions}

\section{GENERAL}

Overall inner diameter

Overall outer diameter

Radial thickness

Overall length

Design operating central field

Stored energy at $1.7 \mathrm{~T}$

Total weight of coils and cryostats
$8.900 \mathrm{~m}, 29.20 \mathrm{ft}, 350.4$ in

$11.272 \mathrm{~m}, 36.98 \mathrm{ft}, 443.7 \mathrm{in}$

$1.186 \mathrm{~m}, 3.89 \mathrm{ft}, 46.7 \mathrm{in}$

$16.250 \mathrm{~m}, 53.31 \mathrm{ft}, 639.8 \mathrm{in}$

$1.7 \mathrm{~T}$

$1400 \mathrm{MJ}$

$\sim 1600$ tonnes (metric tons)

COIL

Number of coil modules

8

Nominal length of coil module

$2 \mathrm{~m}$

Active length of coil module

$1.812 \mathrm{~m}, 5.94 \mathrm{ft}, 71.34$ in

Calculated excitation per module for $1.7 \mathrm{~T}$

2.81 MAt (same for all 8)

Maximum operating current

$5 \mathrm{kA}$

Turns per module

616

Turns per layer

88

Layers per module

7

Excitation available per module

3.08 MAt at $5 \mathrm{kA}$

Total self inductance

$112 \mathrm{H}$

Ground insulation on ID

$75 \mathrm{~mm}, 2.953$ in, G-10

Ground insulation on OD

$75 \mathrm{~mm}, 2.953$ in, G-10

Turn-to-turn insulation

$2.62 \mathrm{~mm}, 0.103 \mathrm{in}, \mathrm{G}-10$

buttons on string

Layer-to-layer insulation

$5 \mathrm{~mm}, 0.197 \mathrm{in}$, slotted G-10

Approximate length of conductor per module

$18.4 \mathrm{~km}, 11.5$ miles

Approximate total length of conductor

$147 \mathrm{~km}, 92$ miles 
CONDUCTOR

General

Overall dimensions

Peak field at conductor

Short sample current specification

$\mathrm{Cu}: \mathrm{SC}$ area ratio

Conductor ( $\sim$ copper) current density at $5 \mathrm{kA}$

Specification of stabilizer copper

Copper RRR, completed coil, $2 \mathrm{~T}$

Copper resistivity at $4.5 \mathrm{~K} \& 2 \mathrm{~T}$

Full surface heat flux at $5 \mathrm{kA}$

Critical current margin

Critical field margin

Cryostable current margin

Fraction of short sample along load line

Temperature margin

\section{QUENCHING}

Fast discharge resistor

Nominal fast discharge time constant (inductance/fast discharge resistance)

${ }_{0} \int^{\infty} \mathrm{J}^{2}(\mathrm{t}) \mathrm{dt} \sim(0.5) \mathrm{J}_{0}{ }^{2} \mathrm{~L} / \mathrm{R}$

$\int_{0}^{\infty} I^{2}(t) d t$

Maximum hot spot temperature

Initial (max.) eddy current heating in coil during fast discharge

Energy deposited in coil during fast discharge
$\mathrm{Cu} / \mathrm{Nb}-\mathrm{Ti}$ cable, soldered

to additional copper

$18 \mathrm{~mm} \times 26 \mathrm{~mm}$,

0.71 in $\times 1.02$ in

\section{$1.8 \mathrm{~T}$}

$10 \mathrm{kA}, 3 \times 10^{9} \mathrm{~A} / \mathrm{m}^{2}$

at $4.5 \mathrm{~K}$ and $2 \mathrm{~T}$

$\sim 140$

$1.07 \times 10^{7} \mathrm{~A} / \mathrm{m}^{2} \sim 11 \mathrm{~A} / \mathrm{mm}^{2}$

CDA 101, ASTM B170-1

100

$1.55 \times 10^{-10} \mathrm{n}-\mathrm{m}$

$9.4 \mathrm{~mW} / \mathrm{cm}^{2}$

1.1

1.94

4.48

0.611

$2.26 \mathrm{~K}$

$0.10 \Omega$

$1120 \mathrm{~s}$

$6.41 \times 10^{16} \mathrm{~A}^{2}-\mathrm{s}-\mathrm{m}^{-4}$

$\sim 14000 \times 10^{6}, 14000$ MIITS

$90 \mathrm{~K}$

$697 \mathrm{~W}$ (8 modules)

$390 \mathrm{~kJ}$ (8 modules) 
Initial (max.) eddy current heating in helium vessel during fast discharge

Total inital eddy current heating

Energy deposited in helium vessel during fast discharge

Total energy deposited in liquid helium during fast discharge

Liquid helium boiled during fast discharge

\section{CHARGING AND SLOW DISCHARGING}

Power supply voltage

Constant voltage charge rate

Charge time with constant voltage

Slow dump resistor

Slow discharge time constant

Exponential slow discharge time, 5 - $3.75 \mathrm{kA}$

Linear slow discharge time, 3.75 - $0 \mathrm{kA}$

Total slow discharge time from $5 \mathrm{kA}$

Eddy current heating--100-V charge--8 modules

Eddy current heating--slow discharge--8 modules
1481 W (8 modules)

$2178 \mathrm{~W}$

$829 \mathrm{~kJ}$ (8 modules)

$1219 \mathrm{~kJ}$

475 L

$100 \mathrm{~V}$

$0.893 \mathrm{~A} / \mathrm{s}$

$93 \mathrm{~min}$

$0.02 \cap$

5600 s

$1600 \mathrm{~s}$

$5600 \mathrm{~s}$

$7200 \mathrm{~s}, 2 \mathrm{~h}$

$87 \mathrm{~W}, 488 \mathrm{~kJ}, 190 \mathrm{~L}$ LHe

87 W-max, $381 \mathrm{~kJ}, 150 \mathrm{~L}$ LHe

\section{ELECTROMAGNETIC FORCES WITH IRON YOKE}

With all 8 coils energized to $1.7 \mathrm{~T}, 2.81 \mathrm{MAt}$

Axial force on 8-m cold mass

Max axial compressive force

$$
\text { in } 2-\mathrm{m} \text { coil module }
$$

Max radial pressure

Max axial stress in conductor

Max axial decentering force, with $25 \mathrm{~mm}$ axial offset

Radial force constant
Negligible

13.3 MN, $3 \mathrm{Mlbf}$

$1.16 \mathrm{MPa}, 168 \mathrm{psi}$

$2 \mathrm{MPa}$, $300 \mathrm{psi}$

12.4 MN, 2.8 Mlbf

$8 \mathrm{kN} / \mathrm{mm}, 45.6 \mathrm{klbf} /$ in 
With 7 coils energized to $2.81 \mathrm{MAt}$, one coil deenergized

Max. axial force on 8-m cold mass

Specification for axial support system

Specification of radial support system
$54.2 \mathrm{MN}, 12.2 \mathrm{Mlbf}$

$54.2 \mathrm{MN}, 12.2 \mathrm{Mlbf}$

$0.2 \mathrm{MN}, 45 \mathrm{klbf}$ in any direction plus 664 tonnes, 1.46 Mlbf cold mass

\section{ELECTROMAGNETIC FORCES WITHOUT IRON YOKE}

Max. testing current (current giving axial conductor stress equal to maximum with eight coils)

\section{DIMENSIONS OF COIL-CRYOSTAT-VACUUM VESSEL}

Radial dimensions

Inner vacuum shell, ID

Inner vacuum shell, OD

Inner vacuum shell thickness

Inner radiation shield, OD

Inner radiation shield thickness

Inner LHe shell, ID

Inner LHe shell, OD

Inner LHe shell thickness

Inner ground insulation thickness

First conductor layer, ID

Layer insulation thickness

Last (eighth) conductor layer, OD

Outer ground insulation thickness

Outer LHe shell, ID

Outer LHe shell, OD

Outer LHe shell thickness

Outer radiation shield, OD
$8.900 \mathrm{~m}, 29.20 \mathrm{ft}, 350.4$ in

$8.958 \mathrm{~m}, 29.39 \mathrm{ft}, 352.7 \mathrm{in}$

$29 \mathrm{~mm}, 1.142$ in

$9.108 \mathrm{~m}, 29.88 \mathrm{ft}, 358.6 \mathrm{in}$

$1 \mathrm{~mm}, 0.039$ in

$9.308 \mathrm{~m}, 30.54 \mathrm{ft}, 366.5 \mathrm{in}$

$9.424 \mathrm{~m}, 30.92 \mathrm{ft}, 371.0 \mathrm{in}$

$58 \mathrm{~mm}, 2.283$ in

$75 \mathrm{~mm}, 2.953$ in

$9.574 \mathrm{~m}, 31.41 \mathrm{ft}, 376.9 \mathrm{in}$

$5 \mathrm{~mm}, 0.197$ in

$9.998 \mathrm{~m}, 32.80 \mathrm{ft}, 393.6 \mathrm{in}$

$75 \mathrm{~mm}, 2.953$ in

$10.148 \mathrm{~m}, 33.29 \mathrm{ft}, 399.5 \mathrm{in}$

$10.288 \mathrm{~m}, 33.75 \mathrm{ft}, 405.0 \mathrm{in}$

$70 \mathrm{~mm}, 2.756$ in

$10.888 \mathrm{~m}, 35.72 \mathrm{ft}, 428.7$ in 
Outer radiation shield thickness

Outer vacuum shell, ID

Outer vacuum shell, OD

Outer vacuum shell thickness

Module interconnection region, OD

Axial dimensions

Vacuum vessel, overall length

Vacuum vessel annular head thickness

2-m module, outside length

2-m module annular head thickness

2-m module inside length

Push bar thickness

Ground insulation thickness

Turn-to-turn insulation thickness

2-m coil length, conductor-to-conductor

Intercoil gap, conductor-to-conductor

Midplane gap, conductor-to-conductor

Yoke gap, conductor-to-iron
$1 \mathrm{~mm}, 0.039$ in

$11.038 \mathrm{~m}, 36.21 \mathrm{ft}, 434.6$ in

$11.102 \mathrm{~m}, 36.42 \mathrm{ft}, 437.1 \mathrm{in}$

$32 \mathrm{~mm}, 1.260$ in

$11.272 \mathrm{~m}, 36.98 \mathrm{ft}, 443.8 \mathrm{in}$

$8.000 \mathrm{~m}, 26.25 \mathrm{ft}, 315.0 \mathrm{in}$

$35 \mathrm{~mm}, 1.378$ in

$1.950 \mathrm{~m}, 6.40 \mathrm{ft}, 76.8 \mathrm{in}$

$35 \mathrm{~mm}, 1.378$ in

$1.880 \mathrm{~m}, 6.17 \mathrm{ft}, 74.0 \mathrm{in}$

$20 \mathrm{~mm}, 0.787$ in

$24 \mathrm{~mm}, 0.945$ in

$2.62 \mathrm{~mm}, 0.103$ in

$1.812 \mathrm{~m}, 5.945 \mathrm{ft}, 71.34$ in

$138 \mathrm{~mm}, 5.433$ in

$568 \mathrm{~mm}, 22.36$ in

$300 \mathrm{~mm}, 11.8$ in

\section{CALCUlated WEIGHTS}

2-m coil module, cold mass

Coil form (outer LHe vessel shell and annular heads)

42.27 tonnes

Axial push bars

0.65 tonnes

Insulation

19.11 tonnes

Conductor

78.00 tonnes

Inner LHe vessel shell

25.88 tonnes

Total module cold mass

165.91 tonnes 
2-m vacuum module

Radiation shields

Outer shell

Total 2-m coil and vacuum module

Inner vacuum shell $(8 \mathrm{~m})$

Vacuum vessel annular flat heads

Total 8-m assembly, w/o support system, storage dewar and interconnecting piping
1.22 tonnes

16.88 tonnes

184.01 tonnes

50.61 tonnes

20.46 tonnes

807 tonnes 
Appendix B: Backup Calculations for Parameters in Appendix A

SUMMARY: This appendix contains preliminary calculations, references, and remarks backing up some of the numbers cited in Appendix A.

COIL

1. Active length of coil module

$$
\mathrm{I}_{2 \mathrm{~m}}=1812 \mathrm{~mm} \text {, from Jim Krebs }
$$

2. Calculated excitation per module for $1.7 \mathrm{~T}$

From Bob Wands, module current density

$$
\mathrm{J}_{\text {coil }}=7.312 \mathrm{MA} / \mathrm{m}^{2} \text { for } \mathrm{B}(0,0)=1.7 \mathrm{~T}
$$

$\mathrm{m})(0.212 \mathrm{~m})$

$$
\mathrm{NI}(\text { calc, } 2 \mathrm{~m}, 1.7 \mathrm{~T})=\mathrm{J}_{\text {coil }} \mathrm{l}_{2 \mathrm{~m}} \Delta \mathrm{R}=\left(7.312 \mathrm{MA} / \mathrm{m}^{2}\right)(1.812
$$

$$
=2.81 \text { MAturns }
$$

3. Maximum operating current

If the as-wound coils all contain the number of turns specified below, the calculated excitation will be attained with $4.56 \mathrm{kA}$. The power supply will be capable of $5 \mathrm{kA}$ and therefore $10 \%$ extra amp-turns. All conductor, stability and quench issues will be calculated at $5 \mathbf{k A}$.

4. Turns, turns per layer, layers

Total of 616 turns, 88 turns/layer $\times 7$ layers, to provide the calculated excitation at $4.56 \mathrm{kA}$.

5. Excitation available per coil module

$$
\mathrm{NI}(\text { available })=616 \text { turns } \times 5 \mathrm{kA}=3.08 \text { MAturns }
$$

6. Total self inductance

$$
\mathrm{L}(16 \mathrm{~m})=2 \mathrm{E} / \mathrm{I}^{2}=(2)(1400 \mathrm{MJ}) /(5 \mathrm{kA})^{2}=112 \mathrm{H} \text {. Because }
$$

all eight, $2-\mathrm{m}$ coils are in series electrically, the current is always the same in all modules we ignored the various mutual inductances.

7. Turn-to-turn insulation

0.103 in

Thickness $=(1 / 87)[1812 \mathrm{~mm}-(88 \times 18 \mathrm{~mm})]=2.62 \mathrm{~mm}=$

8. Layer-to-layer insulation

Thickness $=(1 / 6)[212 \mathrm{~mm}-(7 \times 26 \mathrm{~mm})]=5.0 \mathrm{~mm}=0.197$

in

9. Length of conductor in module

Length $(2 \mathrm{~m}) \sim[\pi(9.5 \mathrm{~m} /$ turn $)](616$ turns $)=18.4 \mathrm{~km}$

10. Total length of conductor required loss,

Assuming eight, 2-m modules, i.e. no spares, and no cutting Length $(16 \mathrm{~m})=8 \times 18.4 \mathrm{~km}=147 \mathrm{~km}=92$ miles 


\section{CONDUCTOR}

11. Overall conductor dimensions

Keep the same conductor as before, but fewer turns per layer and correspondingly thicker turn-to-turn insulation.

12. Peak field at the conductor

Bob Wands has found that the highest fields occur at the coil I.D. at the longitudinal mid-point of the modules, where the field has only an axial component. The total field at the outside-longitudinal--inside-radial corner is about $1.3 \mathrm{~T}$.

13. Short sample conductor specification

The superconductor current density of $3 \times 10^{9} \mathrm{~A}_{\mathrm{g}} / \mathrm{m}^{2}$ came from Al McInturff in 1988. An Outokumpu brochure gives $4 \times 10^{9} \mathrm{~A} / \mathrm{m}$ at $3 \mathrm{~T}$ and $4.2 \mathrm{~K}$. The choice of $10 \mathrm{kA}$ at $2 \mathrm{~T}$ is sort of arbitrary, based partly on the requirement for the CDF conductor $(10.4 \mathrm{kA} @ 1.5 \mathrm{~T})$.

14. Cu:SC area ratio

$$
\begin{aligned}
& A_{\mathrm{SC}}=10 \times 10^{3} \mathrm{~A} / 3 \times 10^{9} \mathrm{~A} / \mathrm{m}^{2}=3.33 \times 10^{-6} \mathrm{~m}^{2} \\
& A_{\mathrm{T}}=0.018 \times 0.126 \mathrm{~m}^{2}=4.68 \times 10^{-4} \mathrm{~m}^{2} \\
& A_{\mathrm{Cu}}=4.65 \times 10^{-4} \mathrm{~m}^{2} \\
& A_{\mathrm{Cu}} / \mathrm{A}_{\mathrm{SC}}=4.65 \times 10^{-4} / 3.33 \times 10^{-6}=141
\end{aligned}
$$

15. Conductor-copper current density $\mathrm{m}^{2}=1.07 \times 10^{7} \mathrm{~A} / \mathrm{m}^{2}=1070 \mathrm{~A} / \mathrm{cm}^{2}$ $11 \mathrm{~A} / \mathrm{mm}^{2}$. It is interesting to note that AWG $16\left(\phi=0.0508^{\prime \prime}=1.29 \mathrm{~mm}\right)$ copper wire is rated for $10 \mathrm{~A}$ in household use, a current density of 7.6 $\mathrm{A} / \mathrm{mm}^{2}$.

\section{Copper RRR}

Although the RRR of typical superconductors can reach 250 in the drawing process, the spooling and winding strain will reduce that. The magnetoresistance effect will increase the resistivity, and decrease the RRR, by about a factor of two at $2 \mathrm{~T}$.

\section{Copper resistivity}

We used the value at $273 \mathrm{~K}$ from the Superconducting Machinery Handbook at an $R R R=100,1.55 \times 10^{-10} \mathrm{n}-\mathrm{m}$. An ORNL reference gives $\rho=1.48 \times 10^{-10}$ at $2 \mathrm{~T}$ for annealed $\mathrm{OFHC}$ copper.

18. Full surface heat flux

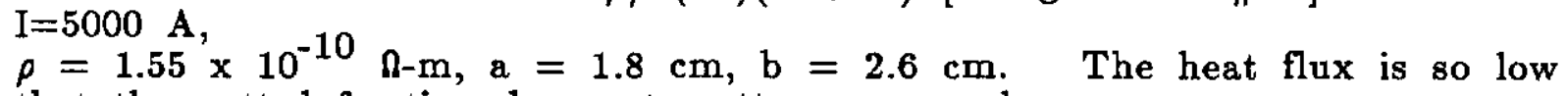

Heat flux $=\mathrm{I}^{2} \rho / 2(\mathrm{ab})(\mathrm{a}+\mathrm{b})$ [Design Note \#18]. We used that the wetted fraction does not matter very much. 
19. Critical current margin

We adopted the General Dynamics definition of this, found in their MFTF report GDC-LLNL-84-001, p. 11-14:

$$
\text { Crit.C.M. }=\left[\left(\mathrm{I}_{\mathrm{c}}-\mathrm{I}_{\mathrm{op}}\right) / \mathrm{I}_{\mathrm{op}}\right]_{\mathrm{Bop}} \text {. }
$$

We constructed the B-I short sample curve (Fig. 1) on either side of the $10 \mathrm{kA} / 2 \mathrm{~T}$ point using the Outokumpu data sheet (Fig. 2).

$$
\text { Crit.C.M. }=[(10.5-5 \mathrm{kA}) / 5 \mathrm{kA}]_{1.8 \mathrm{~T}}=1.1=110 \%
$$

20. Critical field margin

The GDC definition:

$T]_{5 \mathrm{kA}}=1.94$

$$
\text { Crit.F.M. }=\left[\left(\mathrm{B}_{\mathrm{c}}-\mathrm{B}_{\mathrm{op}}\right) / \mathrm{B}_{\mathrm{op}}\right]_{\mathrm{Iop}}=\left[\left(\begin{array}{lll}
5.3 & -1.8 \mathrm{~T}
\end{array}\right) / 1.8\right.
$$

21. Cryostable current margin

Again the GDC definition: Cryo.C.M. $=\left[\left(I_{s}-I_{o p}\right) / I_{o p}\right]_{\text {Bop }}$.

GDC defines the cryostable current I (page 9-290 as the current which gives a surface heat flux equal to the minimum film boiling recovery flux. Van Sciver, "Helium Cryogenics", p. 219, gives the MFBF = $0.3 \mathrm{~W} / \mathrm{cm}^{2}$. For the $18 \times 26 \mathrm{~mm}$ conductor at $5 \mathrm{kA}$, the heat flux is $\sim 0.01$ $\mathrm{W} / \mathrm{cm}^{2}$. Then

$27.4 \mathrm{kA}$.

$$
\mathrm{I}_{\mathrm{s}}^{2}=(0.3 / 0.01) \mathrm{I}_{\mathrm{op}}^{2}=30 \mathrm{I}_{\mathrm{op}}^{2} \text { and } \mathrm{I}_{\mathrm{s}}=5.48 \mathrm{I}_{\mathrm{op}}=
$$

$$
\text { Cryo.C.M. }=[(27.4-5 \mathrm{kA}) / 5 \mathrm{kA}]_{1.8 \mathrm{~T}}=4.48
$$

These three margins were $0.10(10 \%)$ for the MFTF solenoids.

22. Fraction of short sample on load line

The operating point $(5 \mathrm{kA}, 1.8 \mathrm{~T})$ is $0.611(61.1 \%)$ of the way along the $\mathrm{B}_{\max }$ load line, which intercepts the short sample curve at $(8.3 \mathrm{kA}$, $2.9 \mathrm{~T})$.

23. Temperature margin

On the $B_{\max }$ load line the point $(8.3 \mathrm{kA}, 2.9 \mathrm{~T})$ is at $4.2 \mathrm{~K}$, the point $(0,0)$ is at $10 \mathrm{max}$ We assumed a linear decrease of (I,B) along the load line. The operating point is $0.389(38.9 \%)$ of the way from 4.2 to $10 \mathrm{~K}$. The maximum temperature at which the coil will remain superconducting at the operating point is $4.2+0.389(10-4.2) \mathrm{K}=4.2+2.26 \mathrm{~K}=6.46 \mathrm{~K}$. The temperature margin is $2.26 \mathrm{~K}$.

\section{QUENCHING}

24. Fast discharge resistor

The value of the FDR was chosen to give an initial terminal voltage of $500 \mathrm{~V}$ during a fast, non quenching discharge from $5 \mathrm{kA}$. The coil is center tapped to ground (Design Note \#31) so the maximum terminal voltage to ground is $250 \mathrm{~V}$. 
25. Nominal fast discharge time constant

The value is simply the coil inductance divided by the FDR,

$\tau_{\mathrm{FD}}=112 \mathrm{H} / 0.1 \mathrm{n}=1120 \mathrm{~s}$. This will be the time constant for a fast, but non-quenching discharge. The time constant for a quenching discharge will doubtless be less than this over most of the discharge because eddy current heating in the coil will cause the resistance to grow quickly enough that the coil resistance, $R_{Q}(t)$, enters into the equation for the time constant, $\tau=$ $\mathrm{L} /\left[\mathrm{R}_{\mathrm{D}}+\mathrm{R}_{\mathrm{Q}}(\mathrm{t})\right]$.

26. $U\left(\theta_{\mathrm{m}}\right)={ }_{0} \int^{\infty} \mathrm{J}^{2}(\mathrm{t}) \mathrm{dt}$

Reference: Wilson, "Superconducting Magnets", p. 201, 219 $\left.10^{7}\right)^{2}(1120)=6.41 \times 10^{16^{a l c u l a t e d} \text { from } \mathrm{A}\left(\theta_{\mathrm{m}}\right)=(0.5) \mathrm{J}^{2} \tau_{\mathrm{F}}=\left(\mathrm{m}^{-4} \text { is a maximum since the quenching time }\right.}$ constant will be less than $1120 \mathrm{~s}$.

27. $\int_{0}^{\infty} \mathrm{I}^{2}(\mathrm{t}) \mathrm{dt}--$ MIITS

This is simply $A_{\mathrm{Cu}} \mathrm{U}\left(\theta_{\mathrm{m}}\right)$

28. Maximum adiabatic hot spot temperature, $\theta$

From Wilson, "Superconducting Magnets", Fig. 9.1, p. 202:
$\mathrm{U}\left(\theta_{\mathrm{m}}\right)$
$\rho_{0}(\mathrm{n}-\mathrm{m})$
$6.5 \times, 10^{16}$
$1 \times 10^{-10}$
85
$5 \times 10^{-10}$
120
"
$1.55 \times 10^{-10}$
90

$\theta_{\mathrm{m}}(\mathrm{K})$

The value at $1.55 \times 10^{-10} \mathrm{\Omega}-\mathrm{m}$ is a linear interpolation between the other two points.

29. Initial/maximum eddy current heating in conductor during fast discharge Reference: Design Note \#25

$\mathrm{P}(\mathrm{t})\{$ conductor, 2-m module $\}=\left(\mathrm{N} / \mathrm{R}_{\mathrm{C}}\right)\left(\mathrm{A}_{\text {eff }} \mathrm{dB} / \mathrm{dt}\right)^{2}$

With $\mathrm{N}=616, \mathrm{R}_{\mathrm{C}}=1.55(6.4 \mu \Omega)=9.92 \mu \Omega, \mathrm{A}_{\text {eff }}=0.78 \mathrm{~m}^{2}$

$\mathrm{P}(\mathrm{t})\{$ conductor, $2-\mathrm{m}$ module $\}=37.8 \times 10^{6}(\mathrm{~dB} / \mathrm{dt})^{2}$

$\mathrm{P}_{\mathrm{m}}$ \{cond, 2-m $\}=$ maximum power in the conductor of 2 2-m module $=\mathrm{P}_{0}\{$ cond, $2-\mathrm{m}$ module $\}=\left(\mathrm{N} \mathrm{A}_{\text {eff }} / \mathrm{R}_{\mathrm{C}}\right)(\mathrm{dB} / \mathrm{dt})_{0}$

$$
=37.8 \times 10^{6}\left(\mathrm{~B}_{0} / \tau\right)^{2}=87.1 \mathrm{~W} \text { and }
$$

$\mathrm{P}_{\mathrm{m}}$ \{conductor, eight 2-m modules $\}=697 \mathrm{~W}$

$\mathrm{E}\{$ cond, $8 \times 2-\mathrm{m}\}=$ energy deposited in conductor during fast discharge $=(\tau / 2) \mathrm{P}_{\mathrm{m}}=390 \mathrm{~kJ}$ 
30. Initial/maximum eddy current heating in helium vessel during fast discharge Reference: Design Notes \# 20 and 25

During any discharge

$$
\mathrm{P}(\mathrm{t})\{\mathrm{He} \text { vessel }\}=(\mathrm{M} \mathrm{dI} / \mathrm{dt})^{2} / \mathrm{R}\{\mathrm{He} \text { vessel }\}
$$

During a fast, non-quenching discharge, the maximum power occurs at $t_{0}$ $\mathrm{P}_{0}\{\mathrm{He}$ vessel $\}=\left(\mathrm{MI}_{0} / r_{\mathrm{FD}}\right)^{2} / \mathrm{R}\{\mathrm{He}$ vessel $\}$

For an $8-\mathrm{m}$ He vessel $\mathrm{M}=0.028 \mathrm{H}, \mathrm{I}_{0}=5000 \mathrm{~A}, \tau_{\mathrm{FD}}=1120 \mathrm{~s}, \mathrm{R}\{8-\mathrm{m} \mathrm{He}$ vessel $\}=21.1 \mu n$

$$
\begin{aligned}
& \mathrm{P}_{\mathrm{m}}\{8-\mathrm{m} \mathrm{He} \text { vessel }\}=740.5 \mathrm{~W}, \mathrm{P}_{\mathrm{m}}\{2 \times 8-\mathrm{m} \text { He vessel }\}=1481 \mathrm{~W} \\
& \mathrm{E}\{2,8-\mathrm{m} \mathrm{He} \text { vessels }\}=\left(\tau_{\mathrm{FD}} / 2\right) \mathrm{P}_{\mathrm{m}}=829 \mathrm{~kJ}
\end{aligned}
$$

31. Total energy deposited into coils and He vessels during a fast discharge $\mathrm{E}\{$ total $\}=390+829 \mathrm{~kJ}=1219 \mathrm{~kJ}$

32. Liquid helium boiled during fast discharge

A simple-minded calculation is to apply the energy deposited into the cold mass to boiling LHe at one atmosphere, dividing the energy by the heat of vaporization, $1219 \mathrm{~kJ} / 2.56 \mathrm{~kJ} /$ liquid liter $=475$ liquid liters. If the gas from this quantity of boiloff liquid is removed from the magnet system to the refrigerator without raising the pressure/temperature, then this method and value is correct. If this is not the case, then part of the energy goes into raising the internal energy (temperature) at constant volume. The rate at which liquid is boiled is actually an exponential function of time. Furthermore, a fast discharge will almost surely initiate a quench, in which case the rate at which heat is added to the helium and cold mass will obviously be greater than for a non-quenching fast discharge. We have not attempted to do the comprehensive calculation of the pressure in the helium vessel as a function of time after initiation of a fast discharge or a quench or the rate of venting of helium after the reliefs open.

33. Quenching after initiation of a fast discharge

To investigate whether a quench will be initiated by the eddy current heating in the conductor, We considered the heat flux from the surface of the conductor in a 2-m module, at the time of maximum eddy current heating,

$$
\mathrm{Q} / \mathrm{A}=87.1 \mathrm{~W} / 2(1.8+2.6 \mathrm{~cm})\left(18.4 \times 10^{5} \mathrm{~cm}\right)=5 \mu \mathrm{W} / \mathrm{cm}^{2}
$$

which is in the nucleate boiling regime and a normal spot will collapse rather than propogate. However, the heat flux to a $2-\mathrm{m}$ helium vessel $(185 \mathrm{~W})$ will either boil away or blow out the liquid helium surrounding the coil and it will probably quench--I'm guessing that the gas remaining within the coil won't sustain even this low heat flux.

\section{CHARGING AND SLOW DISCHARGE}

34. Power supply voltage and current

A charging voltage of $100 \mathrm{~V}$ (50 V to ground) gives a linear charge time of about 1.5 hours. In order to provide a linear charge to the operating current of $5 \mathrm{kA}$, the power supply will be capable of $6 \mathrm{kA}$ which it will deliver just as the coil reaches the operating current $(5 \mathrm{kA}$ through the coil and $1 \mathrm{kA}$ through the fast discharge resistor). The supply will be rated at $600 \mathrm{~kW}$. The steady state power would probably be a few volts at $5 \mathrm{kA}$. 
35. Charge rate at constant voltage

$$
\mathrm{V}=\mathrm{L}(\mathrm{dI} / \mathrm{dt}) ; \quad \mathrm{dI} / \mathrm{dt}=\mathrm{V} / \mathrm{L}=100 \mathrm{~V} / 112 \mathrm{H}=0.893 \mathrm{~A} / \mathrm{s}
$$

36. Charge time with constant voltage

$$
\text { Charge time }=5000 \mathrm{~A} / 0.893 \mathrm{~A} / \mathrm{s}=5600 \mathrm{~s}=93.3 \mathrm{~min}
$$

37. Slow discharge resistor

A slow discharge consists of two time segments. During the initial, exponential portion the terminal voltage drops exponentially from an initial value to $75 \mathrm{~V}$, the maximum reverse voltage possible from the $100-\mathrm{V}$ power supply (reference: John Stoffel). The coil current is also decaying exponentially from 5000 A during this time. The SDR was chosen so the intial discharge voltage would be the same as the charging voltage, so $\mathrm{SDR}=100 \mathrm{~V} / 5000 \mathrm{~A}=0.02 \mathrm{n}$. During the exponential portion of the slow discharge the coil current decays from 5000 to 3750 A $\left(75 \% \mathrm{I}_{0}\right)$.

The second portion of the slow discharge is linear at a constant voltage of $75 \mathrm{~V}$. At some low current the reverse power supply voltage will droop, but we have ignored this and assumed a linear discharge from 3750 to $0 \mathrm{~A}$.

38. Slow discharge time constant

$$
\tau_{\mathrm{SD}}=\mathrm{L} / \mathrm{SDR}=112 \mathrm{H} / 0.02 \Omega=5600 \mathrm{~s} \text {. }
$$

39. Exponential slow discharge time, 100 to $75 \mathrm{~V}, 5000$ to $3750 \mathrm{~A}$

$$
\begin{aligned}
& \text { In general } I(t)=I_{0} \exp \left(-t / \tau_{S D}\right) . \quad \text { At } t=t_{1}, I(t) / I_{0}=0.75 \text {, so } \\
& -\left(t_{1} / 5600\right)=\ln (0.75) \text { and } t_{1}=1611 \mathrm{~s} .
\end{aligned}
$$

40. Linear slow discharge time, 3750 to $\mathbf{0 ~} \mathbf{A}$

$$
\text { From } t_{1}, I_{1}=3750 A \text { to } t_{2}, I_{2}=0
$$

$$
\mathrm{dI}(\mathrm{t}) / \mathrm{dt}=\mathrm{V}(\mathrm{t}) / \mathrm{L}=75 / 112=0.67 \mathrm{~A} / \mathrm{s} \text { and }\left(\mathrm{t}_{2}-\mathrm{t}_{1}\right)=3750 / 0.67=5600 \mathrm{~s}
$$

41. Total slow discharge time, from $5 \mathrm{kA}$

$$
t_{2}=t_{1}+\left(t_{2}-t_{1}\right)=1611+5600 \mathrm{~s}=7211 \mathrm{~s}=2 \mathrm{~h}
$$

42. Eddy current heating--general

\section{Power}

$$
\begin{aligned}
& \mathrm{P}(\mathrm{t})\{8-\mathrm{m} \mathrm{He} \text { vessel }\}=[\mathrm{M} \mathrm{dI}(\mathrm{t}) / \mathrm{dt}]^{2} / \mathrm{R}\{8-\mathrm{m} \mathrm{He} \text { vessel }\} \\
& \begin{array}{l}
=[\mathrm{M} \mathrm{V}(\mathrm{t}) / \mathrm{L}]^{2} / \mathrm{R}^{\mathrm{R}}\{8-\mathrm{m}, \mathrm{He} \text { vessel }\}=\left[(0.028 / 112)^{2} / 21.1 \times 10^{-6}\right] \mathrm{V}^{2}(\mathrm{t}) \\
=\left(0.00296 \mathrm{~W} / \mathrm{V}^{2}\right) \mathrm{V}^{2}(\mathrm{t})
\end{array} \\
& \mathrm{P}(\mathrm{t})\{2,8-\mathrm{m} \text { He vessels }\}=(0.00592) \mathrm{V}^{2}(\mathrm{t}) \\
& \mathrm{P}(\mathrm{t})\{2-\mathrm{m} \text { coil }\}=37.8 \times 10^{6}(\mathrm{~dB} / \mathrm{dt})^{2} \\
& =37.8 \times 10^{6}[(1.7 \mathrm{~T} / 5000 \mathrm{~A}) \mathrm{dI} / \mathrm{dt}]^{2} \\
& =\left(37.8 \times 10^{6}\right)\left(0.1156 \times 10^{-6}\right)[\mathrm{V}(\mathrm{t}) / \mathrm{L}]^{2} \\
& =\left[(37.8)(0.1156) /(112){ }^{2}\right] \mathrm{V}^{2}(\mathrm{t}) \\
& =\left(0.000348 \mathrm{~W} / \mathrm{V}^{2}\right) \mathrm{V}^{2}(\mathrm{t}) \\
& \mathrm{P}(\mathrm{t})\{8,2-\mathrm{m} \text { coils }\}=(0.00279) \mathrm{V}^{2}(\mathrm{t}) \\
& \mathrm{P}(\mathrm{t})\{\text { total }\}=(0.00871) \mathrm{V}^{2}(\mathrm{t})
\end{aligned}
$$


Energy

$$
\mathrm{E}=\int \mathrm{P}(\mathrm{t}) \mathrm{dt}
$$

43. Eddy current heating during constant $100-\mathrm{V}$ charge

$$
\begin{aligned}
& \mathrm{P}\{2,8-\mathrm{m} \mathrm{He} \text { vessels }\}=59.2 \mathrm{~W} \\
& \mathrm{P}\{8,2-\mathrm{m} \text { coils }=27.9 \mathrm{~W} \\
& \mathrm{P}\{\text { total }\}=87.1 \mathrm{~W} \\
& \mathrm{E}\{\text { total }\}=(87.1 \mathrm{~W})(5000 \mathrm{~A} / 0.893 \mathrm{~A} / \mathrm{s})=488 \mathrm{~kJ}=190 \mathrm{~L} \mathrm{LHe}
\end{aligned}
$$

44. Eddy current heating during slow discharge

Exponential portion, $\mathrm{t}_{0}=0$ to $\mathrm{t}_{1}=1611 \mathrm{~s} ; \mathrm{V}_{0}=100$ to $\mathrm{V}_{1}=75 \mathrm{~V}$

$$
\begin{aligned}
& \mathrm{P}_{0}\left\{\begin{array}{l}
\text { 2, 8-m He vessels }\}=59.2 \mathrm{~W} \\
\mathrm{P}_{0}^{0}\{8,2-\mathrm{m} \text { coils }\}=27.9 \mathrm{~W}
\end{array}\right. \\
& \begin{array}{l}
\mathrm{P}_{1}\{2,8-\mathrm{m} \mathrm{He} \text { vessels }\}=(0.00592)(75)^{2}=33.3 \mathrm{~W} \\
\mathrm{P}_{1}\{8,2-\mathrm{m} \text { coils }\}=15.7 \mathrm{~W} \\
\mathrm{E}_{0,1}\{\text { total }\}={ }_{0} \int^{1} \mathrm{P}(\mathrm{t}) \mathrm{dt}=(0.00871){ }_{0} \int^{1} \mathrm{~V}^{2}(\mathrm{t}) \mathrm{dt} \\
=(0.00871){ }_{0} \int^{1} \mathrm{~V}_{0}^{2} \exp \left(-2 \mathrm{t}_{1} / \tau\right) \mathrm{dt} \\
=(0.00871) \mathrm{V}_{0}{ }^{2}(-\tau / 2)\left[\exp \left(-2 \mathrm{t}_{1} / \tau\right)-\exp \left(-2 \mathrm{t}_{0} / \tau\right)\right] \\
=(0.00871)(10000)(5600 / 2)[1-\exp (-2 \times 1611 / 5600) \\
=244 \mathrm{~kJ}[1-\exp (-0.572)] \\
=244 \mathrm{~kJ}(1-0.563)=107 \mathrm{~kJ}
\end{array}
\end{aligned}
$$

\begin{tabular}{|c|c|c|c|c|}
\hline$V_{\max }$ & $\begin{array}{l}\text { Charge } \\
100 . \text { (const) }\end{array}$ & $\begin{array}{c}\text { Fast Discharge } \\
500 .(\exp )\end{array}$ & 100. (exp) & $\begin{array}{l}\text { Discharge } \\
\text { 75. (const) }\end{array}$ \\
\hline$P_{m} \underset{\text { vessels }\}--W}{\{2,8-m}$ & 59.2 (const) & 1481. (exp) & 59.2 (exp) & 33.3 (const) \\
\hline $\mathrm{P}_{\mathrm{m}}\left\{\begin{array}{c}\text { coils }\}-\mathrm{W} \\
\text { corm }\end{array}\right.$ & 27.9 (const) & 697. (exp) & $27.9(\exp )$ & 15.7 (const) \\
\hline$P_{m}\{$ total $\}--W$ & 87.1 (const) & 2178. (exp) & $87.1(\exp )$ & 49.0 (const) \\
\hline Energy--kJ & 488. & 1219. & 107. & 274. \\
\hline LHe boiled--L & 190. & 475. & 149. & \\
\hline
\end{tabular}

Linear portion

$$
\begin{aligned}
& \mathrm{P}_{1,2}\{\text { total }\}=33.3+15.7 \mathrm{~W}=49 \mathrm{~W} \\
& \mathrm{E}_{1,2}\{\text { total }\}=(49 \mathrm{~W})(5600 \mathrm{~s})=274 \mathrm{~kJ}
\end{aligned}
$$

Entire discharge

$$
\begin{aligned}
& \mathrm{P}_{\mathrm{m}}\{\text { total }\}=\mathrm{P}_{0}\{\text { total }\}=59.2+27.9 \mathrm{~W}=87.1 \mathrm{~W} \\
& \mathrm{E}_{0,2}\{\text { total }\}=107+274 \mathrm{~kJ}=381 \mathrm{~kJ}=149 \mathrm{~L} \mathrm{LHe}
\end{aligned}
$$

45. Summary of eddy current heating 


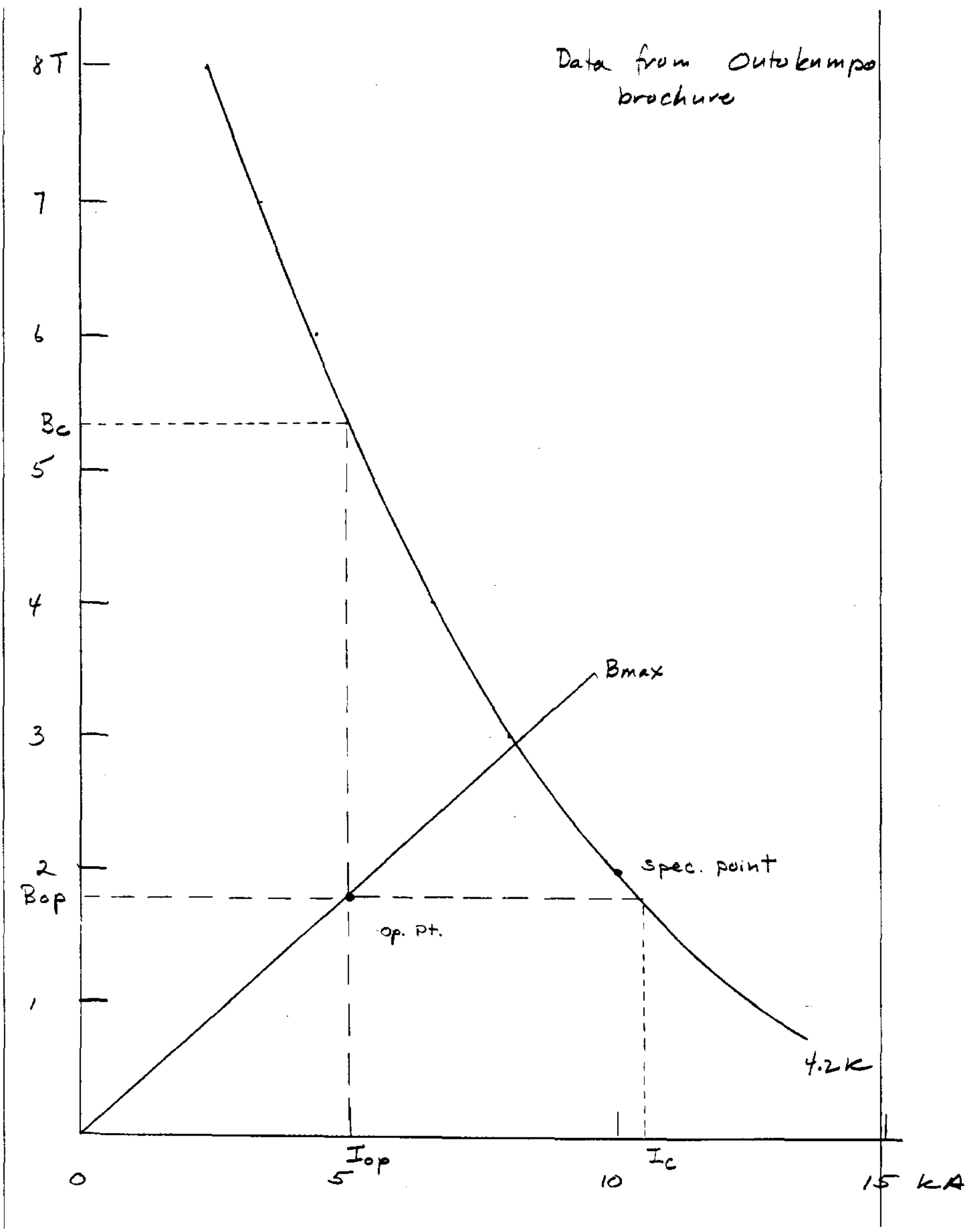

Fig. 1. Short-sample curve and load line 


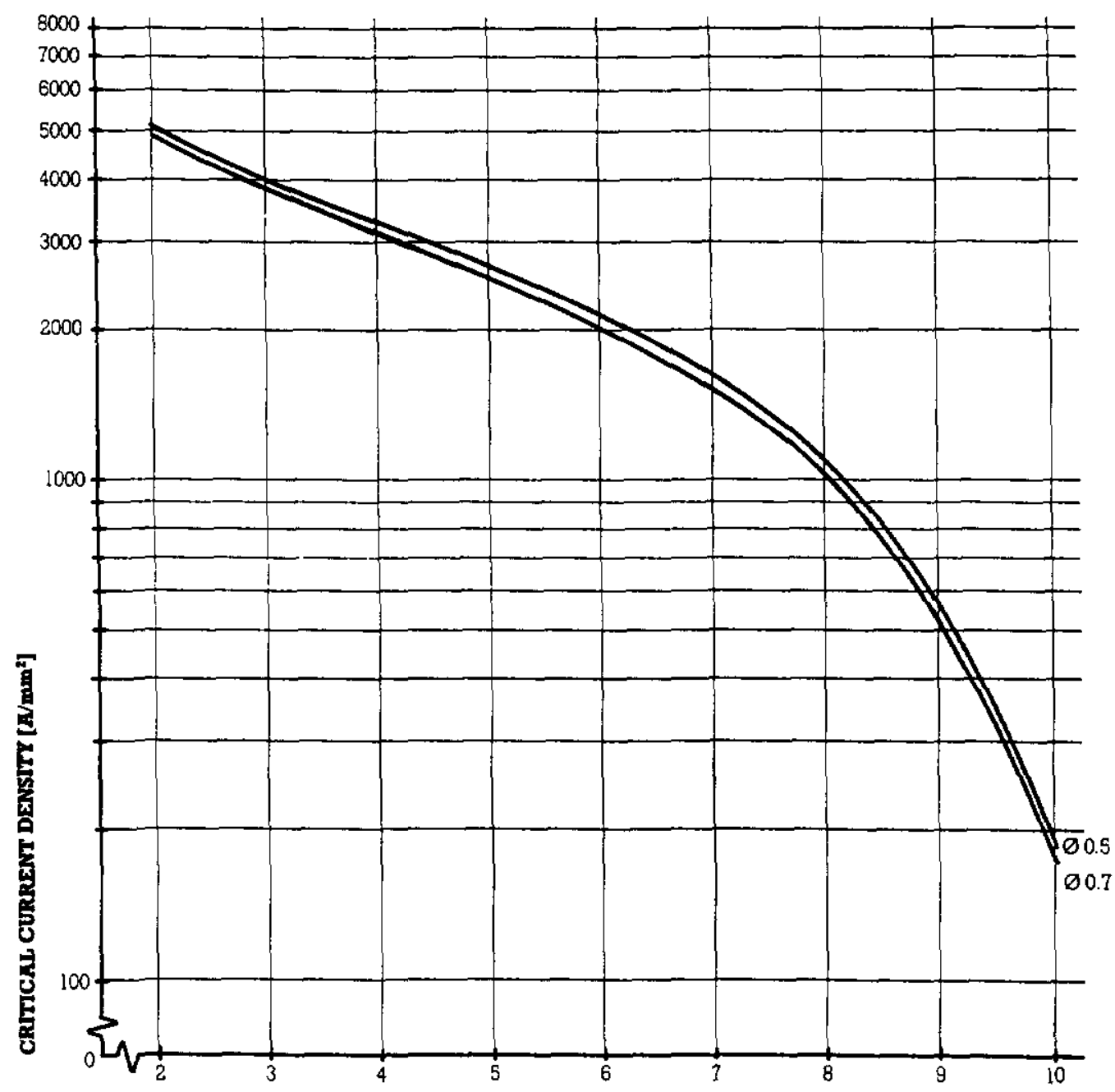

MAGNETIC FIELD [T]

Guaranteed critical current densi- curve for $\varnothing 0.5 \mathrm{~mm}$ and lower ties v.s. magnetic field at $4.2 \mathrm{~K}$ using curve for $\oslash 0.7 \mathrm{~mm}$ SCOK 20 a criterion of $10^{-14} \Omega \mathrm{m}$ for multifilament $\mathrm{Cu} / \mathrm{NbTi}$ wires. Upper SCOK 60 wire types.

SWEDEN

Outokumpu Svenska AB

Exportgatan 81

P.O. Box 321 S-40125 Gothenburg Tel. (0) 31-520330 Telex 21588 okswe s

\section{DENMARK}

Outokumpu Danmark AS

Hvissingevej 116. DK-2600 Glostrup

Tel. (0) 2-966000 Telex 33189 okden dk

FEDERAL REPUBLIC OF GERMANY

Outokumpu Deutschland GmbH \& Co

Grafenberger Allee 68

D-4000 Disseidorf

Tel. (49) $211-679670$ Telex $08586766 \mathrm{okg} \mathrm{d}$

THE NETHERLANDS

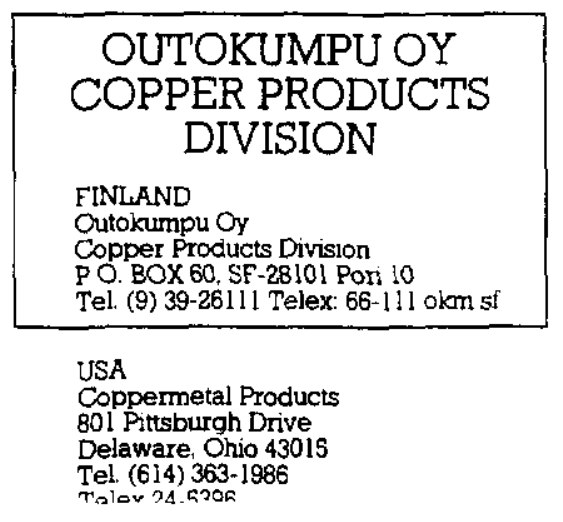

NORWAY

Outokumpu Norge $A / S$

Bärunsvelen 373

P.O. Box 40, 1346 Giettum

Tel. (02) 547800 Telex 18739 oknor $n$

UNITED KINGDOM

Outokumpu (U.K.) Ltd

10 Grosvenor Gardens.

GB-London SWIW ODH

Tel. (0) 1-730 7295 Telex 912500 okeng g

FRANCE

Outokumpu France S.A

168 avenue Charles de Gaulle

F-92200 Neuuly sur Selne

Tel. (0) 1-745 6868 Telex 613045 okfra $f$

Fig. 2. Superconductor current density (from Outokumpu) 
Appendix C: Magnetic Field and Force Calculations

\begin{abstract}
The preliminary design of a large detector for the high energy physics program of the Superconducting Super Collider (SSC) is centered about a large superconducting solenoid magnet producing a field of $1.7 \mathrm{~T}$ over a volume 8 meters in diameter by 16 meters long. Reliability is emphasized due to the difficulty of performing any maintenance or replacement after installation. An important factor in determining reliability is the accuracy with which the solenoid field and electromagnetic forces can be calculated. The ANSYS general purpose finite element program, with 2-d and 3 -d magnetostatic capabilites, was used to calculate magnetic field, Lorentz forces, and stored energy for the proposed solenoid geometry. Axial forces resulting from failure of individual coils were found to be much greater than those expected from initial axial offset of the solenoid from the magnetic center of the iron. Radial decentering forces were found to be negligible in comparison with the overall solenoid weight. Comparison of the $2-d$ and $3-d$ finite element results for field and forces in normal operation showed good agreement.
\end{abstract}

\title{
INTRODUCTION
}

The ANSYS general purpose finite element program has been used previously in the analysis of superconducting detector and accelerator magnets 1,2 . This paper will examine it's use in the 2 -d and $3-d$ analysis of a proposed SSC large detector solenoid, with an emphasis on the effects of mesh refinement and iron characterization on the resulting forces for various normal and upset conditions.

\section{MAGNETOSTATIC ANALYSIS WITH ANSYS}

Magnetostatics belongs to a large class of engineering problems which respond to solution of the Laplace and Poisson equations for potential distribution. Heat conduction, seepage through porous media, and torsion of prismatic shafts are examples of other common problems of the same class. The finite element method is well established as a stable and accurate method of solving these problems.

Two-dimensional magnetostatics is solved by the vector potential approach in $\mathrm{ANSYS}^{3}$, and is exactly analogous to 2 -d heat conduction. The 3-d problem, however, presents special difficulties in a finite element solution, one of which is the three nodal degrees of freedom required by a vector potential formulation. To reduce the degrees of freedom and preserve the heat conduction analogy, ANSYS uses a reduced scalar potential formulation in which the field intensity $\mathrm{H}$ is calculated in two parts. The first part is due to source currents and is found from integration of the Biot-Savart law. The second part is the induced magnetization and is found from a finite element formulation ${ }^{3,4}$. This can lead to numerical cancellation problems when the induced magnetization and current source contributions are nearly equal, as occurs in highly permeable regions.

Lorentz forces on current sources and the Maxwell stress tensor forces on ferromagnetic regions are calculated from the field solution. In the 2-d 
case, ANSYS calculates and stores the Lorentz forces during the solution phase; these can then be listed directly during post-processing. The Maxwell stress tensor forces can be calculated by the user in the post-processing phase by defining a path through the air around a ferromagnetic region. ANSYS then performs the necessary integration to calculate the forces.

The calculation of forces in 3-d varies depending on the way in which the current sources are modeled. Standard source shapes such as bars, arcs, and coils can be input in terms of a few geometric parameters, which are then used for the Biot-Savart integration. The sources do not exist as finite elements, and the program does not calculate and store Lorentz forces for them. However, the user can perform the Lorentz force calculations using the post-processor and the field solution.

Complex 3-d source shapes may be modeled with finite elements which carry a specified current. The program calculates the Lorentz force on each element from the field solution and element current density. Regardless of source definition, forces on ferromagnetic regions can be calculated by a method of virtual work during the solution phase, and retrieved during postprocessing.

Although ANSYS has recently added full 3 -d vector potential and difference scalar potential elements, these were not available at the time this analysis was done.

\section{THE PROPOSED SSC DETECTOR SOLENOID}

An axisymmetric cross section of the proposed SSC detector solenoid is shown in Fig. 1 and consists of eight superconducting, pool-boiling coils, each 1.8 meters in magnetic length and 5 meters in radius. Four coils are assembled into an $8-\mathrm{m}$ assembly, witl the two assemblies independently supported in the magnet iron.

The magnet iron is octagonal in cross section, and includes endplugs which can, if necessary, be designed to extend into the bore of the outermost coils.

\section{OBJECTIVES OF THE ANALYSIS}

The objective of the analysis was to determine:

1. The correct current density for real iron to produce a central field of $1.7 \mathrm{~T}$,

2. The amount of endplug "re-entry" into the bore of the outermost coils to eliminate axial force for nominal assembly,

3. The decentering forces resulting from initial installation offsets of the solenoid from the magnetic center of the iron.

4. The maximum safe test current for single coil without iron,

5. The maximum stored energy and inductance, 


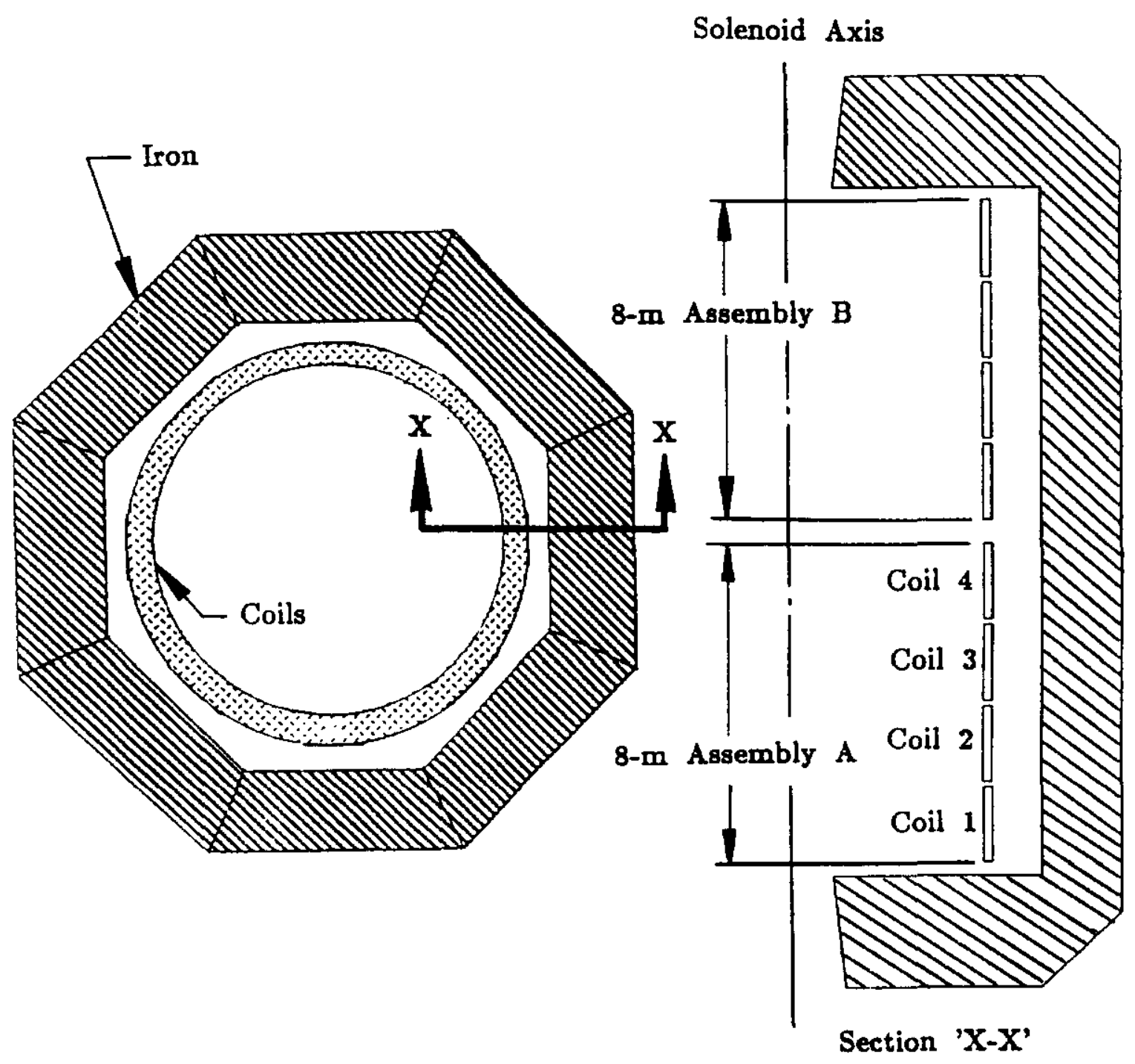

Fig. 1. SSC detector solenoid.

6. The axial forces resulting from the failure of a single coil module and consideration of the possiblity of designing for operation with less than eight coils energized to full current, and

\section{Verification.}

\section{TWO-DIMENSIONAL FINITE ELEMENT MODELS}

All of the analysis objectives except the radial decentering force may be met with a 2-d axisymmetric finite element anslysis. A typical mesh is shown in Fig. 2. This mesh, using elements which are a maximum of 0.5 meters on a side, results in approximately $200 \mathrm{cp}$ seconds/iteration on a VAX3200 workstation. Up to 20 iterations were required by some runs to achieve convergence with real iron. The full model was necessary for coil failure and axial decentering analyses; during normal operation only one half of the solenoid need be modeled. 


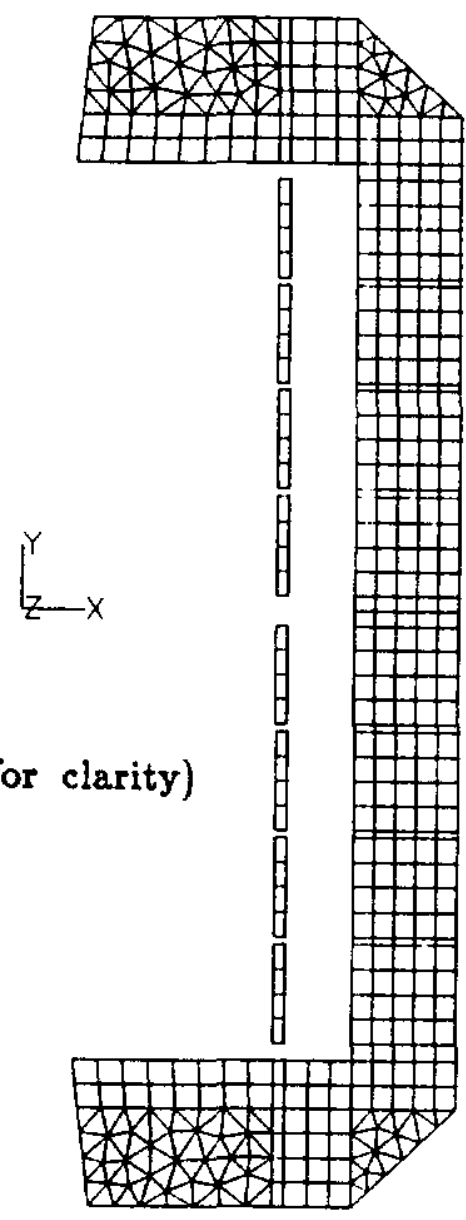

Fig. 2. 2-d axisymmetric finite element model.

Operating current for $1.7 \mathrm{~T}$ central field. The current required for a central field of 1.7 tesla was found for meshes with element sizes varying from 1 meter to 0.125 meters. Runs with infinitely permeable iron showed that the necessary current density was $7.3\left(10^{6}\right) \mathrm{A} / \mathrm{m}^{2}$. For the proposed 616 turns of conductor in each coil, the superconductor operating current was 4560 amps. The central field varied by less than $0.1 \%$ over the range of element sizes considered. Later runs used a real B-H curve for typical 1020 magnet iron with both 0.5 and 0.25 meter element sizes, and the central field decreased by about $0.5 \%$ from the infinitely permeable iron results.

Re-entrant iron to minimize axial force. Results of runs with infinite iron permeability showed that the endplug iron should end approximately 0.3 meters outside of the bore of the outermost coil in order to minimize the axial force for a "perfectly" installed 8-m assembly. Refined models with real iron verified this result.

Axial decentering forces. These forces can result from installing the 8-m assemblies offset axially with respect to the magnetic center of the iron yoke. Five load cases were considered, using real iron and an element size of 0.5 meters. The results are summarized in Table 1 . The maximum force was found for the case of a $25 \mathrm{~mm}$ displacement of each of the $8-\mathrm{m}$ assemblies toward the center of the solenoid, and was $12400 \mathrm{kN}$. 
Table 1. Axial Decentering Forces

Load Case and Axial Offset

1. 8-m assembly A: $25 \mathrm{~mm}$

8-m assembly B: nominal

2. 8-m assembly A: $25 \mathrm{~mm}$

8-m assembly B: $25 \mathrm{~mm}$

3. 8-m assembly A: $25 \mathrm{~mm}$

8-m assembly B: $-25 \mathrm{~mm}$

4. 8-m assembly A: $-25 \mathrm{~mm}$ 8-m assembly B: $-25 \mathrm{~mm}$

5. $8-\mathrm{m}$ assembly A: $-25 \mathrm{~mm}$ 8-m assembly $B$ : nominal
Force on 8-m assembly

$11600 \mathrm{kN}$

$10200 \mathrm{kN}$

$12400 \mathrm{kN}$

$12400 \mathrm{kN}$

$10700 \mathrm{kN}$

$4000 \mathrm{kN}$

$2700 \mathrm{kN}$

$2700 \mathrm{kN}$

$11600 \mathrm{kN}$

$8900 \mathrm{kN}$

Note: Positive offsets and forces are toward solenoid midplane

Maximum test current for coil. The coils will be tested without iron, and so will be subjected to large compressive forces. The maximum test current was established by finding the worst case operational compressive force, and calculating from a finite element model of a coil in air the current which will produce that force. In normal operation, the maximum force occurs in the coils at the ends of the solenoid, and is $13300 \mathrm{kN}$. A finite element model of a single coil shows that a current density of $1\left(10^{6}\right) \mathrm{A} / \mathrm{m}^{2}$ gives a maximum coil force of $300 \mathrm{kN}$. Scaling this force gives a maximum test current density of $6.5\left(10^{6}\right) \mathrm{A} / \mathrm{m}^{2}$, or 4060 amps.

Maximum stored energy and inductance. The stored energy from the two-dimensional models was calculated in the post-processing phase by performing a numerical integration over the volume of the conductor region of the product of the magnetic potential and the current density. The inductance can then be calculated from the stored energy and the total current. The stored energy for normal operation was found to be $1400 \mathrm{MJ}$, while the inductance was $112 \mathrm{H}$.

Axial forces due to coil failure. The coils may be individually energized, and the magnetic field and axial forces resulting from running the magnet with a failed coil were calculated. Figure 3 shows the variation of the field with coil failure. Resulting axial forces are shown in Table 2. The maximum axial force of $54200 \mathrm{kN}$ occurs on $8-\mathrm{m}$ assembly $\mathrm{A}$ when coil 1 fails.

\section{THREE-DIMENSIONAL FINITE ELEMENT MODELS}

The calculation of the radial decentering force on an $8-\mathrm{m}$ module assembly requires a $3-d$ finite element model of one-half of an 8-m assembly (Fig. 4). There are approximately 9000 nodes and elements, and one iteration of the model requires $6100 \mathrm{cp}$ seconds on a VAX3200 workstation. 


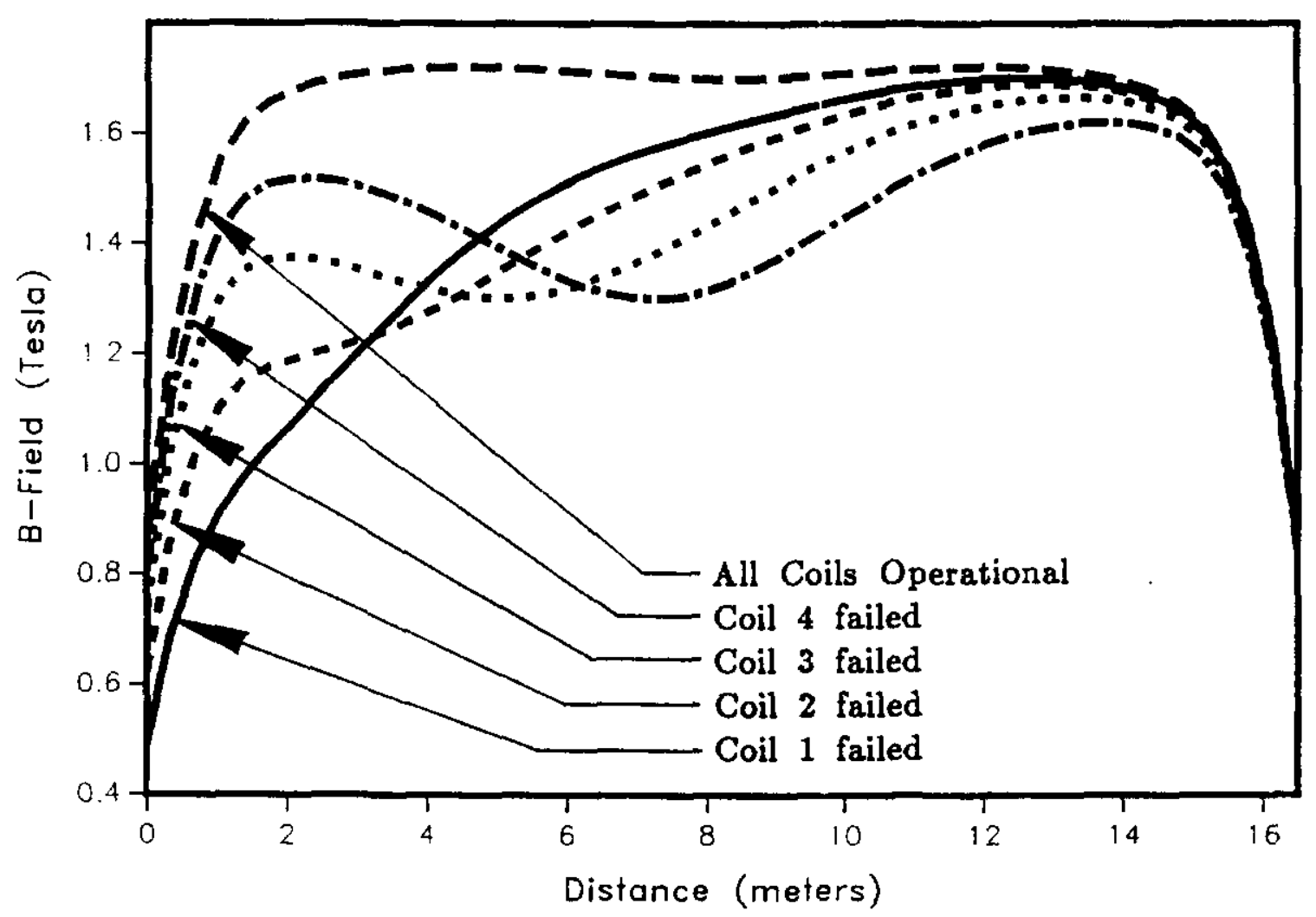

Fig. 3. Field on solenoid axis for coil failure scenarios.

Table 2. Maximum Axial Force on 8-m Assembly Due to Individual Coil Failure

Failed Module

(see Fig. 1)

\section{Model Characteristics}

$\begin{array}{cccc} & \begin{array}{c}\text { Inf. mu, 0.5 } \\ \text { mm element }\end{array} & \begin{array}{c}\text { Inf. mu, 0.2 } \\ \text { mm element }\end{array} & \begin{array}{c}\text { Real iron, } 0.50 \\ \text { mm element }\end{array} \\ \text { Coil 1 } & 54200 \mathrm{kN} & 54200 \mathrm{kN} & 53800 \mathrm{kN} \\ & 8-\mathrm{m} \text { assembly A } & 8-\mathrm{m} \text { assembly A } & 8-\mathrm{m} \text { assembly A } \\ \text { Coil 2 } & 23400 \mathrm{kN} & 23400 \mathrm{kN} & 23350 \mathrm{kN} \\ & 8-\mathrm{m} \text { assembly A } & 8-\mathrm{m} \text { assembly A } & 8-\mathrm{m} \text { assembly A } \\ \text { Coil 3 } & -15300 \mathrm{kN} & -15400 \mathrm{kN} & -15000 \mathrm{kN} \\ & 8-\mathrm{m} \text { assembly B } & 8-\mathrm{m} \text { assembly B } & 8-\mathrm{m} \text { assembly B } \\ \text { Coil } 4 & -37000 \mathrm{kN} & -36900 \mathrm{kN} & -36700 \mathrm{kN} \\ & 8-\mathrm{m} \text { assembly B } & 8-\mathrm{m} \text { assembly B } & 8-\mathrm{m} \text { assembly B }\end{array}$

Note: Positive force is toward solenoid midplane 


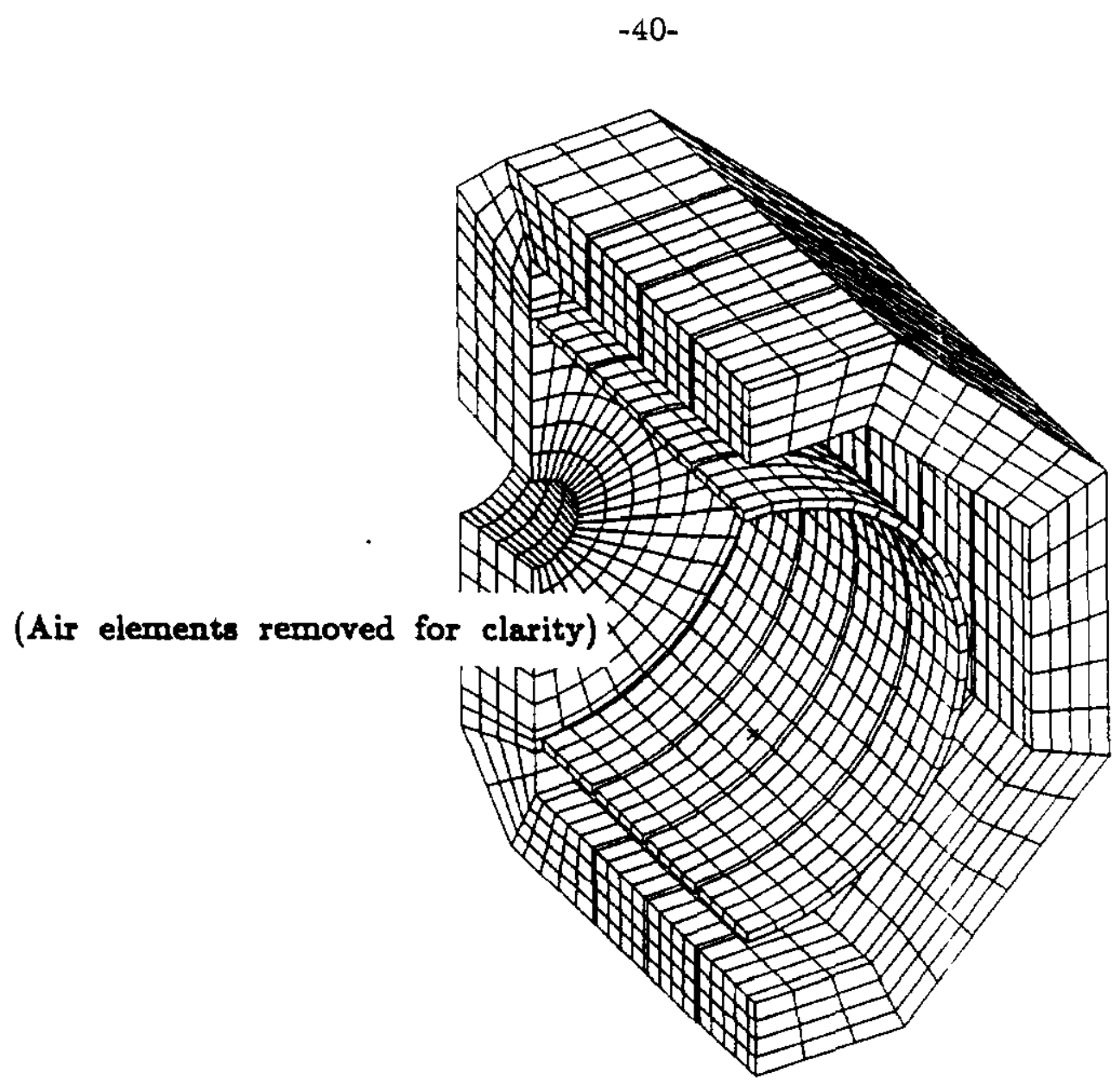

Fig. 4. 3-d finite element model.

Radial Decentering Force. This force was found by displacing the coil centroids by $25 \mathrm{~mm}$ along the $x$-axis of the model. The coil elements were also displaced by $25 \mathrm{~mm}$ so that they were coincident with coil definitions. The virtual work option was used for force calculation. The results of the model showed that the radial decentering force resulting from a $25 \mathrm{~mm}$ offset from magnetic center was $200 \mathrm{kN}$.

\section{VERIFICATION}

Some analytical calculations can be made with which FEA results can be compared. For example, the original coil dimensions and currents were established by approximate hand calculations, and the FEA provided reasonable refinements of these for the present design. Stored energy, calculated by the assumption of uniform $1.7 \mathrm{~T}$ central field, is $1600 \mathrm{MJ}$, comparing with 1400 MJ from the FEA.

Another good indication of modeling accuracy is comparison of 2-d and 3-d FEA results for identical loadings.

Comparison of $2-d$ and $3-d$ FEA results. A 3-d model with $1 / 16$ th azimuthal symmetry was given the same current density as the 2-d model with infinitely permeable iron and an element size of $0.5 \mathrm{~m}$. Figure 5 shows the absolute difference of the axial field as calculated by the two models. Agreement was within $0.03 \mathrm{~T}$ at all points, and much better near the center of the solenoid. 


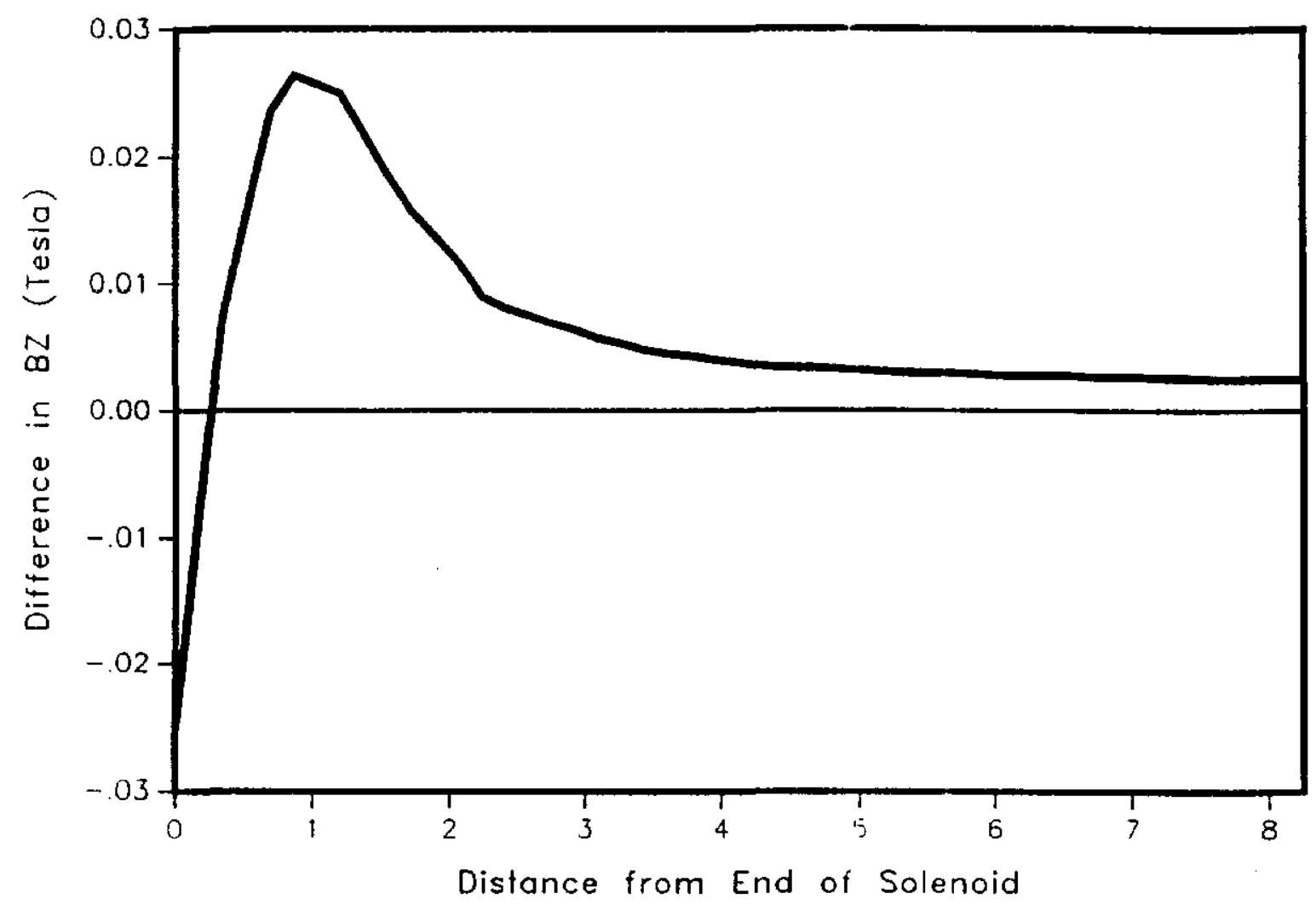

Fig. 5. Difference in axial field for 2-d and 3-d models.

The forces on the coils were extracted from the 3-d model through the post-processor by taking the cross product of the current density and the radial component of the $B$-field. These forces were compared with those from the 2-d model and found to agree to within $7 \%$ for all modules.

\section{CONCLUSION}

The 2-d and 3-d magnetostatic analysis of the SSC solenoid was a straightforward application of the ANSYS program. The largest axial force of $54200 \mathrm{kN}$ on an $8-\mathrm{m}$ assembly was found for a coil module failure scenario. Radial decentering forces were negligible. These results canpes be used to establish the design forces for the $8-\mathrm{m}$ assembly support systems.

\section{REFERENCES}

1. M. Johnson, R. Wands, and E. Wolin, Design of Electromagnetic Devices Using Commercial Finite Element Programs, Rev. Sci Instrum., Vol. 58 , No. 12 (1987)

2. R. Wands and M. Chapman, Finite Element Analysis of Dipole Magnets for the Superconducting Super Collider, in "ANSYS 1989 Conference Proceedings", Vol. II, Swanson Analysis Systems, Inc., Houston, Penn., (1989), p. 7.42

3. D. Ostergaard, "Magnetics for Static Fields," ANSYS Revision 4.3 Tutorials, Vol. II, Swanson Analysis Systems, Inc., Houston, Penn., (1987)

4. O. C. Zienkiewicz, J. Lyness, and D.J.R. Owen, Three-Dimensional Magnetic Field Determination using a Scalar Potential, IEEE Transactions on Magnetics, Vol. Mag. 13, No. 5 (1977) 
Appendix D: Ground Transportation of Solenoid Modules

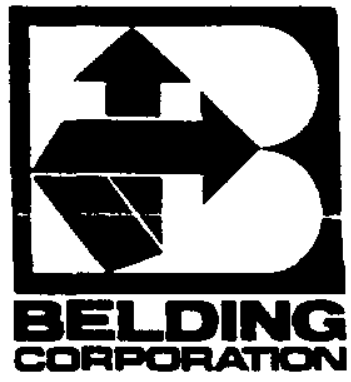

130 WEST GRAND LAKE BOULEVARD

P.O. BOX NO. 227

Suburban: (312) 231.5200

Chicago: (312) 287-0104

WEST CHICAGO IL 60185-0227

FAX: (312) 231.0318

December 9, 1938

Mr. Bob Shovan

Fermi National Accelerator Laboratory

M S 318

P. O. Box 500

Batavia, IL 60510

Reference: Moving eight (8) coils

$33 \mathrm{ft}$. in diameter $-7 \mathrm{ft}$. high

Weighing 100 tons each

From the water at Galveston, Texas

to Waxahachie, Texas

Dear Mr. Shovan:

Our people believe that the state of Texas would cooperate in every way possible to allow this move to be done. Their suggestion is as follows:

Rather than Galveston, go up the Brasos River at Freeport to Columbia. This stretch has been navigable for barging nuclear products and heavy reactors in the past. We would offload in Columbia, and move up Highway 36 to Sealy.

Then: move West on interstate \#10 to Brookshire, then North on Route 359 to Sauney Stand; North on Route 6 to Hearne; then North on Route 14 to Mexia.

From Mexia, take Route 171 Northwest to Brandon; then North on Route 77 to the site at Waxahachie.

Possible cost for this move:

Engineering fee to the state of Texas, which would include examining bridges and possibly moving light and telephone wires for proper clearances: 
(59) Gamesvingy of

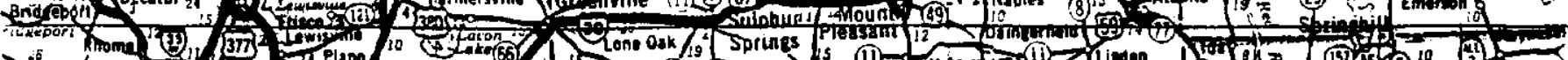

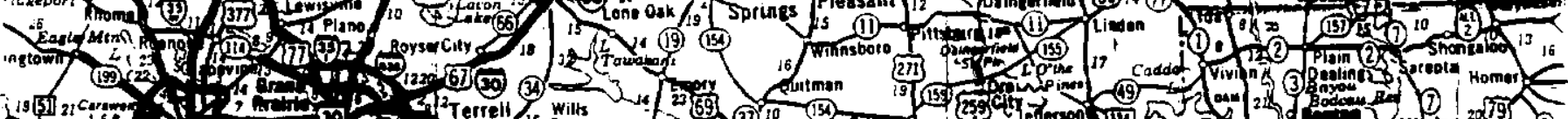

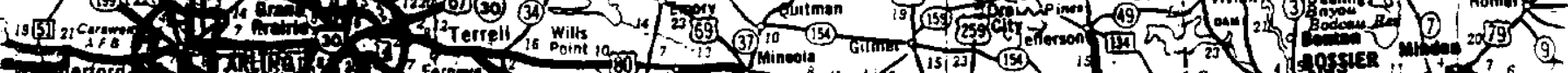

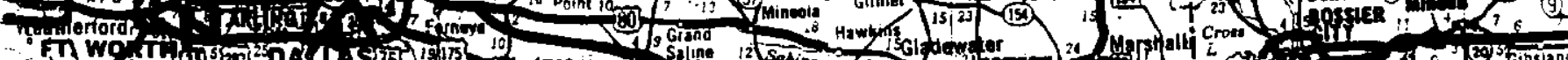

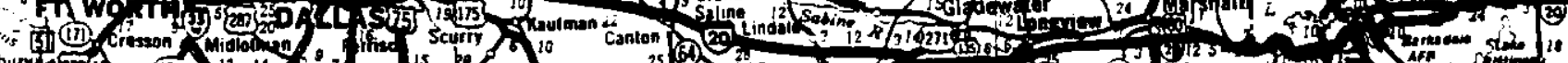

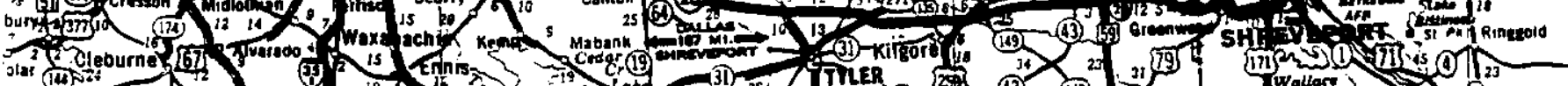

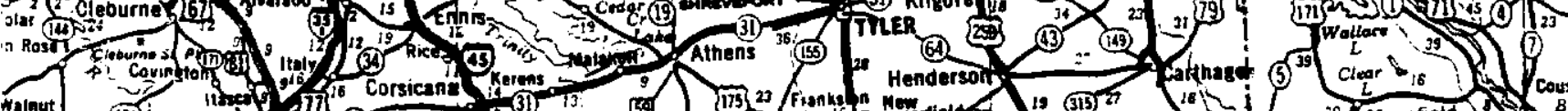

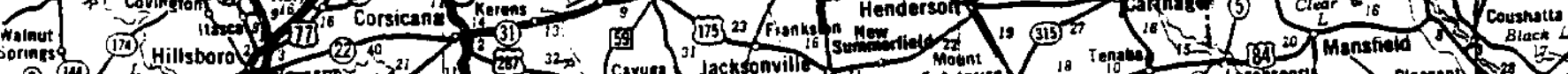
(6) (ii4) whitnev, Meridis 2243920

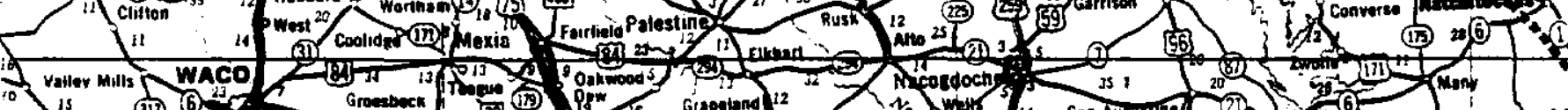
84) Lateavitie a

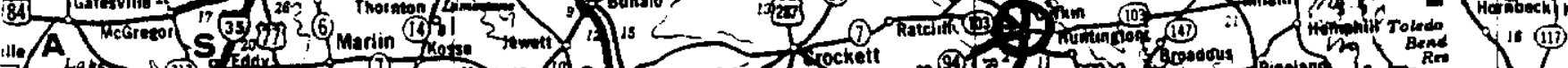
15. (1)

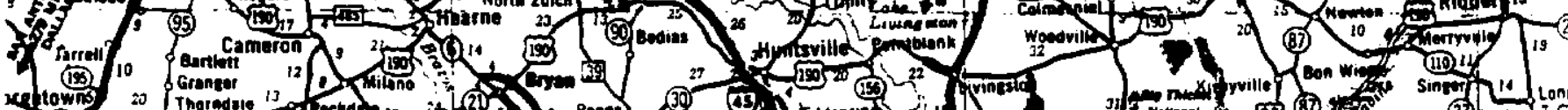

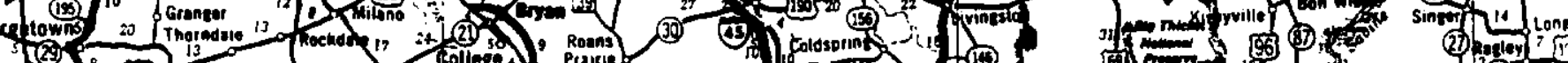

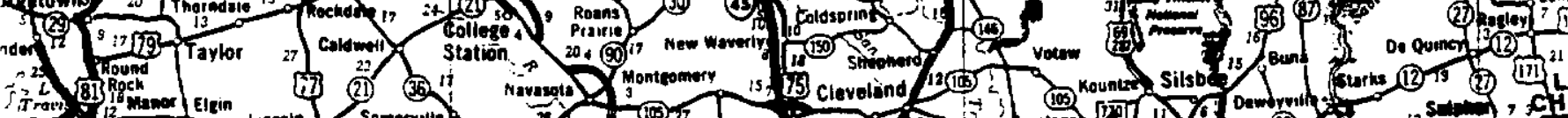

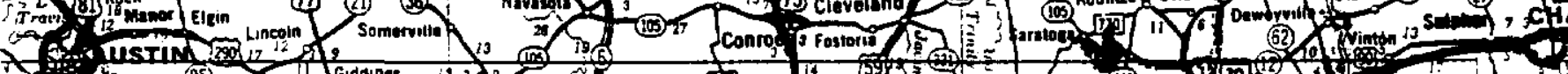

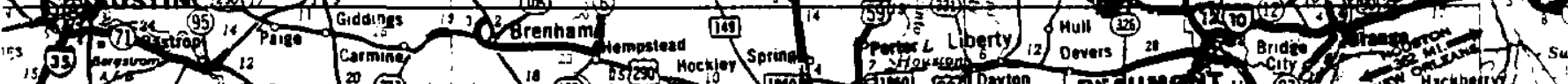
(21) (183)

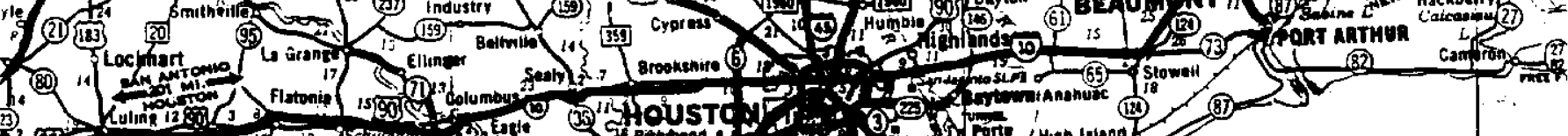

13.

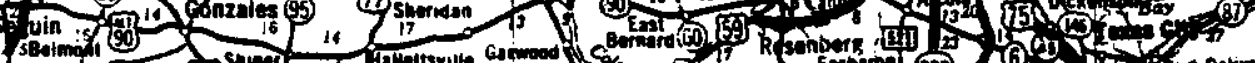

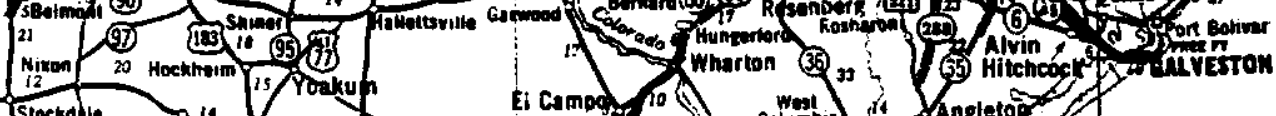

INDEX TOCITIES AND TOW


$-43-$

Page Two

Mr. Bob Shovan

Fermi National Accelerator Lab

December 9,1988

Actual road improvements, cost of moving poles, bracing bridges or ramping other approaches, etc. $\$ 50,000$

cost for moving each piece Approximately $\$ 30,000$

I hope this information will be helpful to you. please call us at any time for help.

Sincerely yours,

BELDING CORPORATION

$P$ Pap

dhip belding

Chairman of the Board \& CEO

el 
Appendix E. Refrigeration System Parameters and Backup Remarks

\section{PARAMETERS}

LIQUID NITROGEN CRYOGENIC SYSTEM

Cooling mode

Average fluid temperature

Total flow rate

Number of circuits

Expected heat load

\section{LIQUID HELIUM CRYOGENIC SYSTEM}

Cooling mode

Number of circuits

Module flow rate, gas fraction

Support intercept flow rate, gas fraction

Heat load per 8-m assembly

Volume of LHe in coil modules

Number of storage dewars

Capacity of storage dewars

Total heat load of magnet system

Specified refrigerator capacity

COOLDOWN REFRIGERATOR

Total cold mass

Cooldown system

Cooldown time forced flow of subcooled liquid

$83 \mathrm{~K}$

$410 \mathrm{~g} / \mathrm{s}$

10 to 12

$5 \mathrm{~kW}$

thermosiphon

14

$25 \mathrm{~g} / \mathrm{s}$ at $1 \%$ gas by weight

$50 \mathrm{~g} / \mathrm{s}$ at $7 \%$ gas by weight

$115 \mathrm{~W}+18 \mathrm{~L} / \mathrm{h}$

(one pair of current leads)

$\sim 10,000 \mathrm{~L}$

2

5000 L each

$230 \mathrm{~W}+36 \mathrm{~L} / \mathrm{h}$

(two pairs of current leads)

$1600-1800 \mathrm{~W}$

1328 tonnes

LIN-GHe HTX, with turbo expander

15 to 20 days 


\section{BACKUP REMARKS}

\section{LIQUID NITROGEN CRYOGENIC SYSTEM}

1. Cooling mode

Reference: Design Note \#10. The LIN cooling system is basically a copy of that planned for the SSC ring magnet system, in which the LIN supply is 77-K, 6 -ata subcooled liquid and the return $89 \mathrm{~K}$ and 4.7 ata. Flow is maintained by liquid circulators (pumps) with a pressure ratio $6 / 4.7=1.28$.

2. Average fluid temperature

$$
=(77+89) / 2=83 \mathrm{~K}
$$

3. Total flow rate

Reference: NBS Technical Note 129

$\mathrm{h}(77 \mathrm{~K}, 6$ ata $)=29.000 \mathrm{~J} / \mathrm{g} \quad \mathrm{h}(83 \mathrm{~K}, 4.7$ ata $)=41.228 \mathrm{~J} / \mathrm{g}$

Assuming a heat load of $5 \mathrm{~kW}$ for the magnet system, flow rate $=5000 \mathrm{~J} / \mathrm{s} /(41.228-29.000) \mathrm{J} / \mathrm{g}=409 \mathrm{~g} / \mathrm{s}$

4. Number of nitrogen cooling circuits

On each 8-m assembly: (1) inner radiation shield, (2) outer radiation shield, (3 \& 4) end radiation shield and radial support intercepts, (5) axial support intercepts. The LHe dewar might have its own circuit (6).

5. Expected heat load

Reference: Design Note 31 , paper at IISSC-89.

A value of $50 \mathrm{~W}$ is given for the $16-\mathrm{m}$ magnet system in this design note, substantiating calculations are not available.

\section{LIQUID HELIUM CRYOGENIC SYSTEM}

6. Cooling mode

We chose a thermosiphon as was used for the MFTF solenoids and the Aleph solenoid at CERN/LEP.

7. Number of circuits

On each 8-m assembly: (1 -4) coil modules, (5) axial support intercepts, (6 $\&$ 7) radial support intercepts.

8. Module flow rate/gas fraction

Reference: Design Note \#24, paper at ICEC-12; also DN \#26 (ASC) and DN \#31 (IISSC). These are the only reference documents on this subject. DN \#24 gives $23 \mathrm{~g} / \mathrm{s}$ with $<1 \%$ by weight, DN \#26 and 31 give $25 \mathrm{~g} / \mathrm{s}$ with $<1 \%$

9. Support intercepts flow rate/gas fraction

Design Note \#24 gives $50 \mathrm{~g} / \mathrm{s}$ at $<7 \%$ gas by weight, DN \#26 and 31 give only the $7 \%$. 
SSC DETECTOR SOLENOID DESIGN NOTE \#10

TITLE: Preliminary $\mathrm{LN}_{2}$ Shield Cooling

AUTHOR: M.E. Stone

DATE: January 26, 1988 


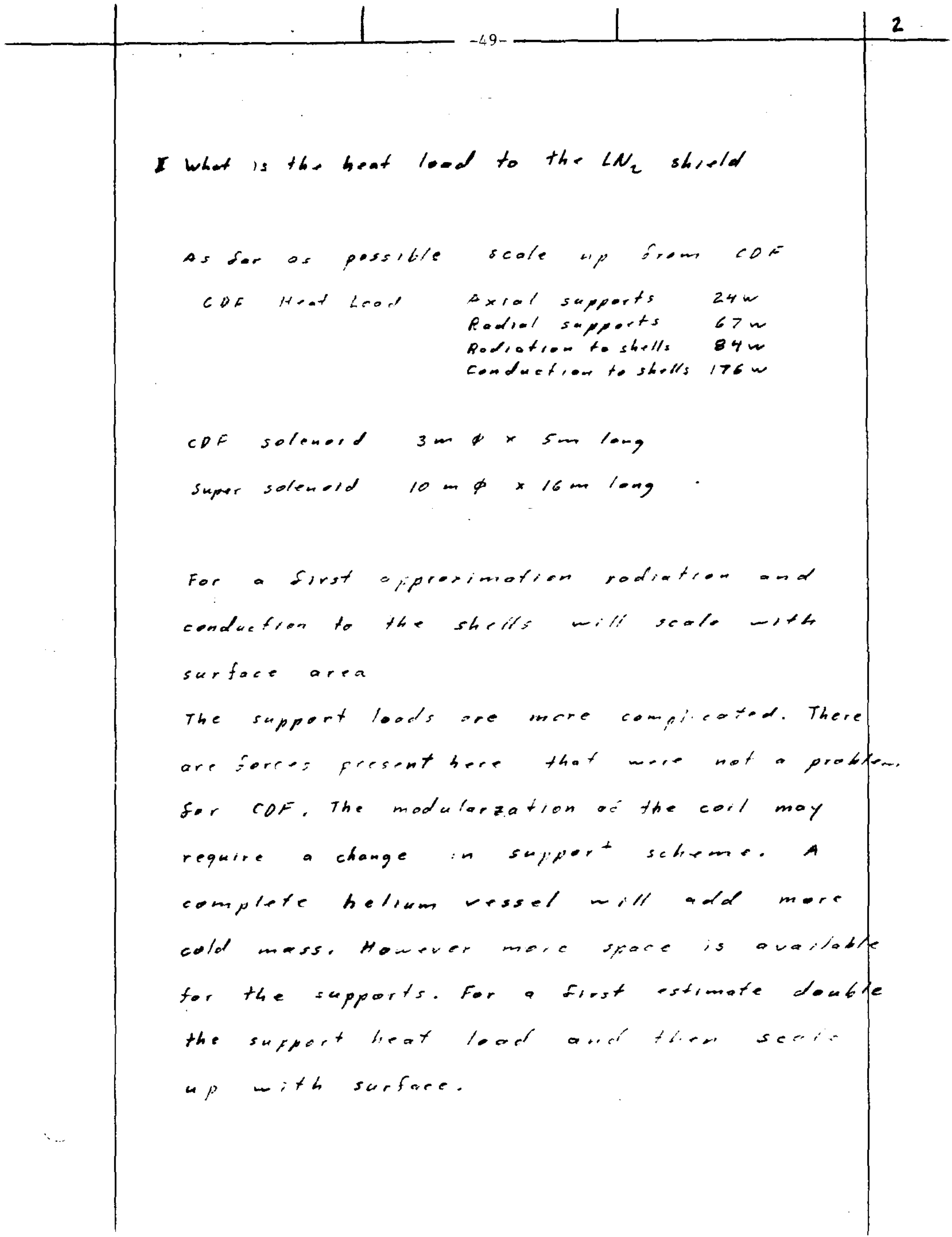




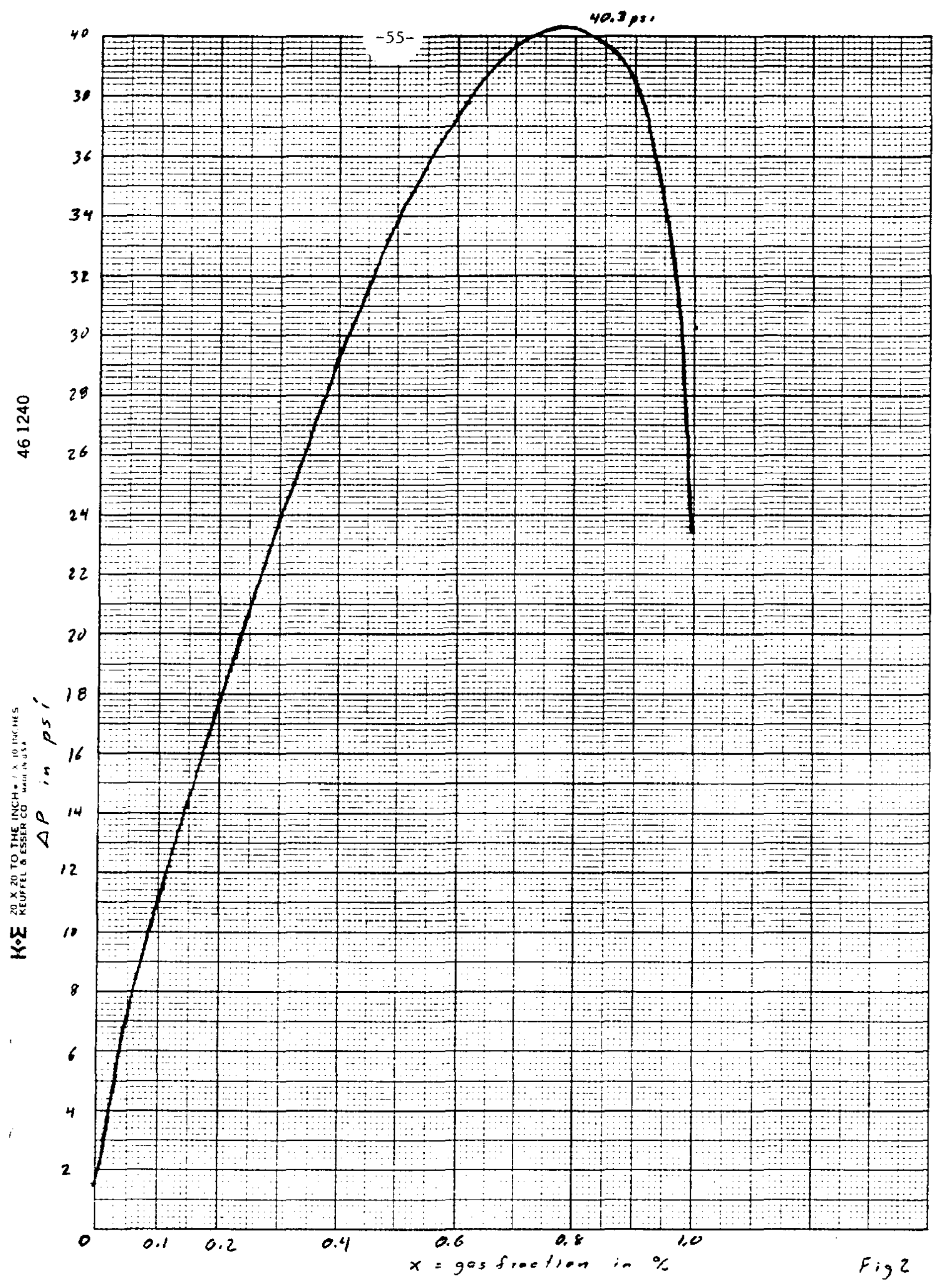




\title{
SSC DETECTOR SOLENOID DESIGN NOTE \#18
}

TITLE: Quench Safety I: Choice of Current Densities

AUTHOR: $\quad$ R.W. Fast

DATE: $\quad$ Apr. 6, 1988

\section{CONCLUSION}

\begin{abstract}
A 4-m coil module, with a conductor current density of $\sim 3000 \mathrm{~A} / \mathrm{cm} 2$, will be safe against a quench and will have a sufficiently low surface heat flux. A 2-m module with $\sim 5000 \mathrm{~A} / \mathrm{cm} 2$ will be safe on quench, but the surface heat flux is a bit high. A current density of 1600 to $1800 \mathrm{~A} / \mathrm{cm} 2$ will permit the coil modules, of whatever size, to be electrically connected into 8-m units.
\end{abstract}


$-57-$

I. Calculate the maximum current density that is consistent with quenching. safely.

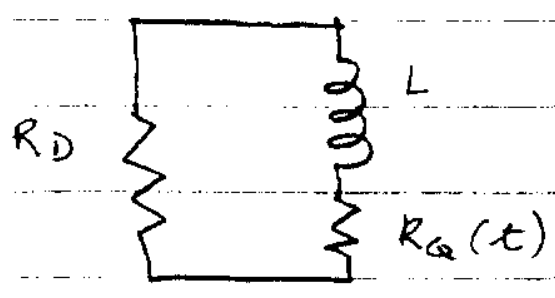

If we ignore the mutual in ductance between coil modules and if $R_{D}>R_{Q}(t)$, the current decay is:

$$
I(t)=I_{0} e^{-\frac{R_{D}}{L} t} ; J(t)=J_{0} e^{-\frac{R D}{L} t}
$$

and

$$
\int_{0}^{\infty} J^{2}(t) d t=\frac{1}{2} J_{0}^{2} \frac{L}{R_{D}}=U\left(\theta_{m}\right) \quad\left(\omega i / s_{m}, p 2 / 9\right)
$$

Solving for Jo:

$$
J_{0}^{2}=\frac{2 U\left(\theta_{m}\right)}{L / R_{D}} ; \quad J_{0}=\sqrt{\frac{2 U\left(\theta_{m}\right)}{L / R_{D}}}
$$

Now let $\theta_{m}=100 \mathrm{~K}$, with $R R R \sim 100$, $\left(\rho_{a_{1}}=10^{-10} \Omega-m\right)$, then

$$
U(\theta m)=Z \times 10^{16} A^{2}-5-m^{-4}
$$

and

$$
J_{0}\left(\theta_{m}=100 \mathrm{~K}\right)=\frac{3.74 \times 10^{8}}{\sqrt{L / R_{D}}} A-S^{1 / 2}-m^{-2}
$$

If we limit the terminal voltage to $500 \mathrm{~V}$ 
$--58-$

then

$R_{D}=0.1 \Omega$ fo a $5 k A$ magnet, independent of 4 .

Solving for $\sigma_{0}(100 K)$ tr different inductances (coil module lengths):

\begin{tabular}{cccc}
$\begin{array}{l}\text { Nominal } \\
\text { Coil length }\end{array}$ & $L^{*}$ & $R$ & $J_{\text {coma }}(100 \mathrm{k})$ \\
$(\mathrm{m})$ & $(\mathrm{H})$ & $(\Omega)$ & $\left(\mathrm{A} / \mathrm{cm}^{2}\right)$ \\
\hline 8 & 49.6 & 0.1 & 1679 \\
4 & 18.1 & 0.1 & 2780 \\
2 & 5.75 & 0.1 & 4932
\end{tabular}

* For 9-m diameter see $D N * 17$

II. Compare current densities of recent large se magnets

Magnet Brian

(7)

Tohokn B.C.

COM

$15^{\prime} B . C$.

$\angle C T / G D$

LCT/Japar

MFTF- yo.

MFTF- Solemn.
4.9

2.8

4.5

8.0

8.0

7. 7

3.2
Tend

$\left(A / \mathrm{cm}^{2}\right)$

6670

9568

3700

4075

3027

4978

4586 max temp Qm.

(K)

$?$

$?$

$?$

2.00

210

124 
$\cdot-59-\cdot$

III. Surface heat flux at Icons $=3000 \mathrm{~A} / \mathrm{cm}^{2}$ and $I=5 \mathrm{kA}$ (a 4-m coil module)

$A_{\text {cone }} \sim A_{\text {cu }}=\frac{5000}{3000} \mathrm{~cm}^{2}=1.7 \mathrm{~cm}^{2}$

If the conductor were square, $a=b=1.3 \mathrm{~cm}$

The Heat $F$ lux $=\frac{I^{2} P}{\gamma(a b)^{2(a+b)}}$

where $x$ function of surface welted

Parameter MFTF-S Dit. Solemn. Det.solen. Current (A) $2866 \quad 5000 \quad 5000$ conductor (anam) $1.25 \times 0.5 \ldots 1.3 \times 1.3 \quad 1.0 \times 1.0$

Alone ( $\left.\mathrm{cm}^{2}\right) \quad 0.625$ $1.7 \quad 1.0$

Fond $\left(A / \mathrm{cm}^{2}\right) \quad 4586$ 3000 5000 $P(\Omega-4 m) \cdot 10^{-8}$ $10^{-8}$ $10^{-10}$

$\left.I^{2} \rho / 2 a b / a+b\right)\left(w / a m^{2}\right) \quad 0.0375$ $0.0283-0.0625=$

$I^{2} p / 2(\gamma a b)(a+b)\left(\omega / m^{2}\right)$ $0.15 t$ 0.118 0.260 $(\log 11-16)$ $\gamma$ 0.24
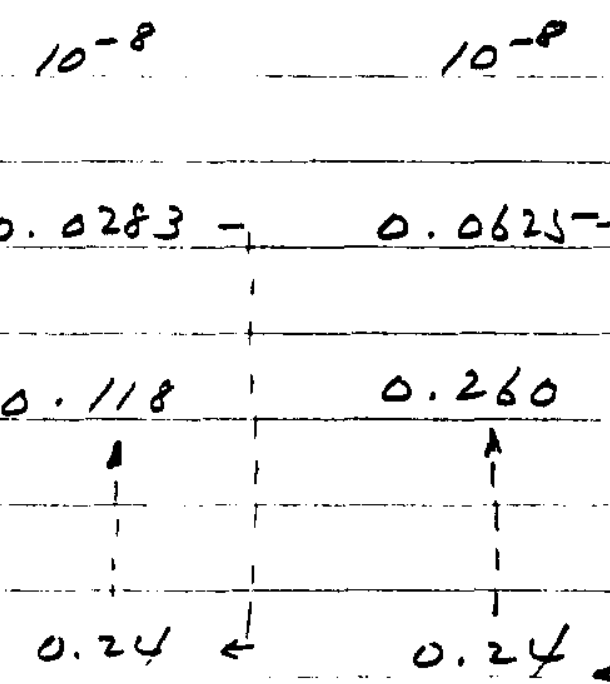
$-60-$

IV. Remarks

For a maximums hot -spot temperature of $100 K$, the conductor current density $\left(3000 \mathrm{~A} / \mathrm{mm}^{2}\right)$ is low in comparison with other cyostable magnets, but not absurdly so... The surface heat flux $\left(0.0283 \mathrm{w} / \mathrm{cm}^{2}\right)$ is $25 \%$ less for a 4-m module than for METF solenoids, again not absurd.

A move detailed quench analysis would probably suggest a higher current density. The coupling of the circuits through the mutual inductance should be considered.

I. Conclusion

A 4-m coil module, with a conductor current density of $\simeq 3000 \mathrm{Alcm}^{2}$, will be safe against a quench and will have a sufficiently low surface heat flux... A 2 -m module with $25000 \mathrm{Alm}^{2}$ will be safe on quench, but the surface hear flux is a bit high. 


\section{SSC DETECTOR SOLENOID DESIGN NOTE \#20}

TITLE: Charge/Discharge Times, Eddy Current Power and Energy

AUTHOR: R.W. Fast

DATE: $\quad$ Apr. 26, 1988

SUMMARY: A charge voltage of $\sim 30 \mathrm{~V}$ will permit the magnet to be charged in about 3 hours with an eddy current power of a few watts in each $2-m$ coil/LHe vessel module. The eddy current heat load during a fast dump $\left(R_{\mathrm{D}}=0.1 \mathrm{\Omega}, \tau=600 \mathrm{~s}\right)$ is $645 \mathrm{~W}$ per $2-\mathrm{m}$ coil module, which would probably quench the module. I propose that the coil be discharged through $R_{F D}$ only if a quench is detected; otherwise it would be discharged through a slow dump resistor $\left(\mathrm{R}_{\mathrm{SD}}=0.01 \mathrm{Q}, \tau=6000 \mathrm{~s}, \mathrm{P}_{\mathrm{E}}(\max )=6.5 \mathrm{~W}\right)$. 
$-62-$

I. Charge time

During a charge

$$
\begin{aligned}
V_{L} & =\text { voltage across coil } \\
& =L d I_{L}(t) /: d t
\end{aligned}
$$

Assuming a constant voltage charge from $I_{L}(t)=0$ to $5 k A$ and $L$ the inductance of an 8-m assembly (four, 2 -m coils in series electrically),

$$
\begin{aligned}
t_{\text {chg }}=L I_{L}(\text { tang }) / V_{L} & =(60 \mathrm{H})(5000 \mathrm{~A}) / V_{L} \\
= & 30 \times 10^{4} \mathrm{~s} / \mathrm{V}_{L}
\end{aligned}
$$

$P_{P S}(t)=$ power drawn from power supply

$$
=V_{L} \cdot\left[I_{L}(t)+I_{R}(t)\right]
$$

At $\left.t=0: I_{L}(0)=0, \quad I_{k} / 0\right)=V_{L} / R_{D}$

$$
t=t_{\text {chg }}: I_{L}\left(t_{\text {chg }}\right)=5 \mathrm{kA}, I_{R}\left(t_{\text {chg }}\right) \sim 0
$$

$$
P_{P S}(\text { max })=V_{L} I_{L} \text { (tach) }
$$

Circuit

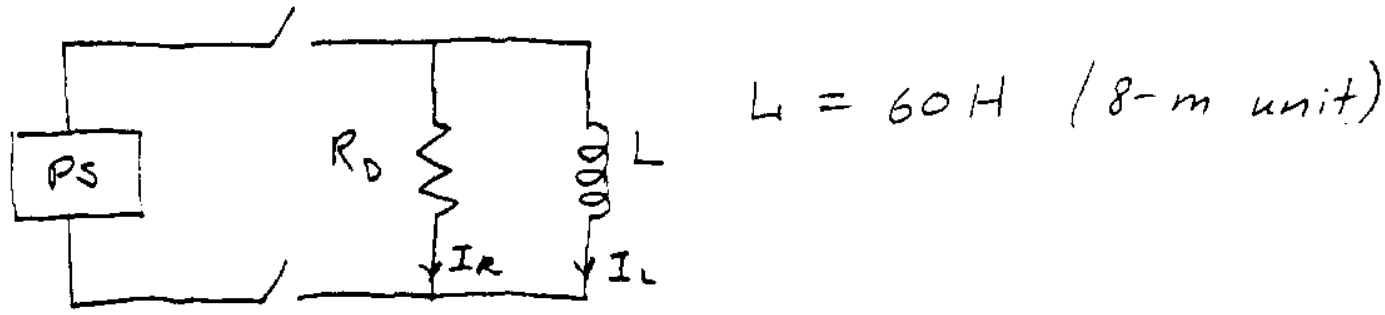


$\cdot-63-$

\begin{tabular}{lcccc}
$\begin{array}{l}V_{L} \\
(V)\end{array}$ & $\begin{array}{c}P_{P S}(\max ) \\
(\mathrm{kw})\end{array}$ & $\begin{array}{c}\text { d IL } / d t \\
(\mathrm{~A} / \mathrm{s})\end{array}$ & $\begin{array}{c}t_{\text {chg }} \\
(\mathrm{s})\end{array}$ & $(\mathrm{h})$ \\
\hline 15 & 75 & 0.25 & $20 \times 10^{3}$ & 5.6 \\
20 & 100 & 0.33 & $15 \times 10^{3}$ & 4.2 \\
30 & 150 & 0.50 & $10 \times 10^{3}$ & 2.8 \\
60 & 300 & 1.0 & $5 \times 10^{3}$ & 1.4
\end{tabular}

II. Discharge time - fast dump

$R_{F D}=0.1 \Omega$ to limit discharge to $500 \mathrm{~V}$ across terminals

$$
\begin{aligned}
I_{L}(t) & =I_{L}(0) e^{-\frac{R_{D} t}{L} t} \\
& =(5000 \mathrm{~A}) e^{-t / 600} \\
V_{L} & =I_{L}(t) R_{F D} \quad\left(\begin{array}{l}
\text { No quench, or for } \\
\end{array}\right. \\
& (500 \mathrm{~V}) e^{\left.-t / 600 \quad R_{F D}>R_{a}\right)}
\end{aligned}
$$

III. Eddy current heating in helium vessel during charge

The changing current in the coil induces a voltage $V_{E}=m d I L / d t$ in the helium vessel and hence an eddy current $I_{E}=V_{E} / R_{E}$. 
$-64-$

The power dissipated in the vessel due to this eddy current

$$
P_{E}(t)=V_{E}^{2} / R_{E}=\left(M d I_{L} / d t\right) / R_{E}
$$

where

$M=$ the mutual inductance between the soil and the helium vessel

$R_{E}=$ circumferential resistance of the helium vessel

To estimate $R E$ of $z-m$ module

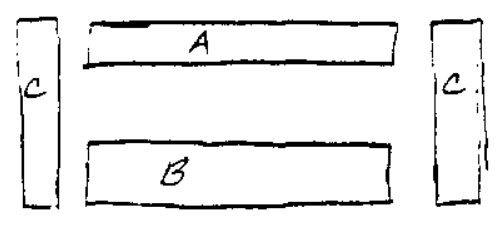

$A_{E}=$ cross section of helium vessel

$$
\begin{aligned}
& =(1880 \times 35)+(1880 \times 50)+2(244 \times 35) \times 10^{-6} \mathrm{~m}^{2} \\
& =0.1769 \mathrm{~m}^{2}
\end{aligned}
$$

$$
\begin{aligned}
R_{E} & =\frac{\left(P_{s s}{ }_{0} 45 \mathrm{k}\right)(\text { vessel circumference })}{A E} \\
& =\frac{\left(50 \times 10^{-10} \Omega-\mathrm{m}\right)^{*}(9.5 \pi \mathrm{m})}{0.1769 \mathrm{~m}^{2}} \\
& =84.4 \mu \Omega
\end{aligned}
$$

* From S.C. machinery Handbook fr 304L at $4.5 \mathrm{~K}$ 


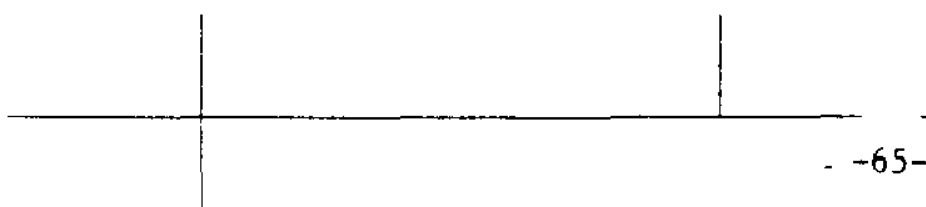

To estimate $M$

$M=$ flux linked by the vessel per unit coil current

$$
=\frac{\Phi\left(I_{\text {Lax }}\right)(1 \text { turn })}{I_{L \text { max }}}
$$

$$
\begin{aligned}
& \sim \frac{(2 T)\left(\frac{1}{4} \pi 9.5^{2}\right)(1)}{5000} \\
& =0.028 H
\end{aligned}
$$

To estimate $P E$ during charge (aam module)

$$
\begin{aligned}
P_{E}(t) & =(0.028)^{2}\left(d I_{L} / 2 t\right)^{2} / 84.4 \times 10^{-6} \\
& =9.3\left(d I_{L} / d t\right)^{2} \mathrm{~W}
\end{aligned}
$$

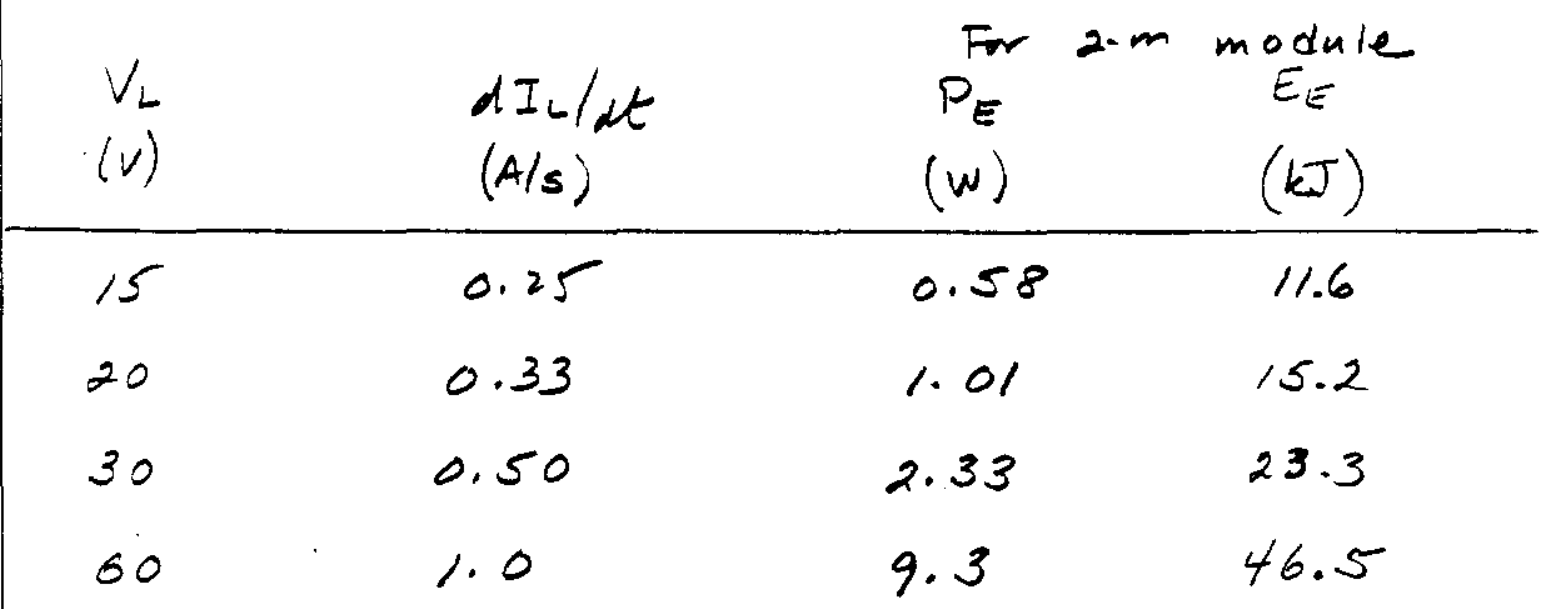

Where $E_{E}=$ energy absorbed by helium vessel during charge

$$
=P_{E} \text { tong }
$$




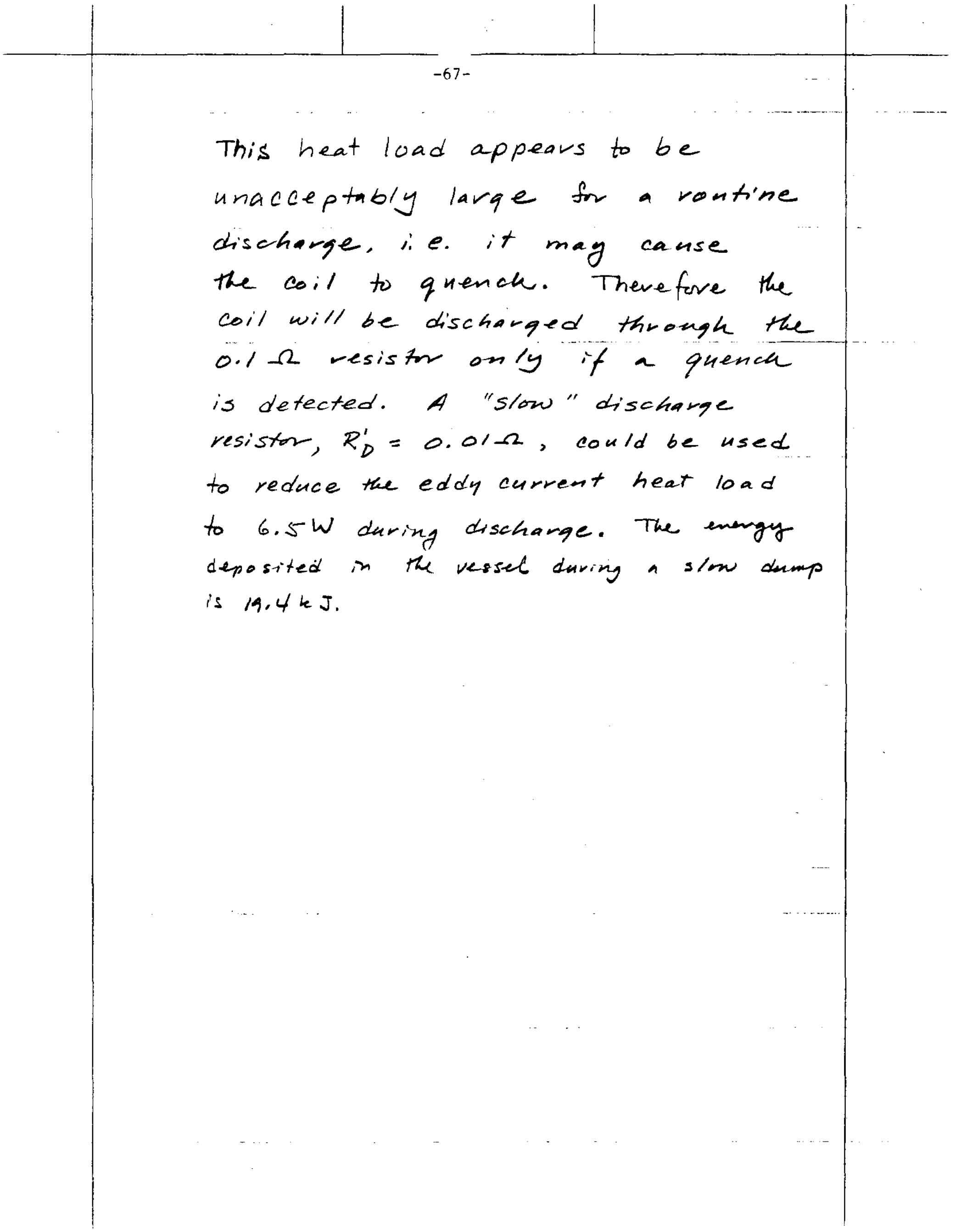




\section{SSC DETECTOR SOLENOID DESIGN NOTE \#24}

TITLE: Conceptual Design of a Superconducting Solenoid for a Magnetic SSC Detector (Paper delivered at the 12th International Cryogenic Engineering Conference and eubmitted for publication in the conference proceedinge.)

AUTHOR: $\quad$ R.W. Fast et al

DATE: $\quad$ July 13,1988 
-69- Paper delivered at the 12th International Cryogenic Engineering Conference and aubmitted for publication in the conference proceedings.

CONCEPTUAL DESIGN OF A SUPERCONDUCTING SOLENOID FOR A MAGNETIC SSC DETECTOR

R.W. Fast, J.H. Grimson, R.D. Kephart, H.J. Krebs, M.E. Stone, D. Theriot, and R.H. Wands

Fermi National Accelerator Laboratory, Batavia, Illinois, USA

The conceptual design of a large superconducting solenoid suitable for a magnetic detector at the Superconducting Super Collider (SSC) has begun at Fermilab. The magnet will provide a magnetic field of $2 T$ over volume $8 \mathrm{~m}$ in diameter by $16 \mathrm{~m}$ long. The particle-physics calorimetry will be inside the field volume and so the coil will be bath cooled and cryostable; the vessels will be stainless steel. Predictibility of performance and the ability to safely negotiate all probable failure modes, including a quench, are important items of the design philosophy. Although the magnet is considerably larger than existing solenoids of this type and although many issues of manufacturability, transportability and cost have not been completely addressed, our conceptual design has convinced us that this magnet is a reasonable extrapolation of present technology.

\section{INTRODUCTION}

A large solenoid is being considered as part of a detector (Fig. 1) for experiments performed on the Superconducting Super Collider (SSC). The conceptual design of a solenoid suitable for a detector has begun at Fermilab and some preliminary specifications have been developed. The field volume proposed to perform proton-proton experiments with the SSC is $8 \mathrm{~m}$ in diameter and $16 \mathrm{~m}$ long; a field of 1.5 to $2 \mathrm{~T}$ is desired. The magnet will have an iron flux return yoke at a field of $1.5 \mathrm{~T}$. A significant feature of this detector is that all the calorimetry will be inside the bore of the rnagnet. This feature impacts the design of both the calorimeter support system and the superconducting coil in a major way. Another feature of the detector that influences the design of the magnet is its location in a detector hall 100 to $150 \mathrm{~m}$ below the surface.

The calorimeter and central tracking chamber for the SSC detector will occupy the entire field volume and will weigh about 5000 tonnes. This weight could be transmitted to the floor of the detector hall either through the vacuum vessel of the magnet coil or through an independent support structure. The calorimeter will be split at the longitudinal center for instrumentation cabling. Taking advantage of this, we have designed two independent calorimeter support structures, each $8 \mathrm{~m}$ long, supported to the iron yoke at both ends. The stainless steel weldment consists of two cylinders with a wet of trusses between; it has a radial thickness of $250 \mathrm{~mm}$. The calorimeter modules will rest on rails along each side of the structure and can be installed from either or both ends.

Because the calorimetry is inside the bore of the solenoid it is not necessary that the coil and vessels be thin in terms of radiation and absorption lengths. We therefore chose a cryostable, bath-cooled coil, able to withstand quenching without damage. The conductor is copper stabilized; the helium and vacuum vessels are stainless steel. We have located as many of the active elements as possible in an aboveground service building; the power supply, dump switches, pumps and control valves. 
For the purpose of this conceptual study, we have adopted a fabrication and assembly scenario as follows: (1) The coil is wound in 2-m long modules about a vertical axis, each module forming a liquid helium vessel. (2) Four coil modules are stacked vertically and bolted together to form an 8-m cold mass; electrical interconnections are made in liquid helium pipes along the top. (3) The outer vacuum shell, with a liquid nitrogen cooled thermal shield attached, is lowered over the cold mass and the supports attached to each end. (4) The inner vacuum shell-thermal shield subassembly is vertically inserted and the flat annular heads welded in place. (5) The assembly is then rotated to a horizontal axis and a 5000-L helium storage dewar attached. (6) The two 8-m assemblies are cryogenically and electrically tested. (7) The 500-tonne assemblies are then lowered into the detector hall and secured to the iron yoke in a way that allows for a $20^{\circ} \mathrm{C}$ thermal contraction of the $8-\mathrm{m}$ vacuum vessel. Figure 2 is a cross section of the coil and cryostat.

\section{CONDUCTOR AND QUENCH PROTECTION}

The inner diameter of the superconducting coil was chosen as $9.5 \mathrm{~m}$, which provides adequate space for vessel shells, insulating vacuum and clearance to the calorimeter support structure. We chose to operate at a current of $5 \mathrm{kA}$ and to electrically connect four 2-m coil modules in series with superconducting bus. Table 1 gives some of the operating parameters of the magnet. We believe that it is essential that the coil survive quenches without damage. We will provide this protection through the use of an external fast dump resistor and by specifying a rather low conductor current density. The parameters associated with a quench are given in Table 2. Because of the large heat load due to eddy current in the helium vessel, a fast dump will be initiated only when a quench is detected. A normal discharge will be through a slow dump resistor, with the power supply reversed so the discharge is at constant voltage.

We selected a built-up conductor with a $\mathrm{Nb}-\mathrm{Ti} / \mathrm{Cu}$ monolith or cable soldered into additional copper stabilizer. The conductor dimensions are $16 \mathrm{~mm} \times 18 \mathrm{~mm}$. With a short sample sating of $10 \mathrm{kA}$ at $3 \mathrm{~T}$ and $4.5 \mathrm{~K}$ and a current density in the superconductor of $3 \times 10^{5} \mathrm{~A} / \mathrm{cm}^{2}$, the copper to superconductor ratio will be about 90 . The surface heat flux with a copper RRR of 100 and $25 \%$ surface wetting is 0.05 $\mathrm{W} / \mathrm{cm}^{2}$.

\section{COIL-HELIUM VESSEL MODULE}

Each 2-m coil module has seven layers of 93 turns for a total of 651 turns. We chose G-10 buttons on a string as the turn-to-turn insulation, slotted G-10 sheets between layers and slotted and channeled G-10 and Kapton as insulation to ground, giving a packing factor of 0.65 . The conductor is layer wound the "easy" way, beginning at the outer layer, on the inside of a coil form which makes up the outer shell and flat heads of the helium vessel. The winding fixture applies the radial preload; compression bars at one end of the coil apply the axial prelosd. The coil module will be closed by welding the inner shell to the coil form.

The 2-m coil-helium vessel module is designed for a gauge pressure of $0.7 \mathrm{MPa}(100$ psi). The inner and outer shells are also designed for the axial electromagnetic force. The radial electromagnetic pressure of $1.6 \mathrm{MPa}(230$ psi) is partially resisted by the conductor and partially by the outer shell, depending on the stiffiness of the coil. The vessel is adequately relieved for a lose of insulating vacuum or a quench.

We propose a thermosiphon to provide a flow of liquid helium through the coil package. Each of the coil-helium vessel modules has a supply line from the storage dewar leading to the bottom of the module. These lines are very well insulated so they contain only liquid helium. Two return and vent lines lead from the top of each module to the storage dewar. 
When installed in the iron yoke, each 8-m cold mass has an axiai body force on it which depends on the geometry of the end wall and reentrant end plug. For the one coil configuration studied thus far, calculations with a cylindrically symmetric iron flux return indicate that this force is a minimum without reentrant iron, being about 7.3 MN $\left(1.64 \times 10^{6} \mathrm{lb}\right)$ toward the symmetry plane. The axial force constant is 149 $\mathrm{MN} / \mathrm{m}\left(8.5 \times 10^{5} \mathrm{lb} / \mathrm{in}\right)$ and the radial force constant is $8.8 \mathrm{MN} / \mathrm{m}\left(5 \times 10^{4} \mathrm{lb} / \mathrm{in}\right)$; from experience with the solenoid at the Collider Detector-Fermilab we have chosen an axial and radial misalignment or the equivalent, due to non-uniform iron properties, of $25 \mathrm{~mm}$. The support system is not designed for independent charging or operation of the two 8-m coil modules; bumpers limit axial travel if only one module is energized because of a control system failure.

The aystem to support the 8-m cold mass in the vacuum vessel could have either separate elements to react the axial and radial force components or combined-function elements. We have tentatively chosen the latter. We believe that the supports ahould be metallic, possibly Inconel 718, with spherical bearings on each end. The attachment points on the vacuum vessel are near the ends to avoid carrying the electromagnetic forces through the vecuum shells. Each support will have an intercept cooled by a forced flow of subcooled liquid nitrogen at about $80 \mathrm{~K}$ and a liquid helium intercept in a thermosiphon circuit independent of the coil module circuit.

\section{REFRIGERATION SYSTEM}

The refrigeration plant is located at ground level, with vacuum jacketed lines going down to the detector hall. The helium plant supplies liquid to the storage dewars on top of the detector. Because of the depth of the detector hall a cold compressor is used to maintain the liquid in the dewars at about $30 \mathrm{kPa}(4.5 \mathrm{paig})$ and $4.5 \mathrm{~K}$. For the proposed electrical insulation scheme and resulting flow pathe through the coil, the helium supply and return lines can be sired to provide a thermosiphon flow rate through each $2-\mathrm{m}$ coil module of at least $23 \mathrm{~g} / \mathrm{s}$ with a return gas fraction lea than $1 \%$ by weight. The flow rate through the support intercept circuit will be about 50 $\mathrm{g} / \mathrm{s}$ at a gas fraction of $7 \%$ or less. The total expected heat load to the helium symitem is $360 \mathrm{~W}$ plus $36 \mathrm{~L} / \mathrm{h}$ ( $540 \mathrm{~W}$ equivalent). The 4.5-K helium refrigerator will probably have a capacity of 1600 to $1800 \mathrm{~W}$. Sub-cooled liquid nitrogen at an average tempersture of $83 \mathrm{~K}$ is forced through the various shield and intercept circuits by a circulator pump at detector hall level. The total heat load to the nitrogen system is expected to be $6 \mathrm{~kW}$.

The total cold mes (two 8-m assemblies) is about 800 tonnes; an overall cooldown time of about two weeks is denired. A separate cooldown refrigerator, consisting of a helium to liquid nitrogen heat exchanger and turboexpander, providing $400 \mathrm{~g} / \mathrm{s}$, of $83 \mathrm{~K}$ helium gas can achieve thin.

\section{CONCLUSIONS}

It appears that the diameter of this detector solenoid will preclude its fabrication at a vendor's off-aite facility, although some components and subassemblies, e.g. the coil form, could posaibly be fabricated elsewhere and shipped by barge and helicopter. A large hall will be necessary on the SSC site for the coil winding, the closure welding of the coil-helium vessel modules, the assembly of the 8-m modules and the testing with the refrigerator. The hall will require at least a 100 tonne crane with a hook height of at least $12 \mathrm{~m}$. The access ahaft from the surface down $100-150 \mathrm{~m}$ to the detector hall will have to be about $14 \mathrm{~m}$ in diameter.

We concluded, as a result of this preliminary study, that the magnet is a reasonable extrapolation of superconducting magnet technology. Additional work on techniques for its manufacture including cost and time estimates are still needed. The optimiration of 
parameters through more detailed study might result in a more cost-effective design, however at this point in the effort we see nothing that would preclude the construction of such a magnet.

\section{ACKNOWLEDGEMENTS}

This work was sponsored by Universities Research Association, Inc. under contract with the U.S. Department of Energy. The authors would like to thank R.W. Baldi and R.A. Johnson of General Dynamics/Space Systems Division for providing us with engineering reports on the MFTF solenoids which were very useful to us in developing the concepts for this magnet.

Table 1. Operating Parameters

Center-line axial field $=2 \mathrm{~T}$

Operating current $=5 \mathrm{kA}$

Total stored energy at $2 \mathrm{~T}=1 \mathrm{GJ}$

Charge time $=100 \mathrm{~min}$ with $50 \mathrm{~V}$

Slow dump resistor $=0.01 \mathrm{a}$

Operating temperature $=4.5 \mathrm{~K}$
Table 2. Quench Parameters

Self-inductance $=60 \mathrm{H}$

Fast dump voltage $=500 \mathrm{~V}$

Fast dump resistor $=0.10$

Maximum hot spot temperature $=100 \mathrm{~K}$

Stabilizer current density $=1766 \mathrm{~A} / \mathrm{cm}^{2}$

Fast dump eddy current head load $=650 \mathrm{~W}$

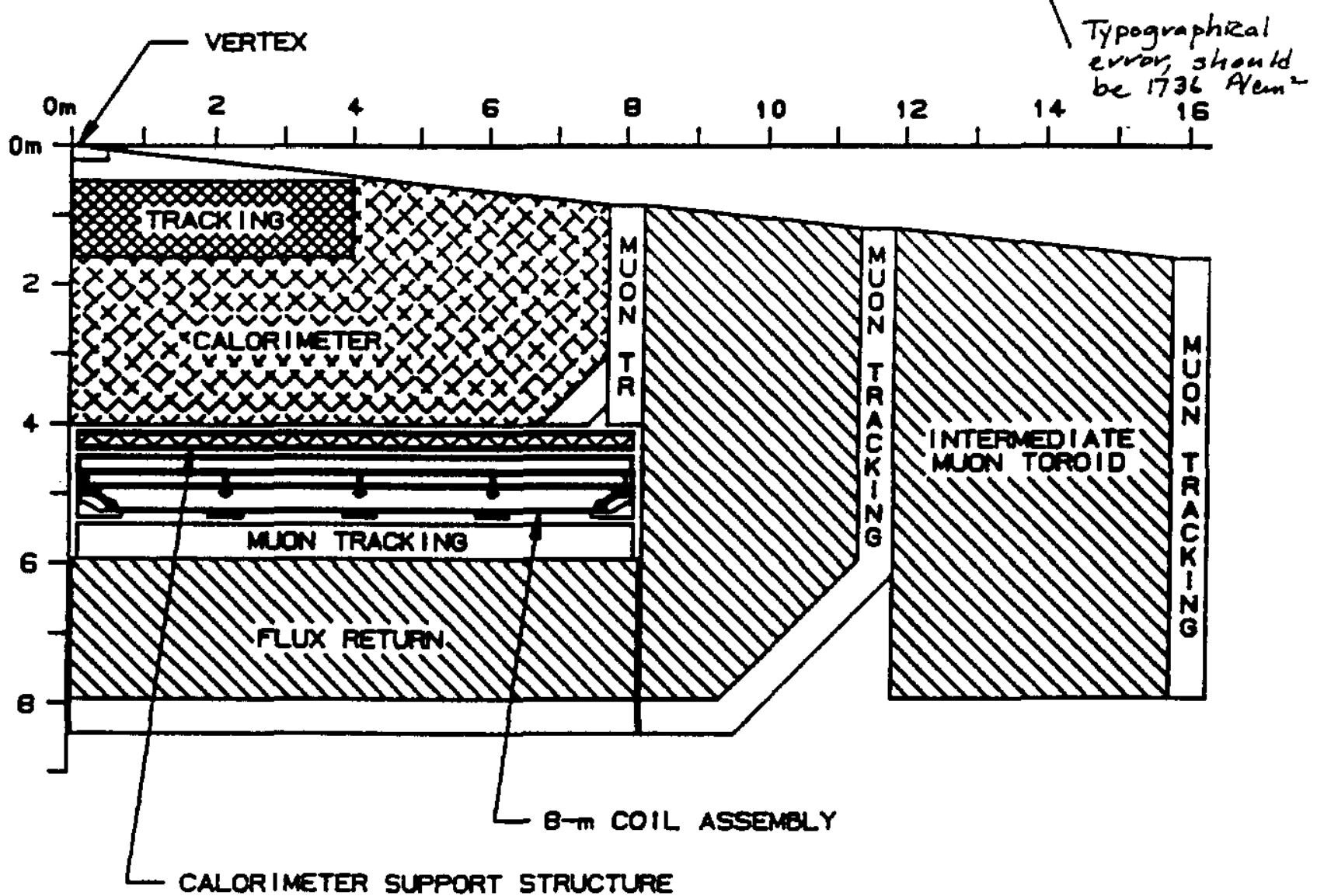

Fig. 1 SSC detector with large supereonducting solenoid. 


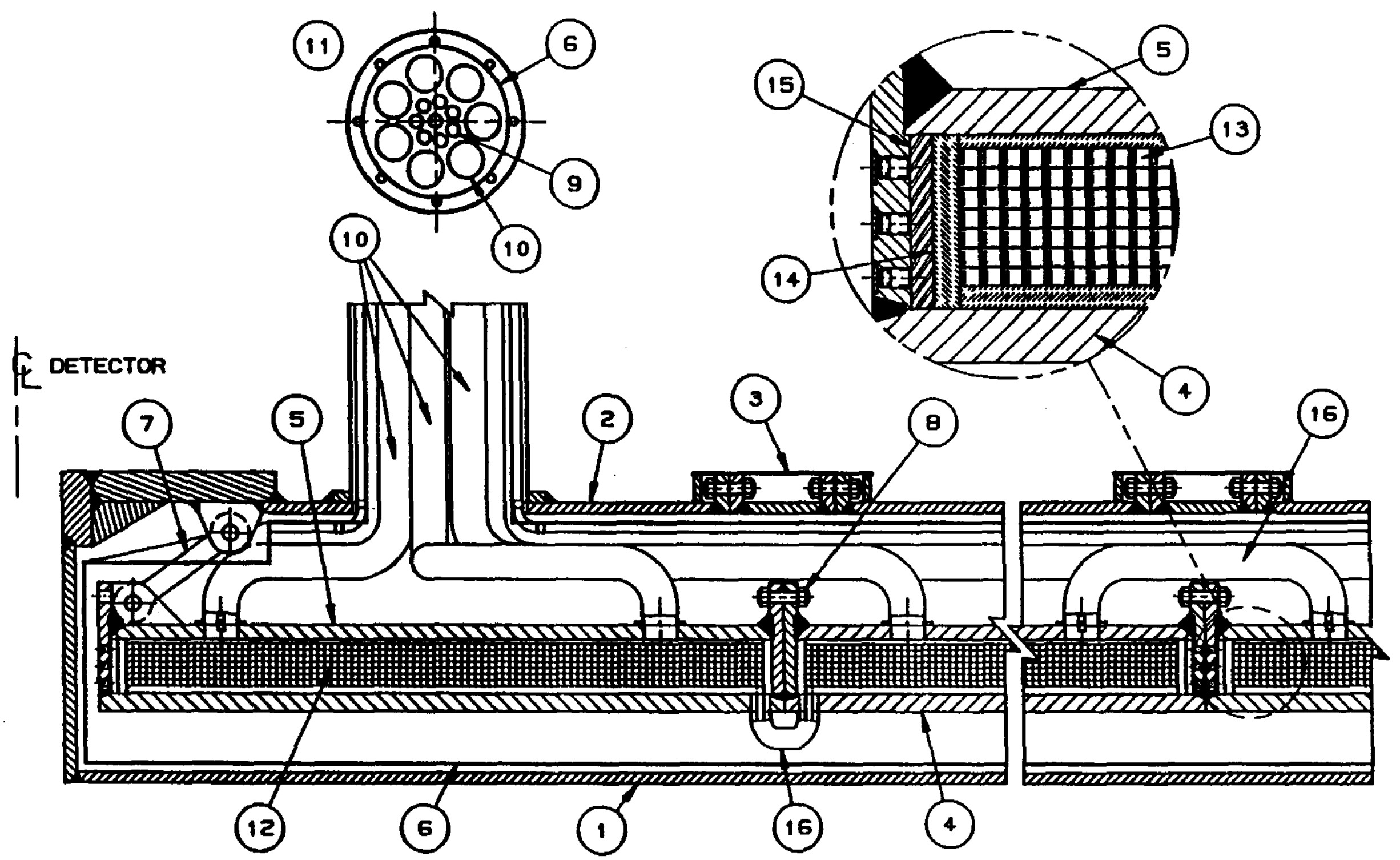

Fig. 2 Axial crose section of coil, helium and racuum resuela: 1 , inner and 2, outer vacuum shell; 3 , assembly joint (if required); 4, inner and 8, outer helium rescel shell; 6, radiation whield; 7 , cold mass support; 8, coil module attachment; 9 , liquid helium supply pipe; 10, helium retum/vent pipe; 11, chimney to storage dewar; 12, coil winding; 13, conductor; 14, G. 10 insulation; 15, axial prelosd bar; 16, electrical interconneet pipe. 


\section{SSC DETECTOR SOLENOID DESIGN NOTE \#25}

TITLE: $\quad$ Conductor and Coil Parameters for Coils in Series Electrically; Eddy Current Heating
AUTHOR:
R.W. Fast
DATE:
Aug. 11,1988

SUMMARY: This coil design has 93 turns per layer and 7 layers. The conductor is $18 \mathrm{~mm}$ axially $x_{2} 26 \mathrm{~mm}$ radially. The conductor current density is $1068 \mathrm{~A} / \mathrm{cm}^{2}$, giving a maximum adiabatic hot spot temperature of $100 \mathrm{~K}$. The eddy current heat loads are given below.

\section{Linear Charge or Slow Dump Heat Land}

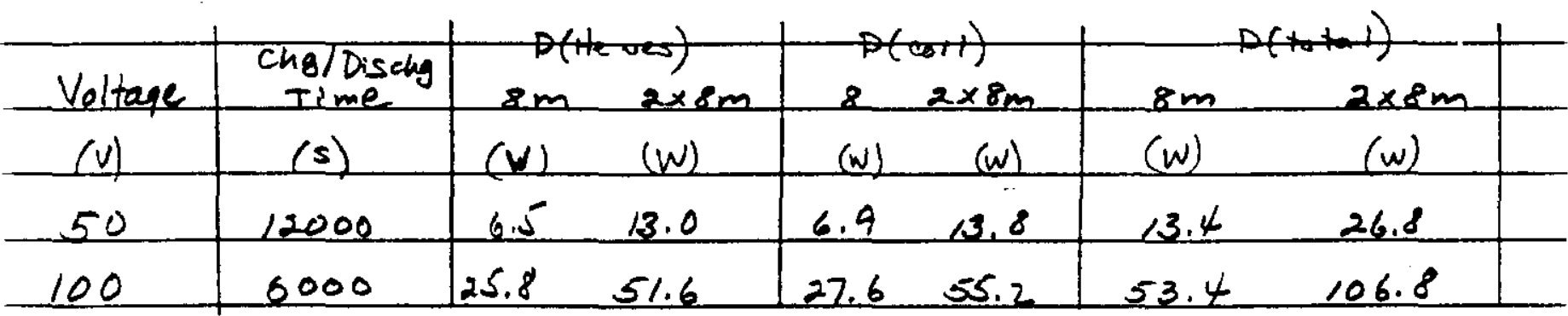

Fast Dump Heat Load

\begin{tabular}{|c|c|c|c|c|c|c|}
\hline \multirow[b]{2}{*}{$\tau$} & \multicolumn{2}{|c|}{$P($ the ves) } & \multicolumn{2}{|c|}{ D(a)il) } & \multicolumn{2}{|c|}{$P($ totat) } \\
\hline & $8 \mathrm{~m}$ & $2 \times 8 \mathrm{~m}$ & $8 m$ & $2 \times 8 \mathrm{~m}$ & $8 \mathrm{~m}$ & $2 \times \operatorname{cm}$ \\
\hline$(s)$ & $(w)$ & (w) & $(w)$ & $(w)$ & $(w)$ & $(w)$ \\
\hline$\angle 2$ & 645 & 1290 & 688 & 1376 & 1333 & 2666 \\
\hline
\end{tabular}


I. Electrical Circuit

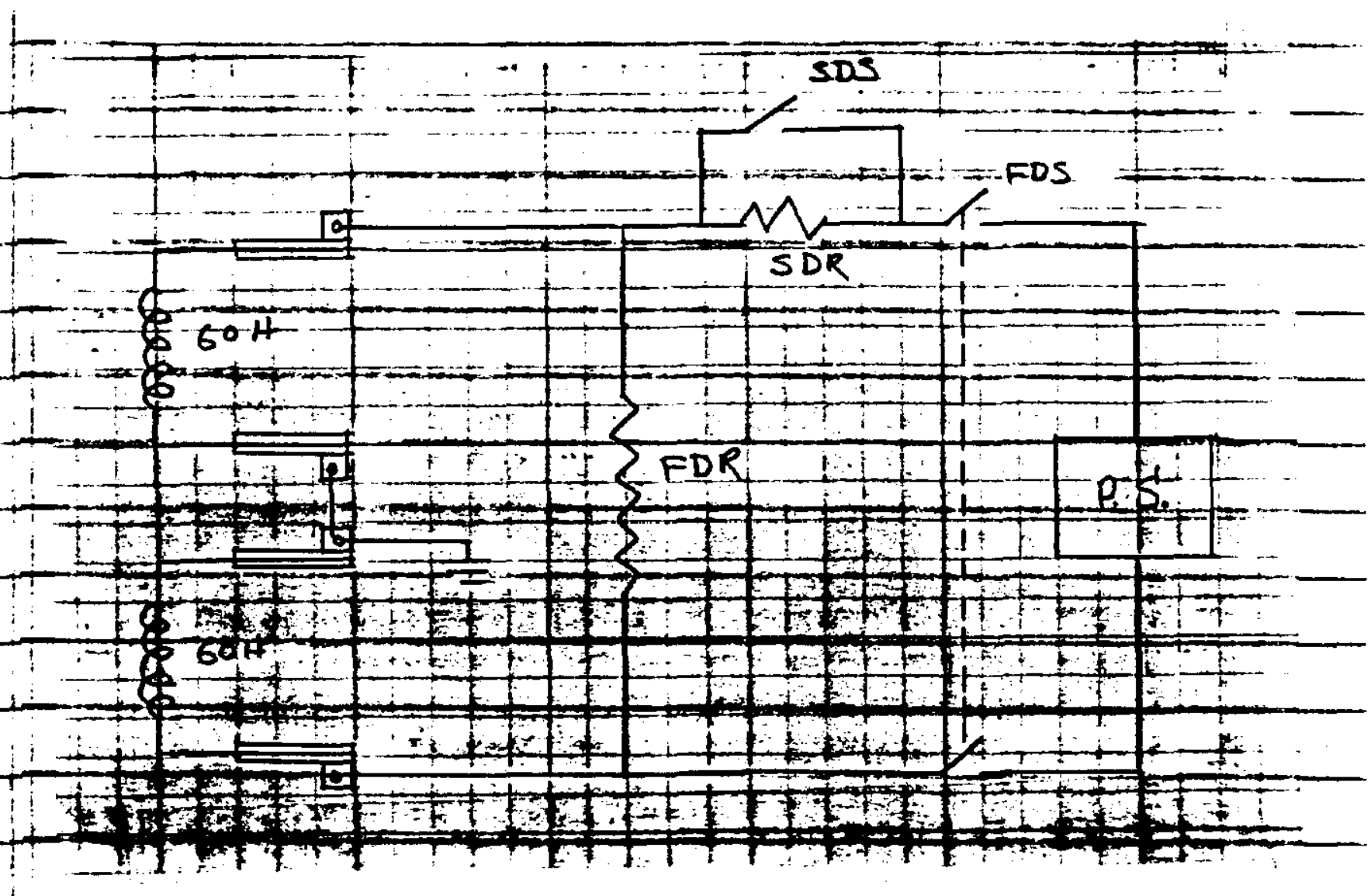

Quench - Fast Dump ariteria:

1. Fast dump Veltequ - all points in coil less than $250 v$ to ground during fast dump 2. Qnench behavior - maximum adiabatic: het spet temperature $=100 \mathrm{~K}$.

II. Conductor Design

Frem $D N * 18$, for $\theta_{m}=100 \mathrm{~K}$ and $R R R \sim 100$ $U\left(\theta_{m}\right)=7 \times 10^{16} A^{2}-s^{2}-m^{-4}$ 
- $-76-$

and $J_{0}\left(0_{m}=100 \mathrm{~K}\right)=\frac{3.74 \times 10^{8}}{\sqrt{L / F D R}} \quad A \cdot s^{1 / 2}-m^{-2}$

With $L=120 H, F D R=0.1 \Omega$ the req'd $T_{0}(100 \mathrm{~K})=1080 \mathrm{~A} / \mathrm{cm}^{2}$

For a conductor which is $18 \times 26 \mathrm{~mm}$ the actual $T_{0}=5000 \mathrm{~A} / 1.8 \times 2.6 \mathrm{~cm}^{2}=1068 \mathrm{~A} / \mathrm{cm}^{2}$, so I chose these conductor dimensions, $18 \mathrm{~mm}$ is along the axis, ie conductor wound the "hard" way.

III. Ceil Design

since the conductor axial is unchanged from the design in $D \triangle D \angle 9 A$, the number of turns per layer is unchanged at 93 .

The number of layers is the same (7), but the radial extent af the coil is larger by $7 \mathrm{~cm}(23 / 4 ")$.

The mass of conductor pere 2 -n coil module increases tram 50.6 Mg (DN 121$)$ to $(26 / 18)(50,6)=23 \mathrm{mg}$ (metric tens). 
$-77-$

IV. Coil Charging

Charge time depends on power supply voltage:

$\begin{array}{cccc}\text { Chg } & d I_{L} / d t & \text { Chg time } \\ \text { Voltage } & (\mathrm{A} / \mathrm{s}) & \text { (s) } & (\mathrm{h}) \\ (\mathrm{V}) & 0.417 & 12000 & 3: 20 \\ 50 & 0.833 & 6000 & 1: 40 \\ 100 & 0.833 & & \end{array}$

Eddy current heating in helium vessel:

From DNA 20

$$
P\left(\text { ching, Heres) }=(M d I / d t)^{2} / R\right. \text { (Heres) }
$$

where $I_{6}=$ current in coil

DN\#20 has a calculation of $M$ \& (tues):

$$
\begin{aligned}
& n=0.028 H \\
& R(2-m \text { w es })=84.4 \mu \Omega \\
& \text { se } R(8-m \text { Hers })=21.1 \mu \Omega
\end{aligned}
$$

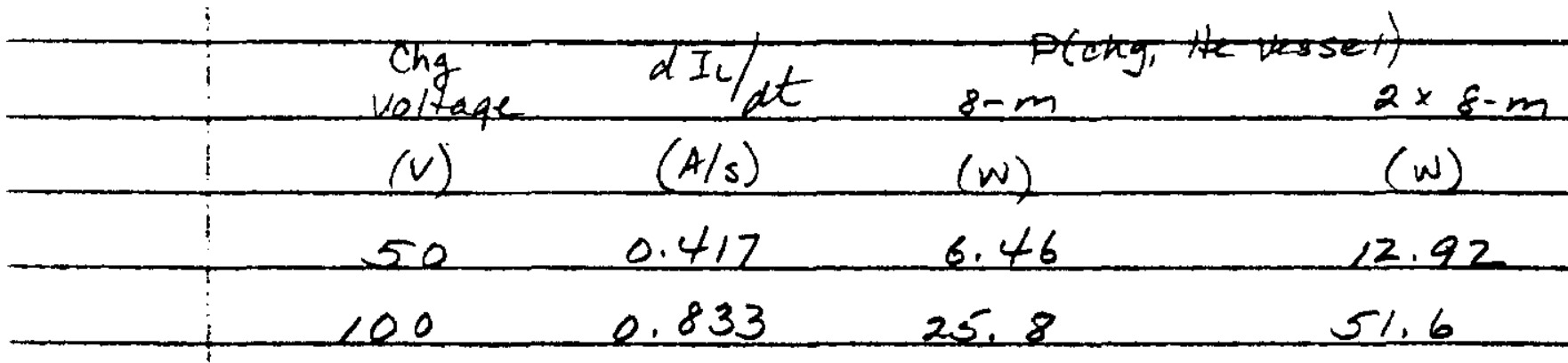


Eddy current heating in conductor.

To get an estimate of this. I used the equation from the CDF Design Report (p. so)

$$
P(\text { coil })=N_{t}\left(A_{e} f \frac{d B}{d t}\right)^{2}
$$

where $N_{t}=$ number of turns on coil

$R_{c}=$ effective resistance of one turn

Def $=$ ". area of concluator pes turn across which flux crosses

For a $2-m$ coil module $(D N \notin 19 A)$

$$
\begin{aligned}
N_{t} & =651 \\
R_{c} & =(10-\Omega \cdot \mathrm{m})(9.5 \pi \mathrm{m}) \\
& \left(18 \times 10^{-3} \mathrm{~m}\right)\left(26 \times 10^{-3} \mathrm{~m}\right) \\
& =6.4 \mu \Omega \\
A_{e f f} & =(9.5 \pi \mathrm{m})(26 \mathrm{~mm})=0.78 \mathrm{~m}^{2} \\
\text { So } P(c 0 i l) & =61.9 \times 10^{6}(\mathrm{~dB} / \mathrm{dt})^{2}
\end{aligned}
$$

And voltage chg $B_{0}^{\text {chime }}$ oBdt $8 \mathrm{~m}$ P(coil) $2 \times 8-\mathrm{m}$

(v)

(s) (T) (T/s)

(w)

(w)

$\begin{array}{llllll}50 & 12000 & 2 & 1.67 \times 10^{-4} & 6.90 & 13.8 \\ 100 & 6000 & 2 & 3.34 \times 10^{-4} & 27.6 & 55.2\end{array}$ 
$-79-$

Total heat load - charge

Chg P( Hes)

Voltage

(v)

50
$2 \times 8 \mathrm{~m} 8 \mathrm{~m}$

$2 \times 6 \mathrm{~m}$

(w)

13.8

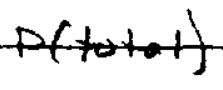

$8 \mathrm{~m} \quad 2 \times 8 \mathrm{~m}$

$(w)$

(w)

$13.4 \quad 26.8$

$53.4 \quad 106.8$

V. Slow Dump

Discharge time:

Reversing the power supply will give a constant-veltage discharge. The SDR is sized such that $5000 A \times S D R=$ P. S. voltage

$\begin{array}{ccccc}\begin{array}{l}\text { Dischg } \\ \text { Voltage }\end{array} & \text { SD } & \text { नII At } & \text { Dischg time } \\ (V) & (\Omega) & (\mathrm{A} / \mathrm{s}) & 1 \mathrm{~S}) & (\mathrm{h}) \\ 50 & 0.01 & -0.417 & 12000 & 3: 20 \\ 100 & 0.02 & -0.833 & 6000 & 1: 40\end{array}$

Eddy current heating in it vessel same equation as for changing:

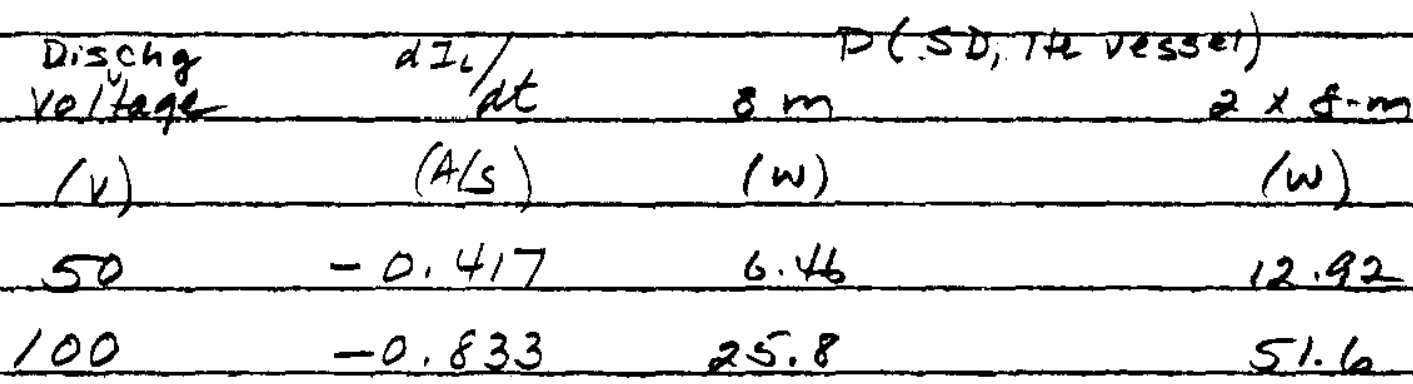


Eddy current heating in conductor some as for charqe:

$\begin{array}{ccc}\begin{array}{l}\text { Dischg } \\ \text { voltege }\end{array} & 8 \mathrm{~m} & 2 \times 8 \mathrm{~m} \\ (v) & (w) & (w) \\ 50 & 6.90 & 13.8 \\ 100 & 276 & 55.2\end{array}$

Total heat load - slow dump

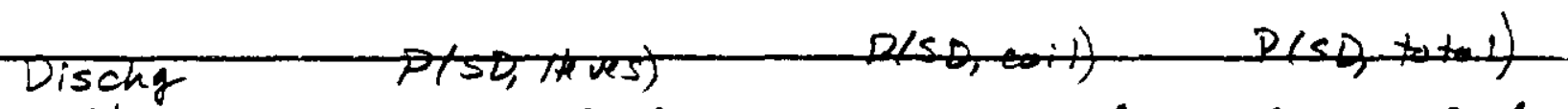
veltage $8 \mathrm{~m} 2 \times 8 \mathrm{~m} \quad \mathrm{fm} 2 \times 8 \mathrm{~m} \mathrm{fm} 2 \times 8 \mathrm{~m}$

$\begin{array}{lllllll}(v) & (w) & (w) & (w) & (w) & (w) & (w)\end{array}$

$\begin{array}{lllllll}50 & 6.5 & 13.0 & 6.9 & 13.8 & 13.4 & 26.8\end{array}$

$\begin{array}{lllllll}100 & 25.8 & 51.6 & 27.6 & 55.2 & 53.4 & 106.8\end{array}$

II. East Dump

Dischacse time.

$$
\text { TSLLFDR }=12 \% .1=1200 \mathrm{~s}
$$

Eddy current beating in th vessel

$$
\begin{aligned}
& P_{\text {max }}\left(E D_{1} \text { Lexes }^{8-m}\right)=\left(\frac{M I_{0}}{\tau}\right)^{2} / R / \text { ) } \\
& =\left(\frac{0.028 \times 5000}{1200}\right)^{2} / 21.1 \times 10^{-6} \\
& =645 \mathrm{~W}
\end{aligned}
$$


$-91-$

Eddy current heating in conductor

$$
\begin{aligned}
& P\left(F D, c_{0 i 1}^{2 m}\right)=61.9 \times 10^{6}(\mathrm{~dB} / \mathrm{dt})^{2} \\
& =61.9 \times 10^{6} \frac{B_{0}^{2}}{\tau^{2}} e^{-2 t / \tau} \\
& P_{\max }(F D, 2 \mathrm{manil})=\left(61.9 \times 10^{6}\right)\left(\frac{2}{1200}\right)^{2} \\
& =172 \mathrm{~W} \\
& \tau \quad B \quad 8 m \quad \max (F D, c 0 i) \\
& \text { (s) }(T)(w) \quad(w) \\
& 1200 \quad 2 \quad 688 \quad 1376
\end{aligned}
$$


SSC DETECTOR SOLENOID DESIGN NOTE \#26

TITLE: SSC Detector Solenoid (Paper delivered at the 1988 Applied Superconductivity Conference and accepted for publication in the conference proceedings.)

AUTHOR: R.W. Fast et al

DATE: $\quad$ Sept 26, 1988 


\section{Abatract}

A detector ntilizing a superconductins solenoid is being disevesed for the Supereonducting Super Colllder (SSC). A uecinl field volume of $8 \mathrm{~m}$ dinmeter $\times 16 \mathrm{~m}$ length at 1.5-2 T $(\sim 1 \mathrm{GJ}$ at $2 \mathrm{~T})$ is sequired. It hes been decided that all of the particle phrifes eslarimatry will be inaide the bore of the eolenoid and that there no need for the coil and cryontat to be "thin" in radietion lengthe. An iron roke will redree the excitation required and will provide muon identification and a redundant momentum mearurement of the mrons. We have dereloped a conceptual deaign to meat theae requirements. The magnet will use copper-atabilised $\mathrm{Nb}$-Ti conductor sized for a errotable pool boilling heat Inx $0.025 \mathrm{~W} / \mathrm{cm}^{2}$. A thermoniphon from a torage vessel above the croutat will be ued to provent bubble stagnetion in the liquid helium bath. The operating current, eurrent density, coil subdirioion and dump renintor have been choeen to guaranten that the coil will be undemaged should a quench oeenr. The axial electromagnetic fores will be reacted by metallic support links; the stainleas ateed coil case will support the radin foree. The 5000 metric tons of celorimetry will be upported from the iron roke through trosed cylindrieal thell strueture separate from the errontat. The coil and case, radintion abivild and athinleas racrum veasel would be fabricatod and errogenienilly tented as two $8 \mathrm{~mm}$ sections. These would be lowered into the underground experimental ball and installed into the iron flux return yole to provide the required 10-m length.

\section{Introdoction}

The SSC will hare oix internetion regions which, depending on the laboratory location, conld be as deap as 120 metars. A lasgo supareonductins solenoid is being connidered as a part of a deteetor tacilits for one of the internction hall. Firuse 1 is the 88C detector. The calorimatry and central tracking chambers, which will be beeted inside the solmoid, requin a fold volume $8 \mathrm{~m}$ in diameter by $16 \mathrm{~m}$ long. The field in the bore will be $2 \mathrm{I}_{\text {; }}$ the field in the iron flux return yole will be -1.8 T. Locating the evlorimatrs internal to the colenoid eliminate the aced to have " "thin" coil and

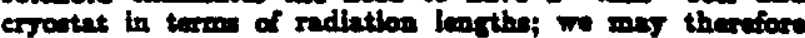
emplos a exportable pool bolling coll.

The required field rolume will be provided by twe colenoide, each $9.5 \mathrm{~m}$ in diamoter and $8 \mathrm{~m}$ in length, connected in eerie electrically with a cotmonon power upply. Ench $8-m$ vait will contain four identical $2-m$ long liquid helinm/coll modulen. The modules axe mechanically connected and share a common racutm reacel. Follium is supplied by thermontphens to an 8 in aciembly from a storase reasel located on top of the iron, with wech of the fore modules haring its own helium supply and return piptas.

The ealoximetry and Ilux return tron will be oplit at the longitudinal center and the halres ean be mored independently; therefore, we will use two o-m anppert

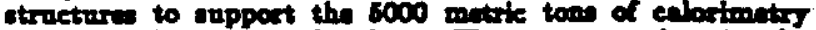
and central traektios chumber. Thare are notehes in the

Manuseript received Augut 23, 1909 iron for hangers for the oupports and for inmtrumentation enbles. The oupport structures are immodintaly inside the colenoids but are completely independent of the errostat and veenum shell. The ends of each structure will be supported from the lron. The enpport

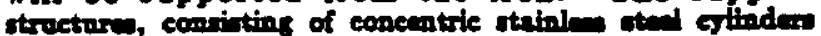
with a truand web, having a radial thlekane of $25 \mathrm{~cm}$

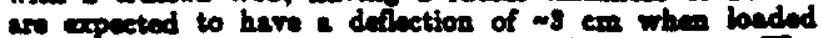
with the tracking chambers and calorimetry. Ipe calorimeter will test on rails and can be insertad from either end.

\section{Onench Protection}

Four 2-m modules are connected in serien with the oupereonducting bus between the module beling in liquid heliom filled intereonnectins pipes. It is encential that the coil ourvire quanchea without damage and to this and a low eurrent dentity and an external fart dump revintor were chowen. This revirtor was chown to be 0.1 a to limit the dincharge roltege to $800 \mathrm{~V}$ sereas the terminais. The edd current heatins in both the coil and belinm rened durting a fast dump is opeated to be

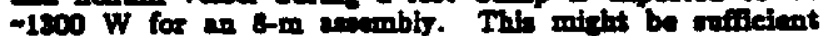
to qoench the coil and 00 the ditchnre will be throveh the fint dump resintor onil if a normel wee in detected. The hichent tempersture resched in the coil dus to quench will be $100 \mathrm{~K}$. A discharge for any other

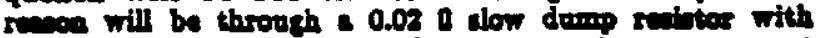
the power suppir zerorsed to maintulin a conatent divehurge roltage. The routine cherge of dinchnses time, whth $100 \mathrm{~V}$ earom the termincle, would be $100 \mathrm{~min}$ and the eddy corrent heat loed would be 36 W per $8-m$

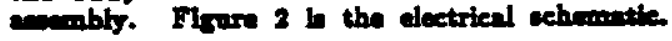

\section{Conductor end Coil specifiention.}

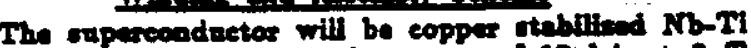

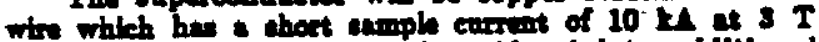
and $4.8 \mathrm{~K}$. Thle wire will be soldered into edditlonal copper utabilises. The final conductor will be $20 \times 18$ min and will have a copper to oupereoudector are ratio of 110 to 1 . The operating enrrent will be 6009 A revilting in e current deneity of $1.56 \times 10^{5}$ A/ $/ \mathrm{em}^{2}$ in the ouperconductor and $1068 \mathrm{~A} / \mathrm{em}^{2}$ orerell. The

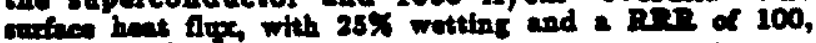
is $0.025 \mathrm{~W} / \mathrm{em}^{2}$.

There are ecven conductor layer hoving a total of

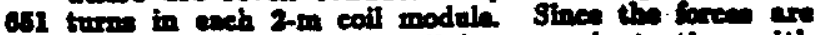
redially outward, the coil will be wound atertins with

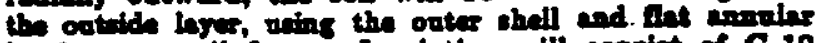
hends an a coil form. Inmulation will conain of G-20 bettone between turns, slotted G-10 ahertis between brem and slotted G-10 and Kapton edjacent to the heling recel. The pecking fector will be $74 \%$ with ISt bathe helfum epace.

Frech 2-m coil modvl will be demicned in secondines whth section VIII of the ABME. Bollex and Preaser Vered Code for an internal precure difierential of 0.8 ve (118 pois) and will be adequataly relieved for a

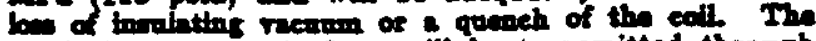
adil electromarnetle foree will be tranemitted through the whill to the supporte, and the radinl fored will be reinted by both the eonduetor and outer aluth 


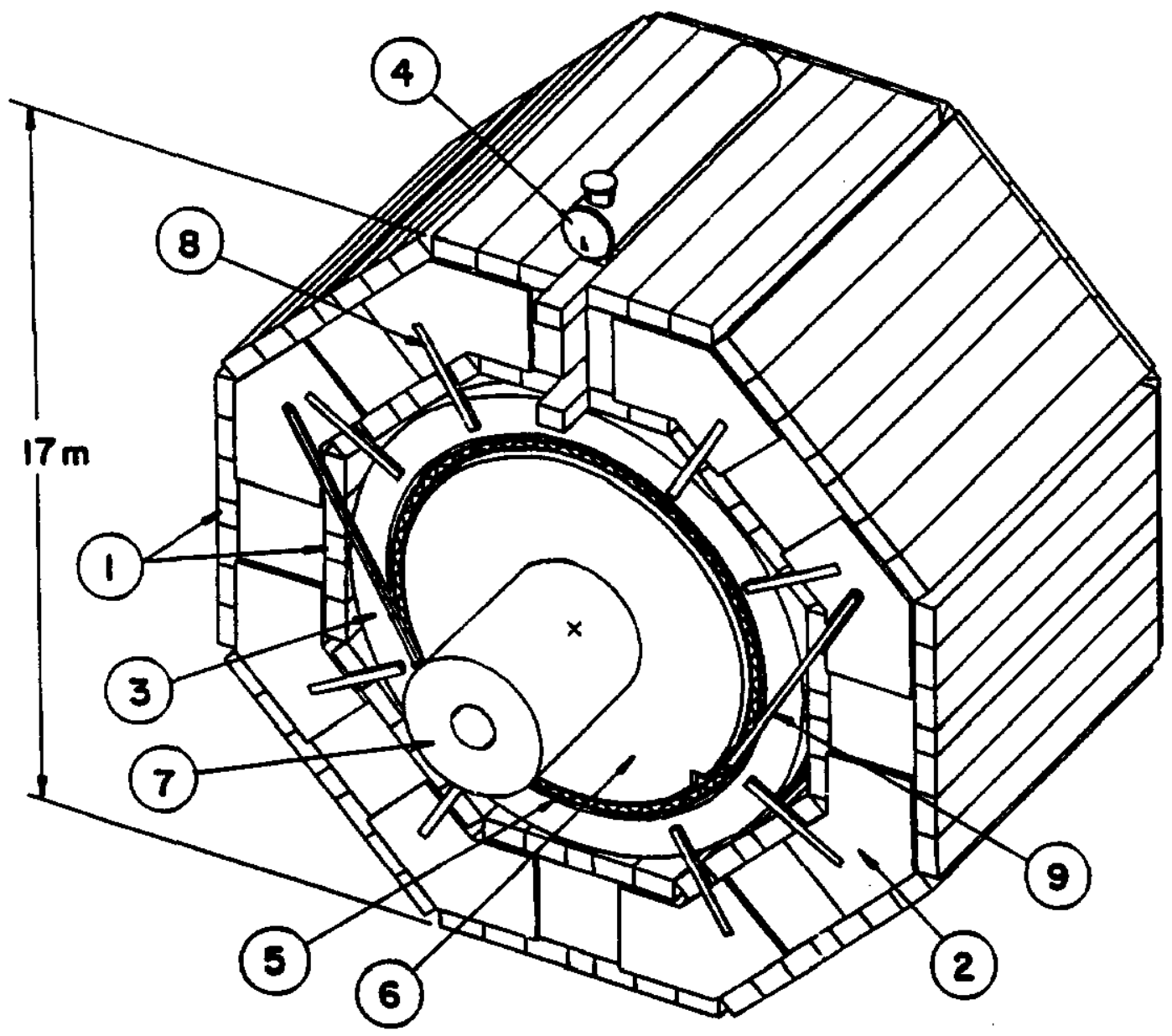

Figure 1. SsC Detector: 1, muan tracking; 2, flex return iron; 3, coil aneembly; 4, 5000 L hellum dowar; 5 , ealorimater support itructure; 6, calorimater; 7, central tracking chmbers; 8, coil upporte; 9, support otsucture hangers.

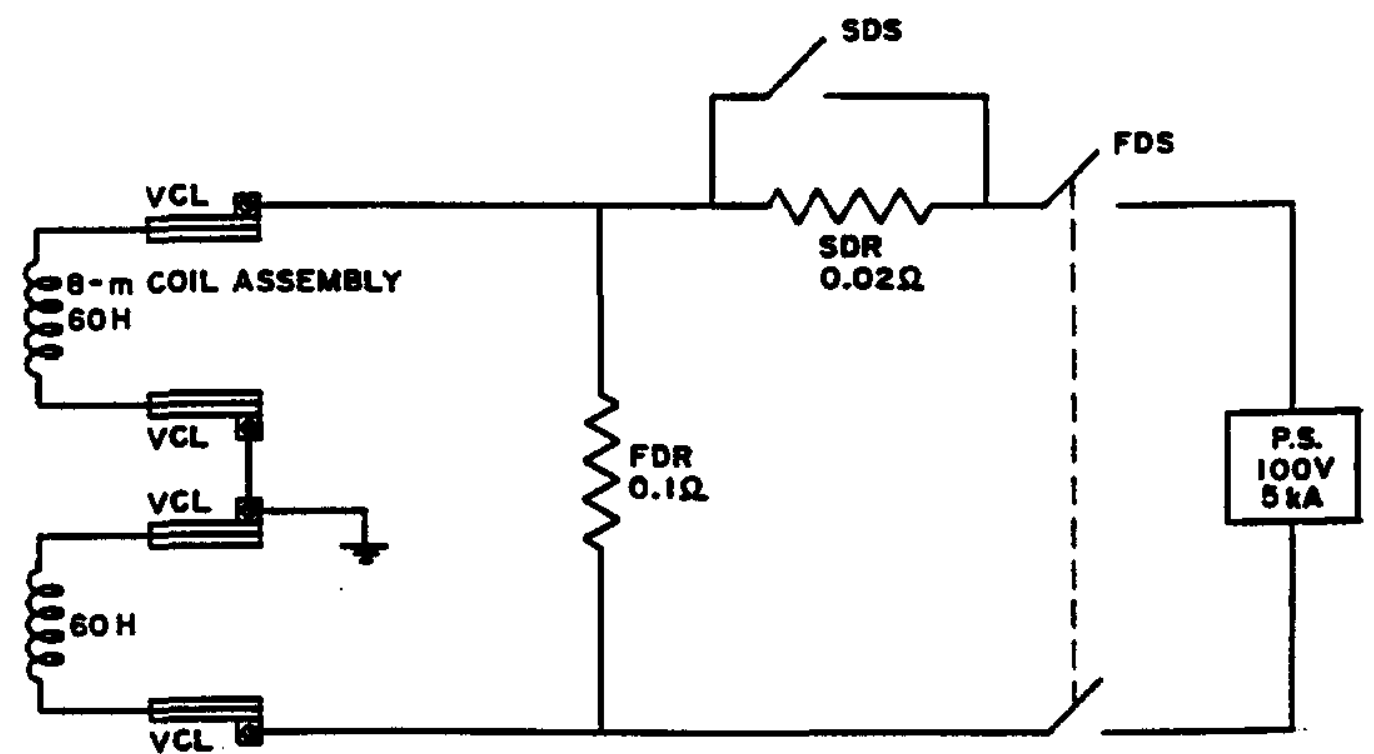

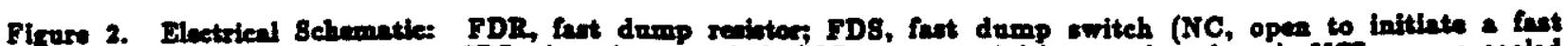

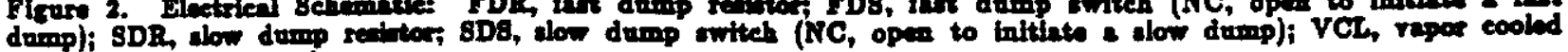
leadi; P.S., powre supply. 
Wiading will bo done with the coil axis rortien. The windins fixture will provide the radial preloed and a ceriv of compreasion bare at one and of esch coil can be individually edjusted to provide eircumferentially uniform arial prulosd. These exial compreasion bars are edjwtable onty during meembly. After windins, the inner shall of the hellum reavel will be wolded to the coil form. After the four 2-m modriles are bolted torather and interconacetione are made, the onter recurm jacket and lategral nitrogen hiald are lowered orer the 8-m cold mese. The coil supports will be attuched, the 8-m asembly rotated to a horisontal povition and the inner recurum shall and nitrogen ahield ciid in. Figure 3 in a erom ecetion of the coil, erjoutet and recuum resal.

\section{Brporte}

The axial body force on the 8-m cold mase is dependent on the geometrs of the end wall and atedied thas far, ealeulations indieate that this foree, which is towards the oymmetey plane, cannot be elieninated bet is a minimum of $7.3 \mathrm{MN}\left(1.64 \times 10^{\circ} \mathrm{lb}\right)$ when there in no re-entrant iron. The eupports are denigned for an arial or radiad minalignment, or the equivalent due to iron non-homogeneity, of $2.5 \mathrm{~cm}$. The force contante ara 8.8 $\mathrm{MN} / \mathrm{m}\left(5 \times 10^{\mathrm{lb}} \mathrm{lin}\right)$ for radial and $149 \mathrm{MN} / \mathrm{m}(8.5 \times$ $\left.10^{3} \mathrm{lb} / \mathrm{in}\right)$ for axial misalignment. The oupporta to the cold mase have been chosen to be metallic and to hare both a foreed flow liquid nitrozen and a thermoniphon liquid helium intercept.
The aupporte for the cold mas ean-be-cither combined function or neparated function whth difierent elements to react the exial and radial forces. Wo initially farored a combined funetion suppeit becaine by properl edjusting the ancie of the eupport with the axial direction, the fores due to thermal contraction conid be eliminated, but, winee thete suppoets. are at an

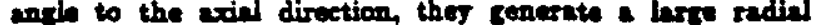
beckling force while reacting the axisl body and decentering forea. Thle dinedrantage dow not oceur with s exparated function aupport, and therefoce wo now faver this otyle. An additionel advantere in that both element of the esparated function support ean be much longer and therefore grently reduce the heat bad.

The warm ends of all oupports will be stiched near the ends of the raenum resecle-to eroid tranomitting the loeds and waikht through the shelly. Both the siril and radial supports are loested on the outer dinmetes of the helinm venel. The axtil aupport will hare thoir cold ende connected neas the inside bolted flance on the ontboard $2-m$ module; whetens the eold ends of the radial enpports will be etteched near aither end of the 8-m areembly.

\section{Refrizeration and Crrosenica}

The thermal ahield cooling tubes and the support intereepts are fed with forced flow unbeoled liquid sittogen it an average temparatere of $83 \mathrm{~K}$. The innex and outer shielde and each sat of supports will have independent heat intereept eirtuits. The expected hent

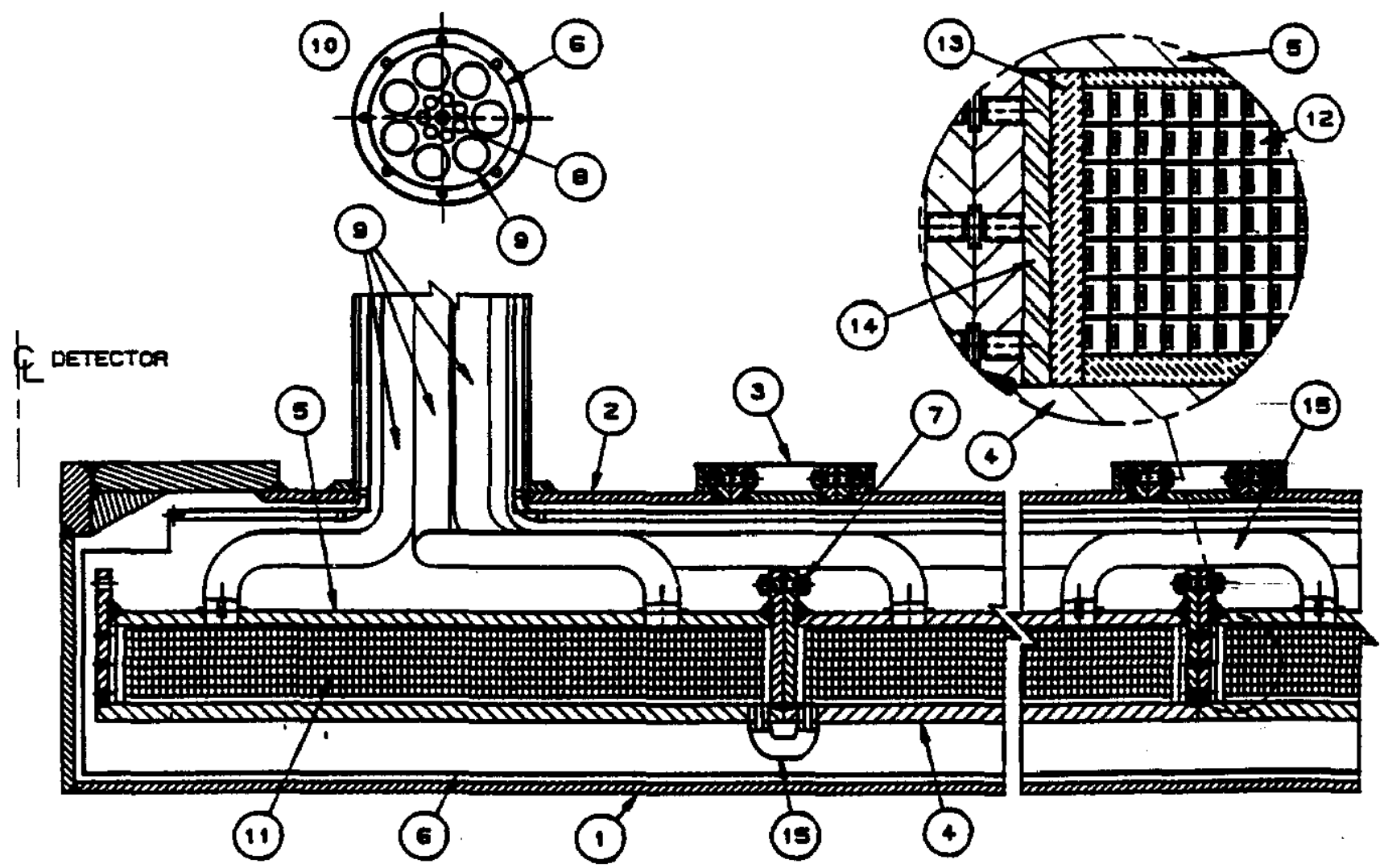

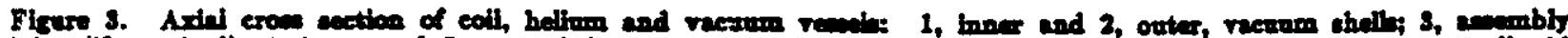

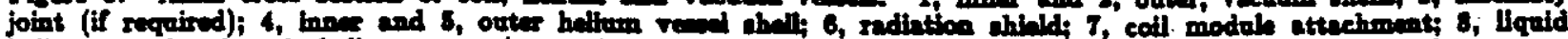

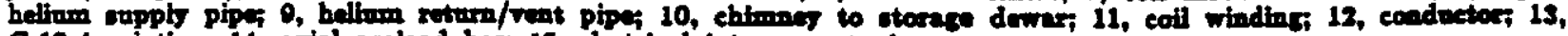

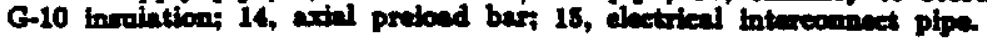


loed to the nitrogen sutem could be as mneh $40.6 \mathrm{~kW}$ for the complote 10-m maget.

A refirisentor at the auface applien haling to two 5000-L storege dewert on top of the iron. A cold comprencor will be uned if needed to maintsin the storege dewar at wboet $30 \mathrm{kPa}$ and $4.5 \mathrm{~K}$. Eech dewr her enpply and return lines to the four module in one 8-m anembly. These lines are sised such that the return helinm is lean than $1 \%$ gas by woight and the exply lines are carafully insuleted to ensare the maximum liquid frection entering the bottom of the magnet. The atends itate thermoniphon flow will be bout $23 \mathrm{~s} / \mathrm{t}$ to esch module. Separate halinm eireuits, which will hare a return flow of leas then $7 \%$ by wight, will intercept the oupports. The heat loed from the eeparated function support orutem mirht be as hish $100 \mathrm{~W}$ depending upon the denige. The total eteady state heat load for the murnat isutem coveld be $410 \mathrm{~W}$ (230 W plus $30 \mathrm{~L} / \mathrm{h}$ for lead flowe). The $4.5 \mathrm{~K}$ refiterestor will hare a eaperity of 1000 to $1800 \mathrm{~W}$.

In order to facilliste cooldown, a ceparate refrizerator would probably be emplojed. It would consiat of GHe/LN, hest axchenger and a turboexpander which coutd provida $400 \mathrm{E} / \mathrm{t}$ of $85 \mathrm{~K}$ hellum sal. Thin would be edequate to cool down the toted cold man (both 8-m seetions) of 1000 tone is

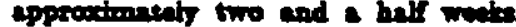

\section{Conetrutons}

Prellminary work has indiented that the oise and fleld requiremente of this magnet are seasonsble extrepolation of exinting aupereondueting mernet technologr. The magnet deeise mate be TerT

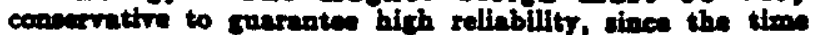
to fa even anall problem coaid have e maioc tompect. on the BSC phyile progam. More detilnd otady must be done to optimise paramatare both in terme of relinbility and cont-affectivences. Fabrieation technianen

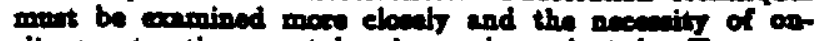

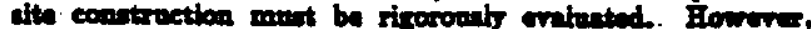
at thin point, we ece nothins that would preilede the conitruction of rech a minet.

\section{A telnowdedrenent:}

Thin work we aponeored by Unfresuitien Reeareh Association, Ine. undes contract with the U.S. Department of Eners. 
SSC DETECTOR SOLENOID DESIGN NOTE \#31

TITLE: A Very Large Superconducting Solenoid (Paper delivered by Bob Kephart at the 1989 International Industrial Symposium on the Super Collider, February 8, 1989, and accepted for publication in the proceedings.)

AUTHOR: Bob Kephart et al

DATE: $\quad$ February 9,1989 
R.W. Fast, J.B. Grimson, R.D. Kephart, H.J. Krebs, M.E. Stone, E.D. Theriot, and R.H. Wands

Fermi National Accelerator Laboratory

P.O. Box 500

Batavia, II 60510

\section{ABSTRACT}

A detector utilizing a superconducting solenoid is being discussed for the Superconducting Super Collider (SSC). A useful field volume of $8 \mathrm{~m}$ diameter $x 16 \mathrm{~m}$ length at 1.5-2 $\mathrm{T}$ is required. The magnet will have a stored energy of $\sim 1.5 \mathrm{GJ}$ at $2 \mathrm{~T}$. All particle physics calorimetry will be inside the bore of the solenoid such that there is no need for the coil and cryostat to be "thin" in radiation lengths. An iron yoke will reduce the excitation required and will provide muon identification and a redundant momentum measurement of the muons. We have developed a conceptual design to meet these requirements. The magnet will use a copper-stabilized $\mathrm{Nb}-\mathrm{Ti}$ conductor sized for a cryostable pool boiling heat flux of $20.025 \mathrm{~W} / \mathrm{cm}^{2}$. A thermosiphon from a storage vessel above the cryostat will be used to prevent bubble stagnation in the liquid helium bath. The operating current, current density, coil subdivision and dump resistor have been chosen to guarantee that the coil will be undamaged should a quench occur. The axial electromagnetic force will be reacted by metallic support links; the stainless steel coil case will support the radial force. The 5000 metric tons of calorimetry will be supported from the iron yoke through a trussed cylindrical shell structure separate from the cryostat. The coil and case, radiation shield and stainless vacuum vessel would be fabricated and cryogenically tested as two 8-m sections. These would be lowered into the underground experimental ball and installed into the iron flux return yoke to provide the required $16-m$ length.

\section{INTRODUCTION}

The SSC will have six interaction regions located approximately 50 meter below grade. A large superconducting solenoid is being considered as a part of a detector facility for one of the interaction halls. Figure 1 schematically shows such an SSC detector. The calorimetry and central tracking chambers, which will be located inside the solenoid, require a field volume $8 \mathrm{~m}$ in diameter by $10 \mathrm{~m}$ long. The field in the bore is required to be 1.5-2.0 T; the field in the iron flux return yoke will be $1.5 \mathrm{~T}$. Locating the calorimetry internal to the solenoid eliminates the need to have a "thin" coil and cryostat in terms of radiation lengths. Because thickness is not a constraint, several coil types are possible. The design presented here is a cryostable pool boiling coil. 
The required field volume will be provided by two solenoids, each $9.5 \mathrm{~m}$ in diameter and $8 \mathrm{~m}$ in length, connected in series electrically with a common power supply. Each 8-m unit will contain four identical 2-m long liquid helium/coil modules. The modules are mechanically connected and share a common vacuum vessel. Helium is supplied by thermosiphons to each module from a storage vessel located on top of the iron. Thus each module would have its own helium supply and return piping.

The calorimetry and nux return iron will be split at the longitudinal center and the halves can be moved independently; therefore, we will use two 8-m support structures to support the 5000 metric tons of calorimetry and central tracking chamber. There are notches in the iron for hangers for the supports and for instrumentation cables. The support structures are immediately inside the solenoids but are completely independent of the cryostat and vacuum shell. The ends of each structure will be supported from the iron. The support structures, consisting of concentric stainless steel cylinders with a trussed web, have a radial thickness of $25 \mathrm{~cm}$ and are expected to have a deflection of $\sim 3 \mathrm{~cm}$ when loaded with the calorimetry. The calorimeter will rest on rails and can be inserted from either end.

\section{QUENCH PROTECTION}

Four 2-m modules are connected in series. The modules could in principle have separate gas cooled current leads. However, to reduce the overall heat load on the magnet, we assume that the modules in each 8-m section will be connected with superconducting bus in the liquid helium filled interconnecting pipes. It is essential that the coil survive quenches without damage and to this end a low current density and an external fast dump resistor were chosen. This resistor was chosen to be 0.10 to limit the discharge voltage to $500 \mathrm{~V}$ across the terminals. The eddy current heating in both the coil and helium vessel during a fast dump is expected to be $\sim 1300 \mathrm{~W}$ for an $8-\mathrm{m}$ assembly. This might be sufficient to quench the coil and $s 0$ the discharge will be through the fast dump resistor only if a normal zone is detected. The highest temperature reached in the coil due to a quench will be $100 \mathrm{~K}$. A discharge for any other reason will be through a 0.020 slow dump resistor with the power supply reversed to maintain a constant discharge voltage. The routine charge or discharge time, with $100 \mathrm{~V}$ across the terminals, would be $100 \mathrm{~min}$ and the eddy current heat load would be $20 \mathrm{~W}$ per $8-\mathrm{m}$ assembly. Figure 2 is the electrical schematic.

\section{CONDUCTOR AND COIL SPECIFICATIONS, WINDING AND ASSEMBLY SCHEME}

The superconduetor will be copper stabilized $\mathrm{Nb}-\mathrm{Ti}$ wire which has a short sample current of $10 \mathrm{kA}$ at $3 \mathrm{~T}$ and $4.5 \mathrm{~K}$. This wire will be soldered into additional copper stabilizer. For the purpose of this study we assume the conductor will be $26 \times 18 \mathrm{~mm}$ and will have a copper to superconductor area ratio of 146 to 1 . Here we have chosen the stabilizer area to insure safe discharge of the coil in the event a normal region in the coil should develop. An operating current of $5000 \mathrm{~A}$ results in qurrent density of $1.56 \times 10^{5}$ $\mathrm{A} / \mathrm{cm}^{2}$ in the superconductor and $1038 \mathrm{~A} / \mathrm{cm}^{2}$ overall. The surface heat flux, with $25 \%$ wetting and a RRR of 100 , is $0.025 \mathrm{~W} / \mathrm{cm}^{2}$.

There are seven conductor layers having a total of 651 turns in each 2-m coil module. Since the forces are radially outward, the coil will be wound starting with the outside layer, using the outer shell and flat annular heads as a coil form. Insulation will consist of G-10 buttons between turns, slotted G10 sheets between layers and slotted G-10 and Kapton adjacent to the helium vessel. The packing factor will be $74 \%$ with $13 \%$ being helium space. 


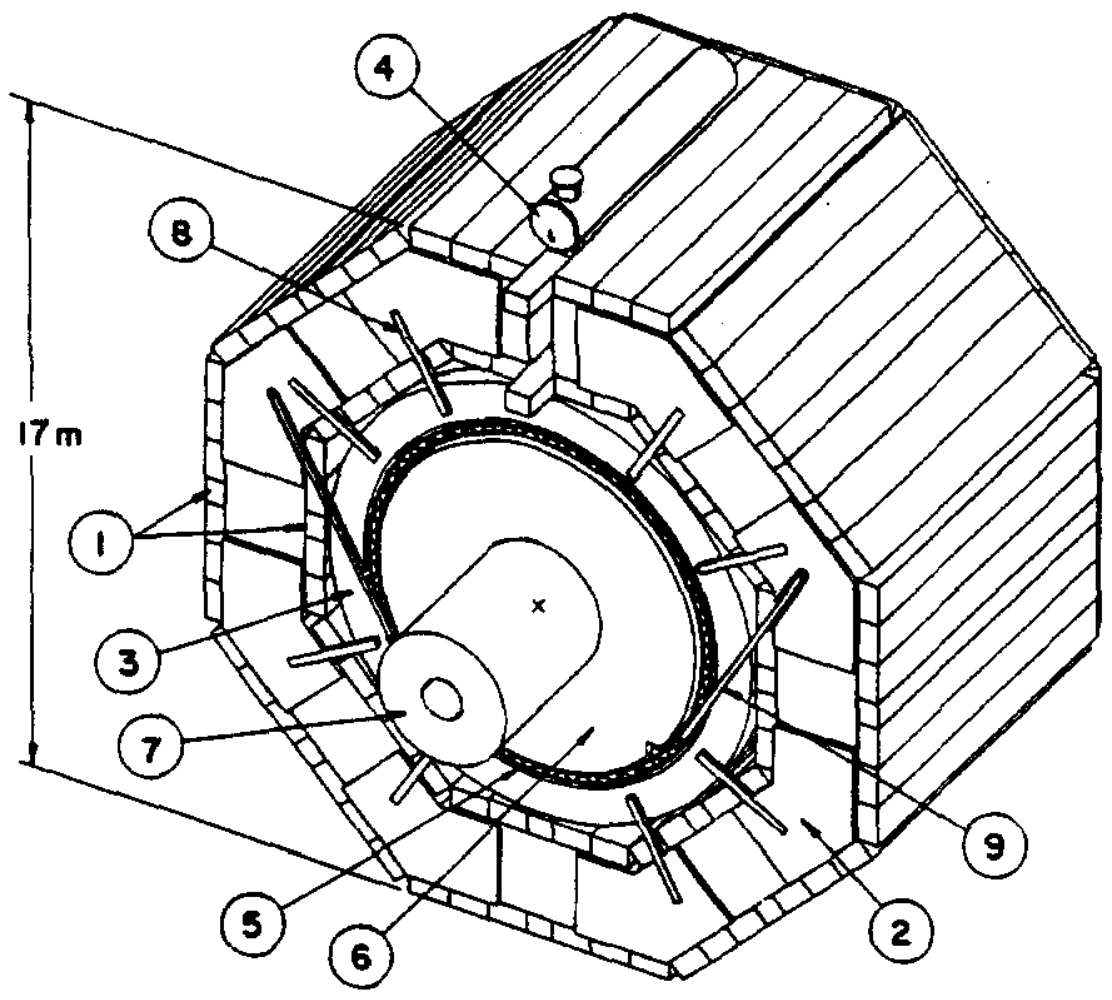

Fig. 1. One-half SSC Detector: 1, muon tracking; 2, flux return iron; 3, coil assembly; 4, 5000 L helium dewar; 5, calorimeter support structure; 6, calorimeter; 7, central tracking chambera; 8, coil supports; 9, support structure hangers.

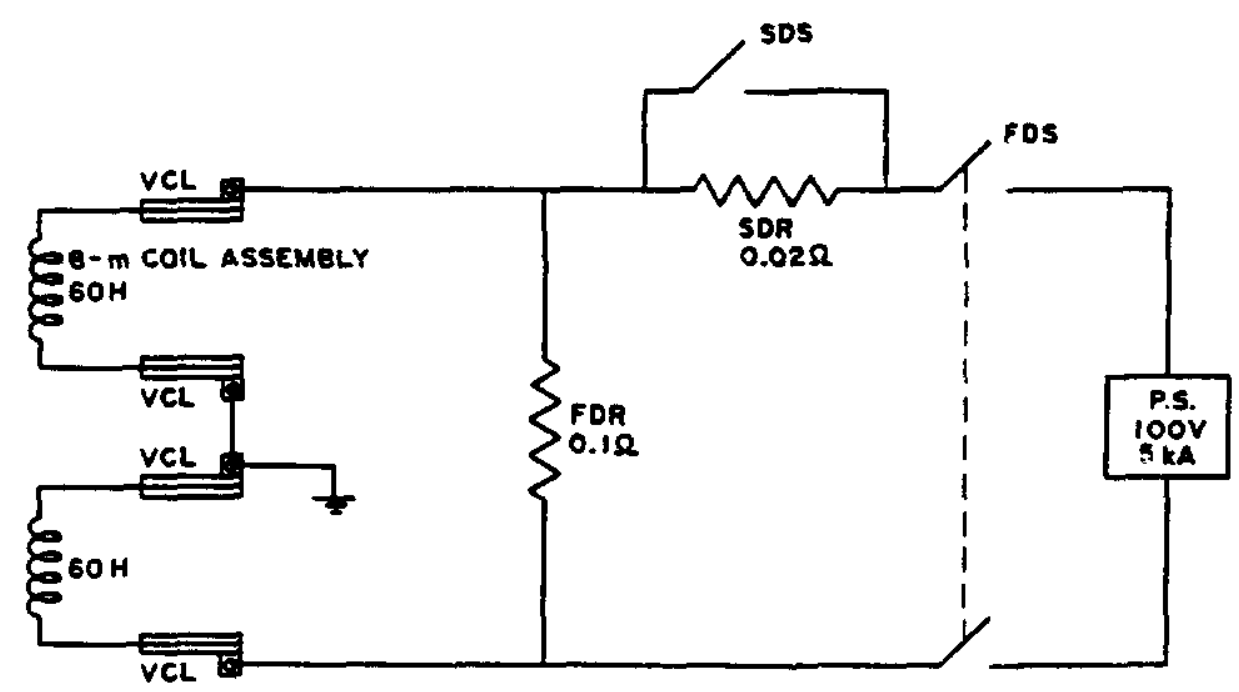

Fig. 2. Electrical Schematic: FDR, fast dump resistor; FDS, fast dump switch (NC, open to initiate a fast dump); SDR, slow dump resistor; SDS, slow dump owitch (NC, open to initiate a slow dump); VCL, vapor cooled leads; P.S., power supply. 
Each 2-m coil module will be designed in accordance with Section VIII of the ASME Boiler and Presaure Vessel Code for an internal presaure differential of $0.8 \mathrm{MPa}(116 \mathrm{paia})$ and will be adequately relieved for a loss of insulating vacuum or a quench of the coil. The axial electromagnetic force will be transmitted through the shells to the supports, and the radial force will be resisted by both the conductor and outer shell.

Winding will be done with the coil axis vertical. The winding fixture will provide the radial preload and a series of compression bars at one end of each coil can be individually adjusted to provide a circumferentially uniform axial preload. These axial compression bars are adjustable only during assembly. After winding, the inner shell of the helium vessel will be welded to the coil form. The four $2-\mathrm{m}$ He vessels are bolted together. Each is located inside an inner and outer vacuum jacket and integral nitrogen shield. The entire 8-m cold mass is supported with respect to the magnet iron by separate metallic radial and axial supports. Figure 3 is a cross section of the coil, cryoutat and vacuum vessel.

\section{SUPPORTS}

The axial body force on the 8-m cold mass is dependent on the geometry of the end wall. The supports are designed for an axial or radial misalignment, or the equivalent due to iron non-homogeneity, of $2.5 \mathrm{~cm}$. The force constants are $8.8 \mathrm{MN} / \mathrm{m}\left(5 \times 10^{4} \mathrm{lb} /\right.$ in $)$ for radial and $140 \mathrm{MN} / \mathrm{m}(8.5$ $\times 10^{5} \mathrm{lb} /$ in) for axial misalignment. The supports to the cold mass have been chosen to be metallic and to have both a forced flow liquid nitrogen and a thermosiphon liquid helium intercept.

The supports for the cold mass are assumed to be separated function with different elements to react the axial and radial forces. We initially favored a combined function support because by properly adjusting the angle of the support with the axial direction, the force due to thermal contraction could be eliminated, but, since these supports are at an angle to the axial direction, they generate a large radial buckling force while reacting the axial body decentering forces. This disadvantage does not oceur with a separated function support. An additional advantage is that both elements of the separated function supports can be much longer which greatly reduces the heat load.

The warm ends of all supports will be attached near the ends of the vacuum vessels to avoid transmitting the loads and weight through the shells. Both the axial and radial supports are located on the outer diameter of the helium vessel. The axial supports will have their cold ends connected near the inside bolted tlange on the outboard 2-m module; whereas the cold ends of the radial supports will be attached near either end of the 8-m assembly.

\section{REFRIGERATION AND CRYOGENICS}

The thermal shield cooling tubes and the support intercepts are fed with forced flow subcooled liquid nitrogen at an average temperature of $83 \mathrm{~K}$. The inner and outer shields and each set of supports will have independent heat intercept circuits. The expected hest load to the nitrogen system could be as much as $5 \mathrm{~kW}$ for the complete 16-m magnet.

A refrigerator at the surface supplies helium to two 5000- $\mathrm{L}$ storage dewars on top of the iron. A cold compressor will be used if needed to maintain the storage dewar at about $30 \mathrm{kPa}$ and $4.5 \mathrm{~K}$. Each dewar has supply and return lines to the four modules in one 8-m assembly. These lines are sized such that the return helium is less than $1 \%$ gas by weight and the supply lines are carefully insulated to ensure the maximum liquid fraction 


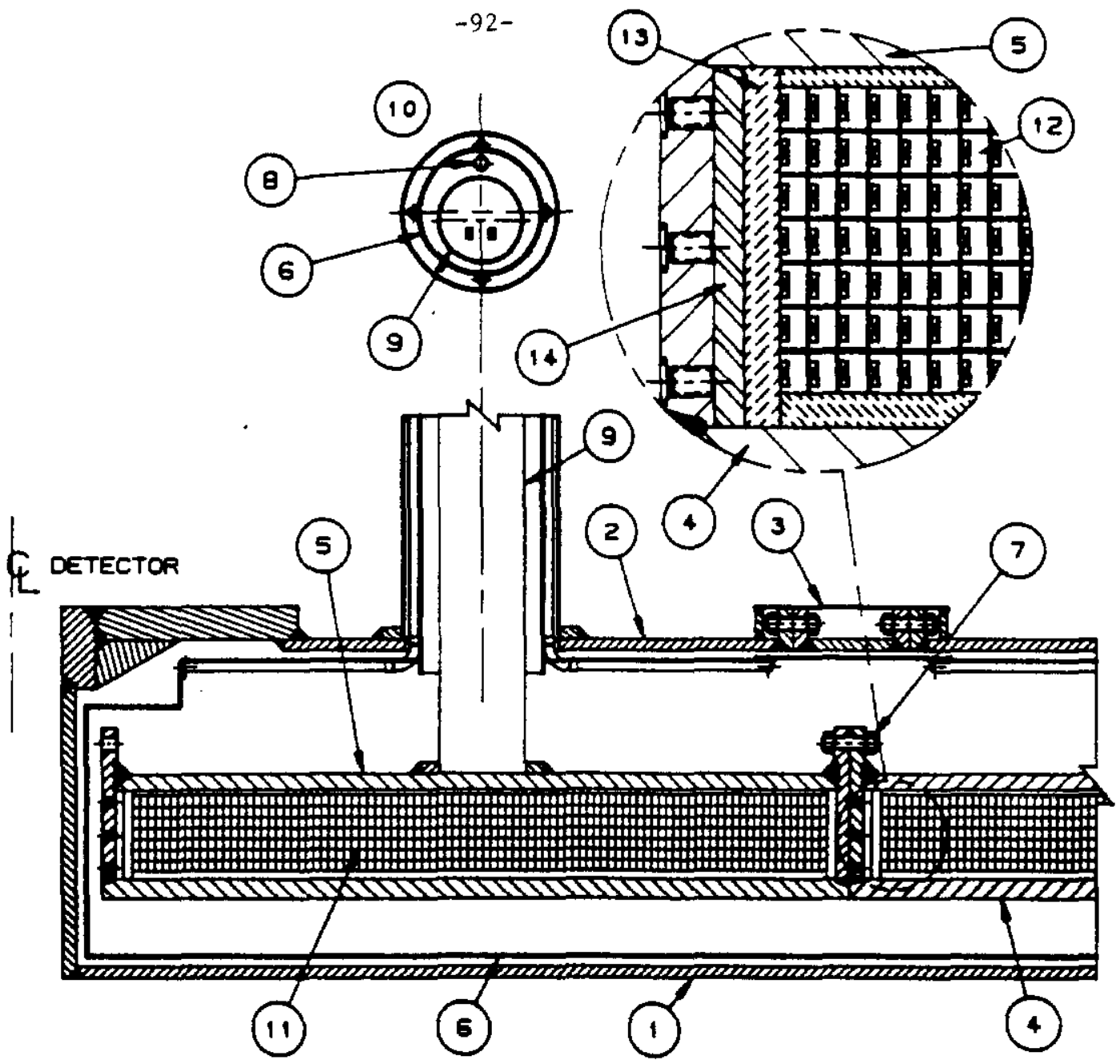

Fig. 3. Axial cross section of coil, helium and vacuum vessels: 1 , inner and 2, outer, vacuum shells; 3, assembly joint (if required); 4, inner and 5 , outer helium vessel shell; 6 , radiation shield; 7 , coil module attachment; 8, liquid helium supply pipe; 9, helium return/vent pipe; 10, chimney to storage dewar; 11, coil winding; 12, conductor; 13, G-10 insulation; 14, axial preload bar.

entering the bottom of the magnet. The steady state thermosiphon flow will be about $25 \mathrm{~g} / \mathrm{s}$ to each module. Separate helium circuits, which will have a return flow of less than $7 \%$ by weight, will intercept the supports. The heat load from the separated function support system might be as high as $100 \mathrm{~W}$ depending upon the design. The total steady state heat load for the magnet system could be $410 \mathrm{~W}$ ( $230 \mathrm{~W}$ plus $36 \mathrm{~L} / \mathrm{h}$ for lead flows). The $4.5 \mathrm{~K}$ refrigerator will have a capacity of 1600 to $1800 \mathrm{~W}$.

In order to facilitate coo'down, a separate refrigerator would probably be employed. It would consist of a GHe/LN, heat exchanger and a turboexpander which could provide $400 \mathrm{~g} / \mathrm{s}$ of $35 \mathrm{~K}$ helium gas. This would be adequate to cool down the total cold mass (both 8-m sections) of 1000 tons in adoroximatelv two and a half weeks. 


\section{CONCLUSIONS}

Preliminary work has indicated that the size and field requirements of this magnet are a reasonable extrapoiation of existing superconducting magnet technologs. The magnet design must be very conservative to guarantee high reliability, since the time to fix even a small problem could have major impact on the SSC physics program. More detailed study must be done to optimize parameters both in terms of reliability and cost-effectiveness. Because of the large size of this magnet, fabrication techniques must be examined very closely and the necessity of on-site construction must be rigorously evaluated. However, at this point, we see nothing that would preclude the construction of such a magnet.

\section{ACKNOWLEDGEMENTS}

This work was supported by the U.S. Department of Energy, Contract numbers DE-AC02-76CH03000 and DE-AC02-89ER40486. 